Aus der gynäkologisehen Klinik zu Kiel.

\title{
Körperliche und geistige Veränderungen im weib- lichen Körper nach künstlichem Verluste der Ovarien einerseits und des Uterus andererseits.
}

\author{
Von \\ Dr. Glaevecke,
}

I. Assistenzarzt.

Von Alters her bis in die neueste Zeit ist die Deutung und Erklärung des Menstruationsprocesses Anlass zu vielen Arbeiten gewesen. Namentlich gehen die Ansichten darüber auseinander, wie man sich den Zusammenhang der Ovulation mit der Menstruation zu denken habe. Dass ein solcher und zwar ziemlich inniger Zusammenhang besteht, kann nach allen vorliegenden Thatsachen nicht geleugnet werden, zweifelhaft bleibt nur, wie man sich denselben zu denken hat. Ich werde an dieser Stelle auf die genügend bekannten verschiedenen Ansichten und Forschungen nicht näher eingehen und verweise auf die zum Theile auch in diesem Archive veröffentlichten Arbeiten von Litzmann¹), Pfl ü ger ${ }^{2}$ ), Leopold ${ }^{3}$ ), Möricke ${ }^{4}$ ), Ruge, Veit ${ }^{5}$ ) Engelmann und Kundrat ${ }^{6}$, Williams ${ }^{7}$, , Wyder ${ }^{8}$, Goodman ${ }^{9}$ ), Jacobi ${ }^{10}$ ),

i) Wagner's Handwörterbuch der Physiologie.

2) Untersuchungen aus dem physiologischen Laboratorium in Bonn. Berlin 1865.

3) Dieses Archiv, Bd. XI und XXI.

4) Zeitschrift für Geburtshülfe und Gynäkologie 1881, Bd. VII.

5) Müllex, Handbuch der Geburtshülfe, Bd. I, S. 148.

6) Wiener medicinische Jahrbücher 1873 .

7) Obstetrical JournaI II, 1874-75; V, 1877.

8) Dieses Archiv 1878, Bd. XIII.

9) American Journal of Obstetrics 1878, Vol. XI.

10) The question of rest for women during menstruation. London 1878. Archiv f. Gynäkologie. Bd. XXXV. Hft. 1 . 
Stephenson ${ }^{1}$, Rabuteau ${ }^{2}$, Rein $1^{3}$ ), v. Ott , $^{4}$. Nach gründlichem Studium der einschlägigen Literatur ist meine persönliche Ansicht über den Menstruationsprocess kurz folgende:

Die Pflüger'sche Theorie scheint mir noch immer diejenige zu sein, welche am besten den Vorgang erklärt und am meisten den Thatsachen entspricht, nur muss sie nach den neueren Forschungen abgeändert werden, wie F eokt is t o w ${ }^{5}$ ) gethan hat. Eine Reihe von Thatsachen spricht dafür, dass die Ovulation unabhängig von der Periode zu jeder Zeit stattfinden kann. Der Anlass zum Platzen des Graaf'schen Follikels wird also nicht immer die reflectorisch hervorgerufene Hyperämie im Ovarium sein, sondern auch die durch das Wachsen des Follikels hervorgerufene Verdünnung seiner Wand. Die Zellen der Membrana granulosa sondern den Liquor folliculi in steigendem Maasse ab, dadurch vergrössert sich der Follikel, seine Wandung dehnt sich hauptsächlich nach der freien, der Oberfläche zugewandten Seite aus, und schliesslich wird hier die Wandung so dünn, dass sie platzt und das Ei austreten lässt. Gewöhnlich wird wahrscheinlich dieser Vorgang sich ungefähr an die Zeit der Menstruation binden, weil dann eine erhöhte Hyperämie des Ovarium reflectorisch hervorgerufen wird. Doch ist dies nicht nothwendig; es kann auch zu jeder Stunde der menstruationsfreien Zeit stattfinden. Durch die Vergrösserung des Graaf'schen Follikels werden gleichzeitig die feinsten, im Ovarialstroma verlaufenden Nervenendigungen gereizt und dieser Reiz fortdauernd auf nervöse Centren, deren Lage wir wohl zunächst im Lendenmark zu suchen haben, übertragen, wo er sich allnölig vermehrt und anhäuft, bis eine gewisse Stärke erreicht ist, zu welcher Zeit dann rom Centrum eine reflectorische Reizwelle auf die vasomotorischen Nerven des Uterus und Ovarium ausgelöst wird, die eine Hyperämie in diesen Organen hervorruft. Ist zu dieser Zeit im Ovarium gerade ein sprungfertiger Follikel vorhanden, so wird derselbe unter der vermehrten Secretion des Liquor folliculi platzen, ist aber keiner vorhanden, so bleibt dieser Erfolg aus. Im Uterus hat sich unter der Zeit die Decidua menstrualis gebildet, und die nun reflectorisch ansgelöste Hyperämie des Uterus trifft

1) American Journal of Obstetrics 1882, VoI. XV.

2) Gazette médicale de Paris 1870, p. 616.

3) Sammlung klinischer Vorträge von Volkmann, Nr. 243.

4) Ebendaselbst.

5) Dieses Archiv, Bd. XXVII. 
schon auf eine gelockerte, stark saftreiche Uterusschleimhaut. Diesen vermehrten Anstoss halten nun die feinsten Capillaren nicht aus, es kommt zur Berstung von Capillaren und zum Austritte von Blutkörperchen durch die Wandung der Capillaren, mit einem Worte, die menstruelle Blutung beginnt. Es bildet also der reflectorisch vom Centrum ausgelöste Nervenreiz nur den letzten Anstoss zum Beginne der Menstruationsblutung, er ist gewissermaassen der Funke, der an dem seit langer Zeit angehäuften Brennmateriale das Feuer anfacht. Findet der reflectorische Reiz zu einer Zeit statt, wo keine Decidua menstrualis im Uterus ist, wo das Endometrium sich im unvorbereiteten Stadium befindet, so kann natürlich auch keine Blutung darauf folgen, der Funke hat kein Brennmaterial gefunden und erlischt wieder. Während der Menstruation findet dann eine capillare Blutung aus der gesammten Uterusschleimhaut statt, die Epithelschicht der Schleimhaut stösst sich theilweise $a b$ und wird mit entleert. Nach und während dieser starken lokalen Blutentziehung schwillt die Uterusschleimhaut ab und geräth in den Zustand der Anämie. Sie bildet zunächst neue Epithelien, die wiederhergestellte Schleimhaut geräth allmälig wieder ins Schwellen und bildet die Decidua menstrualis. Bei dieser Erklärung der Vorgänge trennen wir die Ovulation als einen selbständigen Vorgang los von der Menstruation. Trotzdem bleibt aber die Menstruation abhängig vom Ovarium, von der Follikelreifung. Die Ovulation wird gewöhnlich ungefähr periodisch zur Zeit der Menses stattfinden, sie kann aber auch unperiodisch zu jeder Zeit vor sich gehen, trotzdem die Menstruation periodisch bleibt. Jedenfalls ist die Ovulation ein selbständiger Vorgang, der in keiner Weise an die Menstruation geknüpft ist und ohne dieselbe vor sich gehen kann. Die Menstruation ist aber abhängig vom Ovarium, und kann nur bei functionirendem Ovarium zu Stande kommen. Denn, wenn das Endometrium sich auch selbständig zur Menstruationsblutung vorbereitet, so darf man dasselbe sich doch nicht so selbständig vorstellen, dass es allein im Stande wäre, eine Menstruationsblutung auszulösen. Diese kommt nur zu. Stande, wenn die letzte dazu nöthige Hyperämie vom Ovarium aus durch Nervenreiz angeregt wird. Ohne Funken kann ja die grösste Masse von Brennstoff nicht entzündet werden. Trotzdem die Ovulation nicht an eine regelmässige Periodicität gebunden ist, bleibt die Menstruation regelmässig periodisch. Dies hat seinen Grund erstens im Aufsummen des Reizes im Centralorgane. Durch jahrelange 
Erfahrung wissen wir, dass gerade in vier Wochen die bestimmte Summe von Reizen in den Centren gesammelt wird, welche zur Auslösung eines Reflexes nothwendig ist. Dabei ist es gleichgültig, ob während dieser Zeit ein Follikel springt oder nicht, da sofort nach Berstung eines Follikels ein anderer zu wachsen anfängt, und so von diesom wieder Nervenreiz an das Centrum übertragen wird. Zweitens liegt die Ursache der Periodicität der Menstruation im Verhalten des Endometrium. Der Zustand des Endometrium bewegt sich in einer Wellenlinie, die aus $\mathrm{Zu}$ - und Abnahme der Uterusschleimhaut zusammengesetzt ist und die stets in einem Zeitraume von vier Wochen abläuft. Nur gerade immer, wenn der Nervenreiz zum Uterus auf dem Gipfel der Welle stattfindet, zur Zeit der ausgebildeten Decidua menstrualis, wird der Uterus auf den Reiz mit Blutung antworten können, in der Zwischenzeit nicht. Für gewöhnlich werden nun diese beiden zur menstruellen Blutung nothwendigen Factoren, der reflectorische Nervenreiz und der, der Menstruation günstige Zustand des Endometrium, d. h. das Vorhandensein der Decidua menstrualis, zeitlich zusammenfallen, und wird daher regelmässig alle vier Wochen eine Menstruationsblutung stattfinden. Unter Umständen wird aber einmal ein Factor auf den andern warten müssen, wodurch kleine Unregelmässigkeiten der Menstruation hervorgerufen werden, wie sie täglich vorkommen. Trotzdem nun die Ovulation zu jeder Zeit befruchtungsfähige Eier liefern kann und der Beischlaf ja auch jederzeit stattfinden kann, concipirt die Frau doch nachweislich am häufigsten gleich nach der Menstruation, weil nur zu dieser Zeit das befruchtete Ei sich im Uterus ansiedeln kann und hier einen günstigen Nährboden vorfindet. Wuchert das Ei im Uterus weiter, so braucht der Uterus zu seiner gewaltigen Entwickelung während der Schwangerschaft sehr 'viel -Blut und Nahrungsmaterial. Man könnte sich nun denken, dass durch diese mächtige Entwickelung des Uterus eine Hemmung auf die trophischen Nerven des Ovarium ausgelöst würde und infolge dessen das Ovarium unter ungünstige Ernährungsverhältnisse gesetzt würde, die keine Ausbildung von Follikeln gestatten. So erklärt es sich, dass die Ovulation und. das Heranreifen der Follikel in der Schwangerschaft unterbleibt, somit auch in dieser Zeit keine Menstruation ausgelöst werden kann. Schliesslich haben uns die Untersuchungen von Jacobi, v. Ott, Rein1 u. A. bewiesen, dass mit der Menstruation des Weibes gleichzeitig eine Wellenbewegung durch alle wichtigen Lebensvorgänge hindurchläuft, so dass wir den Begriff der 
Menstruation nicht auf den örtlichen Vorgang in den Genitalien zu beschränken brauchen, sondern auf die Veränderungen, die im Gesammtorganismus zu dieser Zeit vor sich gehen, ausdehnen können. Fast mit jeder normalen Menstruation sind Beschwerden der Frau verknüpft, die sich nicht allein auf die Genitalien besehränken, sondern die an den verschiedensten vom Sympathicus innervirten Stellen localisirt werden, z. B. Kopfschmerzen, Herzklopfen, Beängstigungen $u$. s. w. Gerade diese Beschwerden haben ja der Menstruation den Namen ,das Unwohlsein" gegeben.

Nach diesen einleitenden Worten, welche meinen Standpunkt zur Menstruationstheorie klarlegen, gehe ich zur Besprechung derjenigen Veränderungen über, welche sich im weiblichen Organismus auf körperlichem und geistigem Gebiete entwickeln, wenn wir die Ovulation oder die Menstruation künstlich unterdrücken, dadurch, dass wir bei der Frau einen künstlichen Verlust der Ovarien durch die Castration einerseits schaffen, oder einen künstlichen Ausfall des Uterus durch die Totalexstirpation desselben andererseits herbeiführen.

\section{Körperliche und geistige Veränderungen im weiblichen Körper bei künstlichem Verluste der Ovarien.}

In der gynäkologischen Klinik sind in den letzten Jahren 38 Castrationen und 6 doppelseitige Ovariotomien ausgeführt worden.

Wegen welcher Krankheiten und wie oft diese Operationen nöthig waren, zeigt die folgende Zusammenstellung.

\section{Castrationes:}

Myoma uteri: 23.

Perioophoritis duplex: 1 .

Oophoritis sinistra: 1 .

Perimetritis adhaesiva: 2.

Graviditas extrauterina dextra, Perimetritis sinistra: 1 .

Haematosalpinx lateris utriusque: 1.

Kystoma ovarii sinistri, Hydrosalpinx dextra: 1 .

Kystoma parovarii utriusque: 1.

Neuralgia ovarii utriusque: 1 .

Infaretus et Retroflexio uteri: 2.

Retroflexio uteri, Dysmenorrhoea: 1.

Infarctus uteri, Dysmenorrhoea: 1 .

Narbenstenose des Muttermundes bei engem Becken: 1 .

Narbenstenose der Vagina: 1 . 


$$
\text { Orariotomiae duplices: }
$$

Kystoma ovarii utriusque: 4 .

Papilloma ovarii ntriusque: 2.

In weitaus den meisten Fällen habe ich die 44 Frauen längere Zeit nach der Operation persönlich gesehen und untersucht, indem dieselben entweder sich wieder vorstellten, oder ich dieselben an ihren Wohnorten aufsuchte. Nur in wenigen Fällen musste ich von den Frauen schriftliche Mittheilungen über ihren Zustand einziehen, die oft allerdings etwas lückenhaft ausfielen. Wo ich nach der ersten Anfrage noch nicht ganz klar sah, habe ich sie ein-, selbst zweimal wiederholt, bis ich genügend unterrichtet war. So ist es mir gelungen, mein allerdings nur kleines Material möglichst genau und ausführlich zu ergründen.

Hauptsächlich habe ich mein Augenmerk auf die Verhältnisse gerichtet, die bei dem natürlichen Klimakterium eine Rolle spielen, da die Castration einen ähnlichen Zustand schafft, welchen daher Hegar ,künstliche Klimax“ nannte.

Der nächstliegende und wichtigste Folgezustand der Castration wird sein, dass die Menses mit einem Schlage erlöschen. Richten wir unsere Aufmerksamkeit zuerst auf diesen Punkt.

\section{A. Wirkung der Castration auf die Menses.}

Bei der Aufstellung der folgenden Tabelle über das Verhalten der Menses nach der Castration habe ich von der Uterusblutung abgesehen, welche gewöhnlich am zweiten bis dritten Tage nach der Operation auftritt und dann verschieden lange Zeit anhält. Sie kommt stets zu Stande und ich weiss mich keines Falles zu erinnern, wo dieselbe nicht wenigstens in Spuren vorhanden gewesen wäre. Ihre Menge schwankt bedeutend, ebenso die Dauer, die von einigen Stunden bis zu drei Wochen, wie ich in einem Falle beobachtete, betragen kann. Wir haben diese Blutung nicht als eine pathologische, sondern als die zu früh einsetzende Periode $z u$ betrachten. Wahrscheinlich kommt sie dadurch zu Stande, dass durch die Fortnahme der Ovarien ein sehr bedeutender Nervenreiz auf die Centren ausgeübt wird, so dass diese gleich reflectorisch eine Hyperämie des Uterus erzeugen, die so stark ist, dass sie unter allen Umständen zur Blutung führt. 
nach künstl. Verluste d. Ovarien einerseits u. d. Uterus andererseits.

Tabelle I. Ueber das Verhalten der Menses nach der Castration.

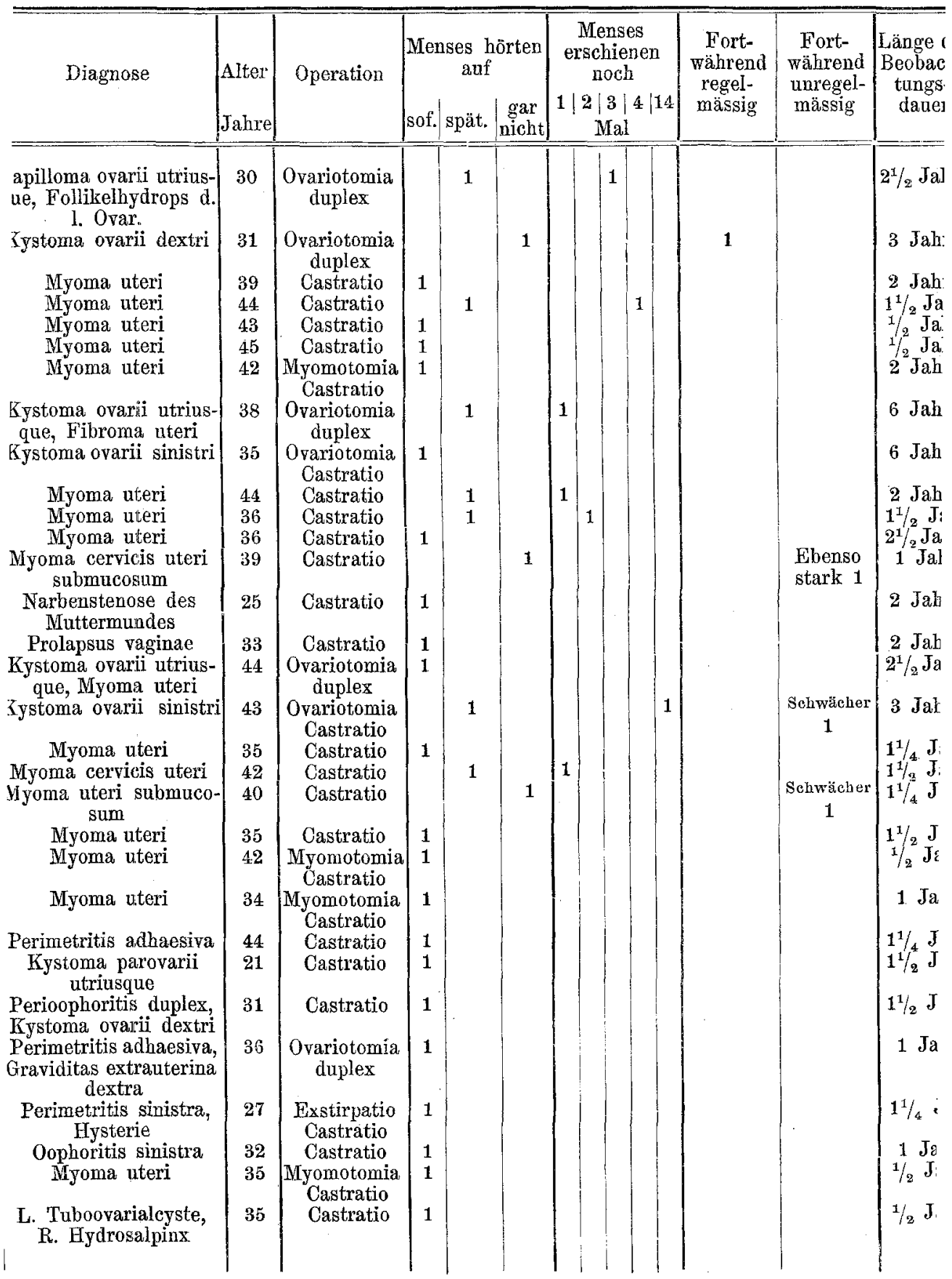




\begin{tabular}{|c|c|c|c|c|c|c|c|c|c|}
\hline Diagnose & $\begin{array}{l}\text { Alter } \\
\text { Jahre }\end{array}$ & Operation & $\mid \begin{array}{l}\text { Men } \\
\text { sof. }\end{array}$ & $\begin{array}{l}\text { ases } \\
\text { auf } \\
\text { spät. }\end{array}$ & $\begin{array}{l}\text { garten } \\
\text { nicht }\end{array}$ & $\begin{array}{c}\text { Menses } \\
\text { erschienen } \\
\text { noch } \\
1|2| 3|4| 14 \\
\text { Mal }\end{array}$ & $\begin{array}{c}\text { Fort- } \\
\text { während } \\
\text { regel- } \\
\text { mässig }\end{array}$ & $\begin{array}{l}\text { Fort- } \\
\text { während } \\
\text { unregel- } \\
\text { mässig }\end{array}$ & $\begin{array}{r}\text { Läng } \\
\text { Beol } \\
\text { tun } \\
\text { dai }\end{array}$ \\
\hline Myoma uteri & 45 & Castratio & 1 & & & & & & $1 \mathrm{r}$ \\
\hline Myoma uteri & 36 & Castratio & 1 & & & & & & $3 / 4$ \\
\hline $\begin{array}{c}\text { Infarctus et retroflexio } \\
\text { uteri }\end{array}$ & 40 & Castratio & & 1 & & 1 & & & \\
\hline Nerralgia ovarii utriusq. & 29 & Castratio & 1 & & & & & & $1 / 2 J$ \\
\hline Myoma uteri & 37 & Castratio & & 1 & & 1 & & & $5 \mathrm{Mc}$ \\
\hline Myoma uteri & 43 & Castratio & 1 & & & & & & $4 \mathrm{M}$ \\
\hline Menorrhagien, & 26 & Castratio & & & 1 & & & Ebs. stark 1 & $1 J$ \\
\hline Infarctus uteri & 38 & Castratio & 1 & & & & & & $3 / 4 \mathrm{~J}$ \\
\hline Infarctus et Retroflexio & 41 & Castratio & 1 & & & & & & $1 \mathrm{~J}$ \\
\hline $\begin{array}{c}\text { Haematosalpinx } \\
\text { utriusque lateris }\end{array}$ & 37 & Castratio & & & 1 & & & $\begin{array}{c}\text { schwächer } \\
1\end{array}$ & $1 / 2 \mathrm{~J}$ \\
\hline
\end{tabular}

Die Ergebnisse aus dieser Tabelle sind, dass von 41 Fällen von Castration oder doppelseitiger Ovariotomie in 27 die Menopause sofort eingetreten ist, in 9 Fällen dagegen erst später, nachdem noch einige Male die Periode sich gezeigt hatte, und nur in 5 Fällen gänzlich ausblieb. Bei den 9 Fällen, in denen die Menopause erst später zu Stande kam, erschienen die Menses in 5 Fällen nur noch $1 \mathrm{Mal}$ und in je einem Falle noch 2, 3, 4 und 14 Mal. Besonders aber nehmen die 5 Fälle unsere Aufmerksamkeit in Anspruch, in denen der Zweck der Operation verfehlt ist und die Periode nach derselben fortbestand. Ich gebe diese 5 Krankengeschichten hier ausführlich wieder.

1. Frl. N. (Fall 2 der Tabelle), 31 Jahre, litt an Kystoma ovarii dextri und Vergrösserung des linken Ovarium, weshalb am 20. Oct. 1884 die Ovariotomia duplex gemacht wurde. Das linke Ovarium war hühnereigross, zeigte klein-cystische Entartung und war mit der hinteren Wand des Ligamentum latum durch Pseudomembranen verwachsen. Nachdem diese durchtrennt waren, wurde das Orarium nebst der Tube abgebunden und abgetragen. Eine im Ligamentum latum dextrum sitzende kindskopfgrosse cystische Geschwulst wurde punktirt und stumpf aus dem Ligamentum latum anfangs leicht herausgeschält. Die am Grunde der Geschwulst sitzenden papillären Wucherungen erschwerten aber die Ausschälung so sehr, dass sie nur unvollkommen gelang and ein kleiner Theil der Cystenwand mit papillären Massen sitzen blieb. Die Convaleseenz wurde durch fast fortwährende geringe Blutungen aus dem Uterus sehr verlangsamt. Als Grund dieser Blutungen fand sich später ein submucöser Uteruspolyp, der am 1. April 1885 entfernt wurde. Seit der Zeit hörten die andauernden Blutungen anf und die Menstruation trat aller 4 Wochen regelmässig in normaler Stärke ein. 
2. Fr. Aa-d. (Fall 13 der Tabelle), 39 Jahre, hatte ein zweimannsfaustgrosses, submucöses Myom der hinteren Uteruswand, welches breitbasig in die Uterussubstanz überging. Es hatte die Cervix nahezu vollständig verstrichen and den Muttermund für einen Finger durchgängig gemacht. Um die sehr reichlichen Blutungen zu stillen, wurde am 6. Juli 1885 die Castration gemacht. Beide Ovarien waren hühnereigross und zeigten klein-cystische Entartung. Das linke wurde leicht entfernt unter Zurücklassung der Tube. Das rechte Ovarium ging mit seinem medianen Pole dicht an den Uterus heran and sass dem Ligamentum latum breit auf. Ausserdem hüllten es zahlreiche Pseudomembranen ein. Es wurde zunächst nach und nach vom Uterus abgetrennt und dann aus den Membranen ausgeschält. Es ist wahrscheinlich, dass etwas Ovarialsubstanz sitzen blieb. Der Verlauf nach der Operation war ohne jede Reaction, und die früheren erschöpfenden Uterusblutungen standen vollkommen. 6 Wochen nach der Operation stellte sich aber wieder eine sehr starke Blutung ein, die in der Folgezeit sich häufig wiederholte. Im December 1887 erfuhr ich zuletzt, dass zeitweilig sehr bedeutende Blutungen stattgefunden hätten.

3. Fr. D. (Fall 20 der Tab.), 40 Jahre, hatte ein mindestens kindskopfgrosses submucöses Myom, das breitbasig aus der hinteren Uteruswand entsprang und bis zum Muttermunde reichte, der etwa fünfmarkstückgross erweitert war. Da die Ausschälung grosse Schwierigkeiten gehabt hätte und vielleicht unausführbar gewesen wäre, wurde 14. August 1886 die Castration gemacht. Das linke, sehr umfängliche Ovarium wurde nach und nach unterbunden und sicher vollständig entfernt. Das rechte Ovarium war aber nicht zu finden. Es musste wohl durch den Druck des Tumor, der hier das Ligamentum latum stark entfaltet hatte, vollkommen abgeplattet und dadurch grösstentheils eingeschrumpft sein. Es wurde daher nur die Stelle, an der es normaler Weise sitzen sollte, exstirpirt und die Vasa spermatica im Ligamentum infundibulo-pelvicum unterbunden. Der Verlauf nach der Operation war vollkommen normal und die Kranke wurde im besten Wohlsein entlassen. In der Folgezeit stellte sich die Menstruation wieder ein, aber nie regelmässig, sondern bald zu früh, bald zu spät. Gewöhnlich war sie nur gering, manchmal aber stärker, doch nie so stark wie früher. Am Tumor trat keine Schrumpfung ein, im Gegentheile vergrösserte sich derselbe langsam. So hat der Zustand sich bis zum Herbste 1887 gehalten. Im Frühjahre 1888 ist die Kranke dann, vielleicht infolge einer Embolie, plötzlich gestorben.

4. Johanna P. (Fall 38 der Tabelle), ledig, 26 Jahre, litt an einer Retroflexio uteri, starken Menorrhagien und Dysmenorrhoea. Nachdem gegen diese Leiden die verschiedensten Kurén erfolglos geblieben waren, wurde die Kranke am 8. Februar 1887 castrirt. Beide Ovarien liessen sich leicht und vollständig mit sammt den Infundibula tubae entfernen. Der Verlauf nach der Operation war normal und die Menses blieben vier Monate nach der Operation vollkommen aus. 
Dann traten aber Blutungen auf, die anfangs sehr hänfig kamen, lange dauerten und stärker als die Menses waren. In diesem Zustande wurde die Kranke am 3. October 1887 wieder aufgenommen. Es fand sich ein kleines Exsudat im linken Parametrium, ausserdem die Uterushöhle weit und anscheinend mit hypertrophischer Schleimhaut ausgekleidet. Der Uterus wurde ausgeschabt, wobei sich nur wenig Schleimhaut abschaben liess, die mikroskopisch ein normales Verhalten zeigte. Seit dieser Zeit wurden die Menses anfangs regelmässig, später mit dem Schrumpfen des Exsudates kamen sie nur jede sechs Wochen und waren bedeutend schwächer als früher; bis zum Mai 1888 waren sie aber noch immer vorhanden.

5. Frau G. (Fall 41 der Tabelle), 37 Jahre, litt an rückfülliger Perimetritis auf beiden Seiten. Es wurde am 12. Juli 1888 die Laparatomie gemacht und beide Tuben sammt den Ovarien entfernt. Die rechte Tube war geschlossen, ziemlich stark aufgetrieben und sammt dem Hierstocke von neugebildetem Bindegewebe dicht umfasst. Es wurde der Eierstock stumpf ausgelöst, dann die Tube unterbunden und entfernt. Auch das linke Ovarium war von Pseudomembranen umgeben und mit dem Mesocoecum breit verwachsen; es wurde ebenfalls grösstentheils stumpf abgelöst und dann mit der Tube, die im geringen Grade aufgetrieben war, entfernt. Es ist möglich, dass etwas Ovarialgewebe sitzen blieb. Glatte Heilung. Bald nach der Entlassung andauernde Blutungen, herrührend von einem birngrossen Polypen im Uterus. Nach Entfernung desselben am 1. October wurden die Menses bis Mai 1888 regelmässig, sechswöchentlich, zwei bis drei Tage hindurch, mit sehr geringem Blutabgange.

Da in vier von diesen Fällen die Ovarien oder der Ovarialtumor aus Pseudomembranen stumpf ausgeschält werden musste, ist das Zurückbleiben von Ovarialresten entweder sicher oder doch wahrscheinlich. Hegarl) hat betont, dass das kleinste im Körper zurückgelassene Theilchen von Ovarialgewebe genügt, um den Menstruationsvorgang zu unterhalten. Im fünften Falle findet sich ein kleines Exsudat im linken Parametrium, welches wohl als Urheber des Fortbestehens der Periode anzusehen ist. Hegar ${ }^{2}$ glaubt wenigstens, dass der Nervenreiz zur Menstruation anstatt vom Ovarium auch von einem an dieser Stelle sitzenden Exsudate ausgehen kann. Alle fünf Misserfolge sind also ungezwungen zu erklären und ändern an der Thatsache nichts, dass nach Exstirpation der Ovarien gewöhnlich Menopause eintritt.

Die Tabelle ergiebt in Procenten, dass in 66 Proc. die Menopause sofort auftrat, in 22 Proc. später und in 12 Proc. ganz ausblieb. Oder,

1) Die Castration der Frauen, S. 65.

2) Der Zusammenhang der Geschlechtskrankheiten mit nervösen Leiden. 
nach künstl. Verluste d. Ovarien einerseits $u$. d. Uterus andererseits.

wenn man die beiden ersten zusammenfasst, so trat in 88 Proc. die Menopause sofort oder später ein, und nur in 12 Proc. ist ein Misserfolg zu verzeichnen.

Ich habe nun dies Ergebniss mit dem bisher in der Literatur vorhandenen verglichen. Hegar ${ }^{1}$ ), der als Erster die Castration ausgeführt hat, erörtert in seiner grundlegenden Arbeit diese Verhältnisse bereits ausführlich. Fr nimmt an, dass nach der Castration die Menstruation nicht mehr auftritt, wenn er auch das ausnahmsweise Vorkommen nicht leugnet. Von 20 Fällen sah er in 16 (80 Proc.) die Menstruation aufhören, ein Ergebniss, das unserem nahe kommt. Schmalfuss ${ }^{2}$ ) stellte 32 Fälle zusammen, von denen in 17 Fällen, also in 53 Proc., die Menopause sofort, in 12 Fällen, also in 37 Proc., erst nach einiger Zeit erfolgte, und in 3 Fällen, also in 10 Proc., ganz ausblieb.

1884 hat $\mathrm{Wiedow}^{3}$ ) die erste grössere Statistik gebracht. Bei 76 Fällen von Castration trat in 61 die Menopause sofort ein, in sechs Fällen waren unregelmässige schwache Blutungen vorhanden, und in zwei Fällen fehlte die Angabe über die Blutungen. In einem Falle traten hinterher Blutungen auf, die nach Entfernung eines submucösen Polypen vollkommen aufhörten. In sechs Fällen traten häufige, theils regelmässige, theils unregelmässige Blutungen hinterher auf. Im Ganzen blieben also die Blutungen in 12 von 74 Fällen hinterher bestehen, das ist in 16,3 Proc., während in 62 von 74 Fällen, das ist in 83,7 Proc., die Menopause sofort oder später eintrat.

1885 stellte Tissier ${ }^{4}$ ) alle bis dahin bekannten Fälle von Castrationen zusammen. Indem er den Wiedow'schen noch etwa 80 weitere Fälle hinzufügt, kann er im Ganzen über 171 Castrationen berichten. Von diesen sind 26 gestorben, so dass man nur an 145 Fällen das Verhalten der Menstruation nach der Operation prüfen kann. Tissier kommt zu dem Ergebnisse, dass nur in zehn Fällen die Menstruation fortgedauert habe, in allen übrigen früher oder später vollkommene Menopause eingetreten sei. Diese Zahlen stimmen mit den Wiedow'schen nicht überein. Ich fand, dass Tissier nur die Fälle als wiederkehrende Menstruation

1) Die Castration der Frauen.

2) Dieses Archiv, Bd. XXVI.

3) Ebendaselbst, Bd. XXV.

4) De la castration de la femme. Thèse de Paris 1885. 
gerechnet hat, wo hinterher regelmässig typische Blutungen eingetreten waren, dagegen sind diejenigen fortgelassen, wo hinterher nur noch schwächere Blutungen oder stärkere, aber unregelmässig in grösseren Zwischenräumen, gekommen waren. Rechnen wir diese Fälle mit als wiederkehrende Menstruation, wie ich es bisher bei den übrigen Zusammenstellungen gethan habe, so bekommen wir 17 Fälle fortdauernder Menstruation von 145, das ist 11,7 Proc. In den übrigen 128 Fällen trat die Menopause ein, und zwar in 21 Fällen erst, nachdem mehrere Male noch eine menstruelle Blutung erfolgt war, in 107 aber sofort nach der Operation.

Auch $\mathrm{P} e ́ a n^{1}$ ) sah die Menstruation nur ausnahmsweise weitergehen, gewöhnlich hörte sie sofort auf, manchmal erst später.

Die folgende Tabelle fasst die Ergebnisse zusammen.

\begin{tabular}{|c|c|c|c|c|}
\hline \multicolumn{3}{|c|}{$\begin{array}{l}\text { Fälle, in denen } \\
\text { die Menopause erfolgte }\end{array}$} & \multicolumn{2}{|c|}{$\begin{array}{l}\text { Fälle, in denen } \\
\text { sie ausblieb }\end{array}$} \\
\hline Hegar: & 80,0 & Proe. & 20,0 & \\
\hline Wiedow: & 83,7 &, & 16,3 &, \\
\hline Tissier: & 88,3 & ," & 11,7 & $"$ \\
\hline Schmalfuss: & 90,0 & 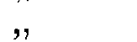 & 10,0 & , \\
\hline Glaevecke: & 88,0 & 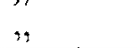 & 12,0 & $"$ \\
\hline $\begin{array}{l}\text { Summa: } \\
\text { Durchschnit }\end{array}$ & $\begin{array}{r}130,0 \\
86,0\end{array}$ & & $\begin{array}{l}70,0 \\
14,0\end{array}$ & pioc. \\
\hline
\end{tabular}

Meine Ergebnisse stehen ungefähr in der Mitte. In 86 Proc. aller Fälle hört also nach der Castration die Periode ganz auf.

In der Literatur giebt es aber Stimmen genug, die sich anders aussprechen.

Goodman fand bei 31 doppelseitigen Ovariotomien, die von den verschiedensten Operateuren in den Jahren 1843-1872 gemacht sind, dass nur in 13 Fällen, 42 Proc., die Menses nicht wieder erschienen (s. Hegar). Peaslee ${ }^{2}$ ) sah sieben Fälle mit unzweifelhafter Rückkehr der Blutungen nach doppelseitiger Ovariotomie, häit sie aber selbst für pathologische Uterusblutungen, die er „Metrostaxis“" nennt. 1880 hat 0 rmières ${ }^{3}$ ) alle bis dahin bekannten Fälle von doppelseitiger Ovariotomie und Castration zusammengestellt, einschliesslich der erwähnten Fälle von Go odman und Peaslee. Seine Ergebnisse sind schon etwas günstiger, denn von

1) Gazette médicale de Paris 1880.

2) Ovarian tumors. New York 1872.

3) Sur la menstruation après l'ovariotomie et l'hysterectomie. Thèse de Paris 1880. 
92 Fällen blieb in 48 Fällen (53 Proc.) die Menstruation aus. Ich habe aber bei $O \mathrm{r}$ mières eine ganze Reihe von Ungenauigkeiten aufgefunden. In einem Falle ist nur ein Theil des linken Ovarium, in einem anderen Falle nur das eine Ovarium entfernt worden und das andere nachweislich cystisch entartet gewesen. Dass hier gesundes Ovarialgewebe zurückgeblieben war, geht daraus hervor, dass. die Frau noch einen Knaben geboren hat. In weiteren acht Fällen sind die Menses nur ein oder mehrere Male nach der Operation gekommen, schliesslich aber vollkommen verschwunden. Ziehen wir diese Fälle $a b$, so steigt der Procentsatz der nicht wiederkehrenden Menstruation auf 63 Proc. In den von Ormières angeführten Fällen handelt es sich nun in weitaus der Mehrzahl um doppelseitige Ovariotomien, bei denen cystisch entartete Ovarien oder andere Ovarientumoren entfernt worden sind. Es ist hier also sehr leicht ein Irrthum in der Diagnose oder das Zurückbleiben eines gesunden Ovarialpartikelchens möglich gewesen. In ziemlich vielen Fällen sind die Angaben von der Frau später brieflich gemacht worden, so dass eine absichtliche Täuschung hat stattfinden können. Sondern wir die Fälle von wirklicher Castration aus, so weit es nach den oft ungenügenden Krankengeschichten möglich ist, so bleiben nur 11 Fälle mit wiederkehrender Periode von allen 92 übrig und Ormières würde dann zu demselben Ergebnisse von ungefähr 12 Proc. kommen wie wir.

Wir können daher wohl als feststehend annehmen, dass nur in etwa 14 Proc. aller Fälle nach der Castration die Menses, theils regelmässig, theils unregelmässig, theils stark, theils schwach andauern. Doch sind diese 14 Proc. durchaus noch nicht immer als Misserfolg der Operation im praktischen Sinne aufzufassen. Denn nicht selten wurden die Blutungen hinterher bedeutend schwächer und seltener. Ein vollkommener Misserfolg war nur sehr selten.

Nach der von mir oben dargelegten Menstruationstheorie muss die Menstruation nach der Castration aufhören. Es fällt der durch das Wachsen der Follikel entstandene Nervenreiz fort und damit die Grundursache zur Menstruation. Woran liegt es nun, dass in den vorhin erwähnten Fällen die Menstruation nach Fortnahme der Ovarien fortdauert? Diese Frage ist schon zum grössten Theile von Hegar) beantwortet worden. Es können entweder Ovarienreste zurückgeblieben sein, oder ein vorhandenes

1) Die Castration der Frauen. Leipzig 1878. 
accessorisches drittes Ovarium wurde nicht mit entfernt. Auch können Exsudate oder Schwielen, die sich an der Stelle der fortgenommenen Ovarien gebildet haben, den Nervenreiz zur Hyperämie und Hämorrhagie noch von Zeit zu Zeit auf den Uterus übertragen. Ferner können submucöse oder interstitielle Myome vorhanden sein, die in das Lumen der Uterushöhle hineinragen und hier einen hyperämischen Reizzustand der Schleimhaut unterhalten, der zu Blutungen Veranlassung giebt. Endlich kann ein sonstiger pathologischer Zustand des Uterus oder speciell der Uterusschleimhaut im Laufe der Zeit zu Blutungen aus der Gebärmutter führen, die dann als fortbestehende Menstruation gedeutet werden.

\section{B. Auftreten von vicariirenden Menstruationsblutungen nach der Castration.}

Es ist oft beobachtet worden, dass, wenn die Menses durch irgend einen kranken Zustand des Uterus oder der Ovarien zeitweilig oder dauernd versiegt waren, anstatt der Menstruationsblutungen vicariirende Blutungen aus anderen Organen sich einstellten. Die zur Zeit der Menstruation auftretende Congestion ist nicht auf die Genitalorgane beschränkt und bei Behinderung des Blutaustrittes in die Gebärmutterhöhle sucht der Organismus sich einen anderen Ausweg, um das gestörte Gleichgewicht in der Blutvertheilung wieder herzustellen. Es sind Fälle genug bekannt, wo solche vicariirende Blutungen aus Mund, Nase, After u. s. w. auftraten. Brière de Boismontl) und Heitzmann ${ }^{2}$ ) haben eine grosse Anzahl derartiger Beobachtungen zusammengestellt. Fricker ${ }^{3}$, , Obermeier ${ }^{4}$ ) und Beigel ${ }^{5}$ ) sahen vicariirende Blutungen aus der Nase zu Stande kommen, Watson ${ }^{6}$ ) und Decaisne ${ }^{7}$ ) aus dem Magen, Franchis) aus den Lungen, Dunlap ${ }^{9}$ ) aus dem Zahnfleische mit tödtlichem Ausgange und

1) Die Menstruation. Berlin 1842.

2) Medicinische Jahrbücher. Wien 1884.

3) Württembergisches medicinisches Correspondenzblatt 1844.

4) Virchow's Archiv 1872, Bd. LIV.

5) Krankheiten des weiblichen Geschlechtes. Erlangen 1874.

6) Lectures on the Principles and Practice of Physic.

7) Gazette des Hôpitaux 1874.

8) Antologia medica. Maggio 1834.

9) Edinburgh monthly Journal, April 1850, p. 371. 
$\mathrm{Law}^{1}$ ) aus dem Ohre. Heusinger ${ }^{2}$ ) und Le Fort ${ }^{3}$ ) beobachteten Fälle, in denen der Ort der Blutungen wechselte zwischen After, Blase, Hand, Ohr, Brustwarze, Magen und Nase. Kri e g e ${ }^{4}$ ) giebt eine Zusammenstellung von $\mathrm{Puech}{ }^{5}$ ), der eine vicariirende Menstrualblutung aus dem Magen $32 \mathrm{Mal}$, aus den Brüsten $25 \mathrm{Mal}$, aus den Lungen $24 \mathrm{Mal}$, aus der Nasenschleimhaut $18 \mathrm{Mal}$ fand.

In allen diesen Fällen war die Menstruation durch irgend einen krankhaften Zustand zeitweilig oder dauernd unterdrückt, aber die Frauen waren doch im Besitze der Ovarien, welche, wie wir annehmen müssen, normal functionirten. Sie decken sich also nicht vollksommen mit meinen Fällen, in denen die Ovarien durch die Castration entfernt worden waren. Immerhin haben sie mit denselben das Gemeinsame, dass keine Menstruation mehr stattfand, dass also ein Blutabgang, an den der Organismus durch Jahre gewöhnt war, nicht mehr zu Stande kam. Es wäre also denkbar, dass der Organismus an Stelle der gewöhnten menstruellen Blutabgänge vicariirende Blutungen treten liesse. Ich habe meine Fälle auch nach dieser Richtung hin verwerthet.

In der Literatur fand ich nur folgende Angaben: Tauffer ${ }^{6}$ ) sah nach einer Castration einmal Nasenbluten statt der Menses auftreten und Schmalfuss ${ }^{7}$ ) berichtet, dass eine an einem Herzfehler leidende Kranke nach Castration angeblich fast täglich $\mathrm{Na}$ sembluten und Blutspeien hatte. Unter meinen 44 Fällen finde ich nur zwei Mal die Angabe von vicariirenden Blutungen. In dem einen Falle stellte sich zur Zeit der wieder erwarteten Periode 2-3 Mal hintereinander geringes Nasenbluten ein, in dem anderen lag die Vermuthung eines Ulcus ventriculi vor. Diese Frau hatte schon früher zuweilen Blutspeien gehabt und erbrach zur Zeit der wieder erwarteten Periode einmal zwei bis drei Mundvoll Blut, woran sich einige Tage lang anhaltende Magenbeschwerden anschlossen.

Man kann diesen vier Fällen kein grosses Gewicht beilegen und darf wohl annehmen, dass die Unterdrückung der Menstruation durch die Castration nur sehr selten Veranlassung zu vicariirenden

1) Churchill, Diseases of women.

2) Schmidt's Jahrbücher, Bd. IX.

3) L'Union 1876, Vol, 91.

4) Die Menstruation. Berlin 1869.

5) Gazette des Hôpitaux, 21. April 1863.

6) Zeitschrift für Geburtshülfe und Gynäkologie 1883 , Bd. IX.

7) Dieses Archiv, Bd. XXVI. 
Blutungen giebt, und dass ihnen, wenn sie überhaupt erfolgen, ihrer geringen Menge wegen praktisch keine Bedeutung beizulegen ist.

\section{Auftreten von Ausfallserscheinungen nach der Castration.}

Fast regelmässig stellen sich nach der Castration eine Reihe von körperlichen Beschwerden ein, welche ich unter derm Namen "Ausfallserscheinungen" zusammengefasst habe, weil sie durch den Ausfall der Ovarien und den dadurch bedingten Ausfall der Menstruation hervorgerufen werden. Hegar ${ }^{1}$ ) hat diese Erscheinungen sofort nach seinen ersten Castrationen beobachtet. Wir sehen dieselben 1) zur Zeit der nicht wiederkehrenden Menstruation und 2) in der Zwischenzeit auftreten.

I. Körperliche Beschwerden, die zur Zeit der nieht wiederkehrenden Menstruation nach der Castration auftreten.

Molimina menstrualia. ${ }^{2}$ )

Nach Hegar bestehen diese Beschwerden gewöhnlich in Kreuzschmerzen, Leibschmerzen zu beiden Seiten des Uterus und verstärktem weissen Flusse. Schmalfuss ${ }^{3}$ ) sah in etwa 18 von 32 Fällen dieselben Beschwerden, oft ziemlich hochgradig und manchmal recht lange dauernd, in einem Falle fünf Jahre. Prochownick sah fast ausnahmslos in regelmässigen vierwöchentlichen $\mathrm{Z}$ wischenräumen alle diejenigen Beschwerden auftreten, welche vorher die Menstruation begleitet hatten, und folgerte daraus, dass durch die Fortnahme der Ovarien nur ein Theil der zur Menstruation Anlass gebenden Momente entfernt sei, welcher besonders die Menstruationsblutungen hervorriefe, dass dagegen andere Ursachen zurückblieben, welche diese regelmässigen Congestionen zu den Genitalien unterhielten. In den Krankengeschichten beschreibt er die Erscheinungen zur Zeit der nicht wiederkehrenden Menses als dieselben Beschwerden, die wir als Molimina menstrualia von Hegar und

1) Die Castration der Franen.

2) Der Ausdruck Molimina menstrualia wird zunächst gebraucht von den bei der Menstruation oft vorhandenen Beschwerden. Man hat ihn aber auch auf die Beschwerden übertragen, die zur Zeit der Pubertät bei nicht zu Stande gekommener Menstruationsblutung auftreten. Ich habe mir daher auch erlaubt, denselben für die nach der Castration zur Zeit der nicht wiederkehrenden Menstruation auftretenden Beschwerden zu gebrauchen, und folge hierin dem Beispiele von Hegar, Schmalfuss and Martin.

3) Dieses Archiv, Bd. XXVI.

4) Ebendaselbst, Bd. XXI. 
Schmalfuss angegeben finden. Ich habe von Anfang an auf diesen Punkt geachtet und genau die Beschwerden, die vor der Castration mit der Menstruation verbunden waren, mit denen verglichen, die sich nach der Operation zur Zeit der nicht wiederkehrenden Menstruation einstellten. Die Ergebnisse sind kurz in umstehender Tabelle (S. 18) zusammengestellt.

Uebereinstimmend mit Schmalfuss, aber entgegen den Beobachtungen von Prochownick, der fast in allen Fällen hinterher Beschwerden auftreten sah, fand ich, dass von 36 Castrirten 18, also 50 Proc., ganz frei von diesen Erscheinungen waren. Ich bemerke ausdrücklich, dass ich in allen Fällen auf diese Beschwerden gefahndet habe, dass ich eine ganze Reihe von Frauen nach der Castration besonders angewiesen habe, auf die Periodenzeit zu achten, so dass mir selbst geringfügige Beschwerden in dieser Hinsicht wohl nicht entgangen sind.

In Bezug auf das Verhältniss der Beschwerden vor und nach der Operation sind alle Fälle in vier Gruppen zu bringen.

Vor der Castration:

Keine Beschwerden

Beschwerden

Beschwerden

Keine Beschwerden
Nach der Castration:

Keine Beschwerden $7=19,4$ Proc.

Keine Beschwerden $11=30,6$;,

Beschwerden

Beschwerden

$$
\begin{aligned}
13 & =36,1 \quad, \\
5 & =13,9,, \\
36 & =100 \text { Proc. }
\end{aligned}
$$

In einer kleinen Reihe von Fällen bestanden also weder vor, noch nach der Castration Beschwerden zur Zeit der Periode, in einer etwas grösseren Anzahl verschwinden die früheren Beschwerden durch die Operation vollkommen. Meistens sind es Fälle von Myoma uteri, in denen vor der Operation Beschwerden vorhanden waren. Dieselben verschwanden nach der Operation, die zu einem. raschen Schrumpfen der Tumoren führte, und neue wurden durch die Operation nicht hervorgerufen. Am häufigsten sind vor und nach der Operation Beschwerden zu verzeichnen, und zwar in einer nur sehr kleinen Anzahl dieselben Beschwerden, in den meisten Fällen sind dagegen nach der Operation andere und zahlreichere Beschwerden angegeben, als vor derselben. Vor der Castration gehen gewöhnlich wehenartige Schmerzen von einem Myom oder von einem in einer Seite des Leibes liegenden Tumor aus. Nach der Operation sind es mehr durch einen Nervenreiz entstandene Beschwerden, deren Grund im Fortfalle der Ovarien zu suchen ist. Ich bin also zu anderen Ergebnissen als Prochownick gekommen, der immer dieselben Beschwerden vor und nach der Operation auftreten sah. 
18 Glaevecke, Körperl. u. geistige Veränderungen im weibl. Körper

Tabelle II. Verhalten der Molimina menstrualia.

\begin{tabular}{|c|c|c|c|c|c|}
\hline \multirow{2}{*}{ 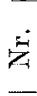 } & \multirow{2}{*}{ Name } & \multicolumn{2}{|c|}{ Nähere Beschreibung der Molimina menstrualia } & \multirow{2}{*}{$\begin{array}{l}\text { Ende der } \\
\text { M. m. }\end{array}$} & \multirow{2}{*}{$\begin{array}{r}\text { Noch } \\
\text { nicht z } \\
\text { Endena }\end{array}$} \\
\hline & & vor der Operation & nach der Operation & & \\
\hline 1 & Vo. & Schmerzen im Cnterleibe & Keine & & \\
\hline 2 & Schl. & $\begin{array}{l}\text { Schmerzen über der Sym- } \\
\text { physe und im Kreaze }\end{array}$ & & & \\
\hline 3 & Wn. & Keine & Vermehrte Wallungen & & $1^{1 / 2} \mathrm{Ja}$ \\
\hline $\begin{array}{l}4 \\
5\end{array}$ & $\begin{array}{l}\text { Fu. } \\
\text { Pe. }\end{array}$ & $\begin{array}{l}\text { Leichte Kreuzschmerzen } \\
\text { Wehenartige Schmerzen }\end{array}$ & $\begin{array}{l}\text { Kopfschmerzen und Vebelkeit } \\
\text { Kopfschmerzen }\end{array}$ & $1 / 2 \mathrm{Jahr}$ & $\mathbf{1}^{1 / 2} \mathrm{Ja}$ \\
\hline $\begin{array}{l}6 \\
7\end{array}$ & $\begin{array}{l}\mathrm{Ha} . \\
\mathrm{Ho} .\end{array}$ & $\begin{array}{l}\text { Keine } \\
\text { do. }\end{array}$ & $\begin{array}{l}\text { Leichte Kreuzschmerzen } \\
\text { Keine }\end{array}$ & $13 / 4 \mathrm{Jahr}$ & \\
\hline 8 & La. & $\begin{array}{l}\text { Schmerzen im Kreuze und } \\
\text { denSchenkeln,Erbrechen }\end{array}$ & $\begin{array}{l}\text { Schmerzen im Rücken und in den } \\
\text { Schenkeln }\end{array}$ & 2 Jahre & \\
\hline 9 & $\mathrm{Nis}$. & $\begin{array}{l}\text { Wehenartige Schmerzen } \\
\text { vor u. während derRegel }\end{array}$ & $\begin{array}{l}\text { Kopfschmerzen, Ziehen imLeibe, in den } \\
\text { Beinen und in den Brüsten }\end{array}$ & & 2 Jahri \\
\hline 10 & Bo. & $\begin{array}{l}\text { Heftige Schmerzen über } \\
\text { der Symphyse }\end{array}$ & $\begin{array}{l}\text { Wühlen und Unruhe im Leibe, Angst, } \\
\text { Wallungen, Fluor albus }\end{array}$ & 2 Jahre & \\
\hline 11 & L. & $\begin{array}{l}\text { Schmerzen in d. Schooss- } \\
\text { gegend }\end{array}$ & $\begin{array}{l}\text { Schmerzen und Brennen im Rücken } \mathbf{u} . \\
\text { Leibe, Fluor albus, Schwellend.Varicen }\end{array}$ & 4 Monate & \\
\hline 12 & Mo. & Leichte Kreuzschmerzen & Keine & $1 \mathrm{Jahr}$ & \\
\hline 13 & Ni. II & Keine & $\begin{array}{l}\text { Krampfhafte Schmerzen im Leibe, ver- } \\
\text { mehrte Uebergiessungen }\end{array}$ & $1 / 2 \mathrm{Jahr}$ & \\
\hline 14 & Schr. I & & Keine & & \\
\hline 15 & v. L. & Kopfschmerzen & $\begin{array}{l}\text { Leichtes Ziehen im Leibe, vermehrte } \\
\text { Wallungen }\end{array}$ & & $\mathbf{4}_{\mathscr{2}}^{1} \mathrm{Jahr}$ \\
\hline 16 & An. & Kreuz- u. Leibschmerzen & $\begin{array}{l}\text { Kreuz- und Leibschmerzen, starke } \\
\text { Kopfschmerzen }\end{array}$ & 4 Monate & \\
\hline $\begin{array}{l}17 \\
18\end{array}$ & $\begin{array}{l}\text { Ma. } \\
\text { Pet. I }\end{array}$ & $\begin{array}{l}\text { Keine } \\
\text { Starke Rücken- und Leib- } \\
\text { schmerzen }\end{array}$ & $\begin{array}{l}\text { Keine } \\
\text { do. }\end{array}$ & & \\
\hline 19 & Schm. & Schmerzen im Unterleibe & do. & & \\
\hline 20 & Kö. & Drän & do. & & \\
\hline 21 & Ka. & $\begin{array}{l}\text { Schmerzen } z \text {, beiden Seiten } \\
\text { des Leibes }\end{array}$ & OP & & \\
\hline 22 & Gr. & Keine & $\begin{array}{l}\text { Ziehen durch den ganzen Körper, } \\
\text { Drängen in der Vagina }\end{array}$ & & $1 \frac{1}{2} \mathrm{Ja}$ \\
\hline 23 & Schr. II & Wehenartige Schmerzen & $\begin{array}{l}\text { Kopfschmerzen, heisse Uebergiessungen, } \\
\text { Schwindel }\end{array}$ & & $11 / 4 \mathrm{Ja}]$ \\
\hline 24 & Fra. & $\begin{array}{l}\text { Schmerzen in der linken } \\
\text { Seite }\end{array}$ & $\begin{array}{l}\text { Schmerzen in der linken Seite, starke } \\
\text { Kopfschmerzen, Schwindel, Ohnmach- } \\
\text { ten, Menstruationsexanthem }\end{array}$ & & $1 \mathrm{Jah}:$ \\
\hline 25 & Na. & Schmerzen i. d. link, Seite & Keine & & \\
\hline 26 & Fr. & $\begin{array}{l}\text { Geringe Schmerzen im } \\
\text { Rücken }\end{array}$ & $\begin{array}{l}\text { Schneiden u. Stechen zu beiden Seiten } \\
\text { des Unterleibes, Uebelsein, Frösteln, } \\
\text { Schmerzen in den Brüsten }\end{array}$ & & $1 \frac{1 / 4}{} \mathrm{Jal}$ \\
\hline 27 & Bob. & Ger. Schmerzen im Leibe & Keine & & \\
\hline & Lü. & belkeit und Aufstossen & do. & & \\
\hline & & im Leibe & do. & & \\
\hline & $\begin{array}{l}\text { Je. } \\
\text { Ap. }\end{array}$ & $\begin{array}{l}\text { Keine } \\
\text { do. }\end{array}$ & $\begin{array}{l}\text { do. } \\
\text { do. }\end{array}$ & & \\
\hline 32 & Ju. & $\begin{array}{l}\text { Krampfhafte Schmerzen im } \\
\text { Leibe, starkes Erbrechen }\end{array}$ & $\begin{array}{l}\text { Rücken-, Leib- und Kopfschmerzen, } \\
\text { Ziehen in allen Gliedern, Ohrensausen }\end{array}$ & 1 Jahr & \\
\hline 33 & $\begin{array}{l}\text { Lüb. } \\
\text { Ro. } \\
\text { He. }\end{array}$ & $\begin{array}{l}\text { Keine } \\
\text { do. } \\
\text { do. }\end{array}$ & $\begin{array}{l}\text { Meteorismus u. Drang nach dem Rectum } \\
\text { Keine } \\
\text { do. }\end{array}$ & & $1 / 2 \mathrm{Jah}$ \\
\hline 60 & Re. & Wehenartige Schmerzen & $\begin{array}{l}\text { Kopf- und Kreuzschmerzen, allgemeine } \\
\text { Mattigkeit }\end{array}$ & & 1. Jahn \\
\hline
\end{tabular}


nach künstl. Verluste d. Ovarien einerseits u. d. Uterus andererseits.

In der kleinsten Anzahl von Fällen sah ich Beschwerden nach der Castration auftreten, wo vor derselben keine vorhanden gewesen waren: Diese Fälle beweisen am deutlichsten, dass lediglich durch den Fortfall der Ovarien Beschwerden in der Menstruationszeit auftreten können.

Ich werde hier selbstverständlich nur diejenigen Beschwerden betrachten, welche nach der Castration auftraten und welche als Ausfallserscheinungen anzusehen sind.

Am häufigsten waren es Leibschmerzen, die gewöhnlich als ziehende, krampfhafte Schmerzen zu beiden Seiten des Uterus geschildert werden, nächstdem Kreuzschmerzen, die sich entweder bis in die Oberschenkel hinunter zogen, oder mehr nach oben, nach dem Rücken zu, ausstrahlten, zwei Mal sogar bis in die Brüste. In einem Falle bemerkte die Kranke jedesmal ein Anschwellen der seit langer Zeit am Beine vorhandenen Varicen. In mehreren Fällen klagten die Kranken über Kopfschmerzen oder vermehrte Wallungen nach dem Kopfe, in anderen über ein Ziehen im ganzen Körper. Auch Uebelkeit, Meteorismus, verbunden mit Wühlen oder Völle im Leibe, ein Mal auch häufiger Stuhldrang, ferner rein nervöse Erscheinungen, wie: Schwindel, Angstzustände, Ohnmachten, Obrensausen und Frösteln, kamen nicht selten vor. Als unmittelbar von den Geschlechtstheilen ausgehende Erscheinungen sind in zwei Fällen vermehrter Fluor albus, in einem Dranggefühle in der Vagina angegeben. Interessant waren folgende zwei Fälle, in denen jedes Mal zur Zeit der Menses ein Menstruationsexanthem auftrat.

1) Frau Fr. (Fall 24 der Tabelle II) wurde wegen einer linksseitigen Oophoritis und der Erscheinungen der Hysterie am 8. Febr. 1887 castrirt. In den ersten vier Menstruationsperioden (April bis Juli) erschien jedesmal ein kleines papulöses, knötchenförmiges Exanthem, das besonders auf den Beugeseiten der Extremitäten auftrat. Dasselbe juckte stark, so dass die Fran sich häufig kratzen musste und dadurch die Sache Aehnlichkeit mit Seabies bekam, die jedoch sicher auszuschliessen war. Das Exanthem nahm gewöhnlich vier bis fünf Tage zu und verschwand in den nächsten fünf bis sechs Tagen langsam. Die Kranke will dasselbe Exanthem frither bei den Schwangexschaften häufig zur Zeit der nicht wieder erschienenen Menses gehàbt haben. Bei einer Menstruationsepoche hatte ich selbst Gelegenheit, das Exanthem kommen und schwinden zu sehen. Nach einem halben Jahre verlor sich dieser Aussehlag und ist nicht wiedergekommen.

2) Eine 37 jährige Frau (Fall 33 der Tabelle II) wurde wegen Myoma uteri castrirt. Etwa vier Monate darauf trat zuerst zur Zeit der Menses ein papulöses Exanthem auf beiden Beugeflächen der 
Arme auf, das sehr stark juckte, aber ohne weitere Störungen zu machen nach vier bis fünf Tagen wieder verschwand. In den nächsten sechs Monaten kam dann das Exanthem regelmässig zur Zeit der Menses wieder, blieb aber dann für immer weg. Diesen Fall berichte ich aber nur nach den Angaben der Frau.

Fälle von Exanthemen vor oder während der wirklich erscheinenden Periode sind in der Literatur mehrfach bekannt. Schramm ${ }^{1}$ ) sah bei einer Frau regelmässig zur Zeit der Periode Knötchen und Papeln am Handrüicken und am Halse, bei einer anderen feine rothe Knötchen, die streifenartig angeordnet waren, am Rücken auftreten. Wilhel $\mathrm{m}^{2}$ ) beschreibt haselnussgrosse, dunkelblaue Flecken an den Oberschenkeln, die kurz vor der Periode kamen und mit Nachlass derselben verschwanden. S till e ${ }^{8}$ ) veröffentlichte drei Fälle. In einem trat ein juckender Ausschlag an den oberen und unteren Gliedmaassen auf, in einem anderen kleine rothe Papeln an beiden Hand- und Fussrücken. Aehnliche Fälle sind von $\mathrm{Joseph}^{4}$ ), Pauli ${ }^{5}$ ), Janovsky und Schwing ${ }^{6}$ ) beschrieben worden. In zwei Fällen von Heitzmann ${ }^{7}$ ) zeigten sich die Hautaffectionen bei Frauen, denen die Menses theils vollkommen, theils zeitweise fehlten. Bei einer 20jährigen Magd, welche noch nie menstruirt gewesen war, zeigten sich aller vier Wochen vereinzelte, stark juckende, zerkratzte Knötchen auf einer lebhaft gerötheten Basis. Im zweiten Falle bestanden linsengrosse, rosenrothe bis tiefrothe Flecke, nur zwei bis drei Tage, welche nicht wiederkehrten, als es Verfasser gelungen war, die Menses wieder zu regeln.

Alle die beschriebenen Erscheinungen von Molimina menstrualia traten besonders stark stets in den ersten Monaten nach der Castration auf. In den meisten Fällen ist dann ein allmäliger Nachlass bis zum vollkommenen Verschwinden hin festzustellen, in einigen wenigen Fällen bleiben aber die Beschwerden lange Zeit hin beständig, bis sie dann ziemlich plötzlich endigen. Ihre Dauer ist ebenfalls grossen Schwankungen unterworfen. Während ich zwei bis drei Fälle verzeichnen konnte, in denen sie nur

1) Berliner klinische Wochenschrift 1878.

2) Ebendaselbst 1878 .

3) Ebendaselbst 1877 .

4) Ebendaselbst 1879 .

5) Ebendaselbst 1880 .

6) Centralblatt für Gynäkologie Bd. VI.

7) Wiener medicinische Jahrbücher 1884. 
während der ersten vier bis fünf Monate vorhanden waren, blieben sie in weitaus den meisten Fällen ein Jahr lang und darüber bestehen, ja wir finden in der Tabelle einen Fall, wo sie nach $4 \frac{1}{2}$ Jahren, wenn auch in vermindertem Maasse, noch vorhanden waren. Ihre Stärke ist meistens nicht sehr bedeutend, so dass die Frauen sie gewöhnlich erst auf specielles Nachfragen angaben. In einzelnen Fällen aber, besonders bei nervösen oder neurasthenischen Personen, truibten diese alle vier Wochen wiederkehrenden sehr heftigen Beschwerden doch manchmal den sonstigen guten Operatiouserfolg.

Die Erklärung dieser Molimina menstrualia müssen wir für die vier von uns aufgestellten Gruppen verschieden geben. Die erste Gruppe bedarf keiner weiteren Erklärung, ebenso ist die zweite Gruppe leicht verständlich. Von vornherein sollte man erwarten, dass nach der Operation mit dem Ausfalle der Menstruation auch die Beschwerden in allen Fällen aufhören würden; indess sehen wir in der dritten Gruppe, dass sie weiter fortgehen, ja sich noch steigern. Diese Thatsachen erkläre ich mir in folgender Weise.

Durch die Castration fallen die Ovarien und damit die von den Ovarien nach dem Centrum hin ausgehenden Nervenreize fort, das Centrum bleibt aber ungestört thätig. Man könnte sich denken, dass durch jahrelange Gewöhnung das Centrum so in seine Thätigkeiten eingearbeitet ist, dass es noch eine Zeit lang auch ohne erneuten Anstoss von Seiten des Ovarium fortarbeitet. Es würde dann auch nach Entfernung der Ovarien vom Centrum aus alle vier Wochen eine vorübergehende Hyperämie der Beckenorgane zu Stande kommen, die allerdings so schwach ist, dass sie eine menstruelle Blutung nicht hervorruft, die aber doch genügt, um die mit der Menstruation verbundenen Beschwerden zu unterhalten. So würden sich die krampfhaften Schmerzen im Unterleibe, die Kreuzschmerzen, das Gefühl von Völle im Leibe, das Dranggefühl in der Vagina und der vermehrte weisse Fluss erklären lassen. Ja man könnte sogar annehmen, dass vom Menstruationscentrum aus vasomotorische Bahnen, die auch sonst während der Menstruation thätig waren, nach verschiedenen Richtungen hin erregt werden, zumal da auf die nach dem Uterus hin gesandte Erregung keine Reaction von Seiten desselben erfolgen kann. So würden sich die heftigen Kopfschmerzen, die Magen-Darmerscheinungen, die Ohnmachten, Schwindelanfälle und Angstzustände erklären'lassen. Wenn wir in der dritten Gruppe sehen, dass die Beschwerden 
nach der Operation öfters stärker werden und in der vierten Gruppe sogar nach der Castration erst auftreten, so liessen sich diese Thatsachen dadurch erklären, dass die Molimina stärker werden oder überhaupt erst entstehen, weil die Menstruationsblutung fehlt. Da die Menstruationsblutung die im Uterus herrschende Hyperämie sofort vermindert und die Beschwerden abschwächt, so muss der Fortfall der Menstruationsblutung auch eine Steigerung der Beschwerden nach sich ziehen.

Meine Erklärungsversuche würden auch das nur noch zeitweilige Fortbestehen der Molimina menstrualia und das allmälige Abklingen derselben am besten verständlich machen, und zu denselben würde anch die Thatsache passen, dass die Molimina nur in der Hälfte aller Fälle vorkommen. Eben nicht in allen Fällen ist der nervöse Apparat so leicht reizbar und es erlischt die Nerventhätigkeit daher auch mit dem Aufhören des Reizes sofort.

\section{Die nach der Castration in der menstruationsfreien Zwischenzeit auftretenden Beschwerden. \\ Klimaleterische Beschwerden.}

Im Folgenden werden wir eine Reihe von körperlichen Beschwerden kennen lernen, die sich bei der Frau nach der Castration zu entwickeln pflegen. Sie kommen vorwiegend in der menstruationsfreien Zwischenzeit vor, sind aber an dieselbe nicht immer gebunden; sondern stellen sich auch, wenn auch seltener, zu der Menstruationszeit ein. Sie sind entschieden als Ausfallserscheinungen zu betrachten, das heisst sie sind durch den Fortfall der Ovarien bedingt. Hierfür spricht schon der Umstand, dass sie grosse Aehnlichkeit mit den nach der Menopause sich bei der Frau entwickelnden klimakterischen Beschwerden haben.

Wir werden in den folgenden Kapiteln sehen, wie durch die Castration gewissermaassen das Klimakterium antecipirt wird, und ich glaube daher auch mit Recht diese Beschwerden als klimakterische bezeichnen zu dürfen. Es sind dies:

1. Das Gefühl von heissen Uebergiessungen.

Hegar ${ }^{1}$ ) fand in recht vielen Fällen nach der Castration Anfälle von plötzlichem Hitzegefühl, gewöhnlich begleitet von einem Erröthen der Haut. Schmalfuss beobachtete in vielen seiner

1) Die Castration der Frauen. 
Fälle Anfälle von fliegender Hitze, P éan ${ }^{1}$ ), ,des bouffées de chaleur" bald mehr, bald weniger stark hervortretend. Auch Tissier") sah häufig „,des poussées de chaleur vers la tête". Meine Fälle sind in Tabelle III. kurz zusammengestellt.

Unter allen Beschwerden sind die heissen Uebergiessungen die häufigsten und stehen gewöhnlich im Vordergrunde. In meinen 42 Fällen fehlen sie nur 9 Mal. 5 von diesen 9 Fällen (Fall 2, 13, 20, 38 und 41) betreffen Frauen, bei denen die Menstruation nach der Castration weiter ging, also wahrscheinlich Ovarialgewebe sitzen geblieben ist. Schalten wir sie aus, so bleiben nur 4 Fälle, also 10,8 Proc. übrig, bei denen die heissen Uebergiessungen fehlen. Man hat ihnen die verschiedensten Namen gegeben, „Wallungen", „Fliegende Hitze“, „Congestionen nach dem Kopfe“, „Brühhitze“, „Heisse Uebergiessungen“, ,ardor fugax“ u. s. w. Der Vorgang wird fast von allen Frauen übereinstimmend genau geschildert, so dass man von ihm ein ganz typisches, scharf charakterisirtes Bild aufstellen kann. Die Anfälle beginnen gewöhnlich mit einer Art Aura, mit einem Schmerzgefühl, das im Unterleibe oder im Epigastrium localisirt wird, oft auch mit einem Frösteln; ihm folgt gewöhnlich blitzschnell ein starkes Hitzegefühl, das von unten nach dem Kopfe zu aufsteigt. Dabei wird die Haut der betreffenden Körpertheile, am stärksten die Haut des Gesichts hoch geröthet, so dass man die Anfälle auch sehen kann. Gewöhnlich gesellt sich dazu ein gewisses Angstgefühl und eine Beklemmung, die in die Herzgegend verlegt wird. Die Hitze verschwindet nach kurzer Dauer und unter Nachlass des beklemmenden Gefühls tritt ein bald stärkerer bald schwächerer Schweissausbruch auf. Mit dem Gefühle von Mattigkeit und Abgeschlagenheit schliesst dann die ganze Scene. Die Dauer beträgt nur 20 Secunden bis längstens 3 Minuten. Neben dem ausgebildeten Anfalle kommen auch abortive vor, bei denen die eine oder andere Theilerscheinung fehlt oder übersprungen wird.

Ich fand, dass die Anfälle gewöhnlich nicht sofort nach der Castration einsetzen, sondern meistens erst nach vier bis fünf Wochen, durchschnittlich in der fünften Woche pach der Castration Das spätere Einsetzen findet sein Analogon in den Wechseljahren, wo auch gewöhnlich, wie Börner ${ }^{3}$ ) betont, die fliegende Hitze

1) Gazette médicale de Paris 1880.

2) De la castration de la femme. Thèse de Paris 1885 .

3) Die Wechse]jahre der Frau. Stuttgart 1886. 
24 Glae vecke, Körperl.u. geistige Veränderungen im weib]. Körper

Tabelle III. Verhalten der Wallungen nach der Castration.

\begin{tabular}{|c|c|c|c|c|c|c|c|c|}
\hline \multirow[b]{2}{*}{ Ir } & \multirow[b]{2}{*}{ Name } & \multirow[b]{2}{*}{$\begin{array}{l}\text { Beginn } \\
\text { der Wal- } \\
\text { lungen }\end{array}$} & \multirow[b]{2}{*}{$\begin{array}{l}\text { Nähere Beschreibung der } \\
\text { Wallungen }\end{array}$} & \multicolumn{2}{|c|}{ Hinterher } & \multirow[b]{2}{*}{$\begin{array}{c}\text { Wal- } \\
\text { lungen } \\
\text { auch } \\
\text { Nachts }\end{array}$} & \multirow[b]{2}{*}{$\begin{array}{c}\text { Ende } \\
\text { der } \\
\text { Wal- } \\
\text { lungen }\end{array}$} & \multirow[b]{2}{*}{$\begin{array}{c}\mathrm{I} \\
\mathrm{he} \\
\mathrm{r} \\
\mathrm{J}\end{array}$} \\
\hline & & & & $\begin{array}{c}\text { Angst } \\
\text { a. Be- } \\
\text { klem- } \\
\text { mungen }\end{array}$ & $\begin{array}{r}0 \\
0 \\
0.0 \\
0 \\
0 \\
0 \\
0 \\
0 \\
0 \\
\end{array}$ & & & \\
\hline 1 & Vo. & & Sehr häufig. Allmälige Abnahme & - & - & - & $3 \mathrm{~J}$. & \\
\hline 2 & Ni. I. & & Keine & 0 & 0 & 0 & & \\
\hline 3 & Schl. & & Zuerst etwa $10 \mathrm{Mal}$ am Tage & - & - & - & $2 \mathrm{~J}$ & \\
\hline 4 & Wu. & 7 Wochen & $\begin{array}{l}\text { 3-4 Mal in } 24 \text { Stunden. Nach einem } \\
\text { Jahre jeden 3.-4. Tag }\end{array}$ & Ja & Ja & $\mathrm{Ja}$ & $11 / 2 \mathrm{~J}$ & \\
\hline 5 & Fu. & 6 Wochen & $4-5 \mathrm{Mal}$ in 24 Stunden & $\mathrm{Ja}$ & $\mathrm{Ja}$ & $\mathrm{Ja}$ & & 1, \\
\hline 6 & Pe. & 6 Wocben & Wiederholt am Tage & - & - & - & & \\
\hline 7 & Ha. & & Mehrmals täglich. Allmälige Abnahme & $\mathrm{Ja}$ & Ja & $\bar{T}$ & $1 \frac{1}{4} \mathrm{~J}$ & \\
\hline 8 & Ho. & & Mehrmals täglich. Allmälige A bnahme & - & - & Ja & & 6 \\
\hline 10 & $\begin{array}{l}\text { La. } \\
\text { Nis. }\end{array}$ & 3 Wochen & $\begin{array}{l}\text { In der ersten Zeit häufig, später selten } \\
\text { Mehrmals täglich. Zunme bei den }\end{array}$ & - & - & - & $2 \mathrm{~J}$ & \\
\hline 11 & Bo. & & $\begin{array}{l}\text { Regelzeiten } \\
\text { Zuerst etwa } 14 \mathrm{Mal} \text { täglich. Allmälige }\end{array}$ & $\mathrm{Ja}$ & $\mathrm{Ja}$ & $\ldots$ & & 2 \\
\hline L2 & L. & 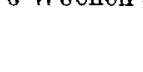 & $\begin{array}{l}\text { Besserung } \\
\text { Anfangs } 20 \mathrm{Mal} \text {, später } 2-3 \mathrm{Mal} \text { in }\end{array}$ & $\mathrm{Ja}$ & $\mathrm{Ja}$ & $\mathrm{Ja}$ & & $1^{1}$ \\
\hline & & & 24 Stunden & Ja & Nein & - & & $2^{3}$ \\
\hline $\begin{array}{l}13 \\
14\end{array}$ & Aa. & & Keine & 0 & 0 & 0 & & \\
\hline & Mo. & & $\begin{array}{l}\text { Zuerst senr hautg, jede } 5 \text { Mln. Nach } \\
2 \text { Jahren noch } 10-\mathbf{1 2} \mathrm{Mal}\end{array}$ & $\mathbf{J a}$ & Ja & Ja & & $2^{x}$ \\
\hline$! 5$ & Ni. II. & & Hänfige Uebergiessungen & - & Ja & - & & $\mathbf{1}^{1}$ \\
\hline 6 & Schr. I. & & Keine & 0 & 0 & 0 & & \\
\hline $\begin{array}{l}7 \\
8\end{array}$ & $\begin{array}{l}\text { v. L. } \\
\text { Au. }\end{array}$ & 5 Wochen & $\begin{array}{l}\text { Mehrmals }_{\varepsilon} \text { am Tage } \\
10 \text { Mal in } 24 \text { Stdn Allmälige Abnahme }\end{array}$ & - & $\overline{-}$ & $\begin{array}{l}\mathrm{Ja}_{\mathrm{a}} \\
\mathrm{Ja}\end{array}$ & & 4 \\
\hline 9 & Ma. & 5 prochen & 6 Mal, am Tage & Nein & Nein & - & & 1 \\
\hline 0 & De. & & Keine & 0 & 0 & 0 & & \\
\hline 11 & Pet. I. & 3 Wochen & $3-4$ Mal täglich & - & $\mathrm{Ja}$ & $\mathrm{Ja}$ & $11 / 2 \mathrm{~J}$ & \\
\hline : & Schm. & 8 Wochen & & - & $\mathrm{Ja}$ & $J a$ & & $1^{1}$ \\
\hline 3 & $\begin{array}{l}\mathrm{K} o ̈ . \\
\mathrm{Ka} .\end{array}$ & 7 Wochen & $\begin{array}{l}\text { Keine } \\
20 \text { Mal Tags, } 5-6 \text { Mal Nachts. }\end{array}$ & 0 & 0 & 0 & & \\
\hline 15 & Wor & 3 Worhen & Nach 1 Jahr nur noch selten & $\mathrm{Ja}$ & $\mathrm{Ja}$ & $\mathrm{Ja}$ & & $1^{1}$ \\
\hline 10 & Gr. & 3 wocnen & Nach $1 \frac{1}{4}$ Jahr $5-6$ Mal täglich & Nein & Ja & $\mathrm{Ja}$ & & $1^{3}$ \\
\hline 6 & Schr. II. & & 10 Mal Tags und etwa 3 Mal Nachts & $\ldots$ & $\mathrm{Ja}$ & Ja & & $1^{1}$ \\
\hline $\begin{array}{l}7 \\
18\end{array}$ & $\begin{array}{l}\text { Fr. } \\
\text { Na. }\end{array}$ & 5 Wochen & $\begin{array}{l}5-6 \text { Mal täglich } \\
6-7 \text { Mal täglich. Zunahme zor Zeit }\end{array}$ & $\mathrm{Ja}$ & $\mathrm{Ja}$ & $\mathrm{Ja}$ & & 11 \\
\hline i9 & Fra. & & $\begin{array}{l}\text { der Periode } \\
\text { Seltene Uebergiessungen. Zunahme }\end{array}$ & Nein & Nein & Nein & & 1 \\
\hline & & & $\begin{array}{l}\text { zur Zeit der Periode } \\
2-3 \text { Mal täglich }\end{array}$ & Ja & Nein & Nein & & 11 \\
\hline 1 & $\begin{array}{l}\text { Don. } \\
\text { Lî̀. }\end{array}$ & & $\begin{array}{l}2-3 \text { Mal täglich } \\
\text { Zeitweilig aufsteigende Hitze }\end{array}$ & Nein & Nain & & & \\
\hline 2 & Sa. & & $7-8$ Mal in 24 Stunden & - & $\mathrm{Ja}$ & Ja & $1+1$ & $\%$ \\
\hline 3 & Je. & 4 Tage & Seltene Uebergiessungen, nehmen ste- & & & & 1 J. & \\
\hline 4 & & & & Ja & $T$ & $\mathrm{Ja}_{\mathrm{a}}$ & & \\
\hline 5 & Ju. & & Anfangs $20-30$ Mal täglich, später & - & Ja & & & \\
\hline & & & nur selten & $J_{a}$ & Ja & $\mathrm{J} a$ & & 1 \\
\hline 6 & Lüb. & & 4-5 Mal täglich, später weniger & $\mathbf{J a}_{\mathbf{a}}$ & Ja & Ja & & $1 / \varepsilon$ \\
\hline 7 & Pet ir & & Keine & 0 & 0 & 0 & & \\
\hline $\begin{array}{l}8 \\
9\end{array}$ & $\begin{array}{l}\text { Pet. } 11 . \\
\text { He. }\end{array}$ & & Keine & $\begin{array}{l}0 \\
0\end{array}$ & $\begin{array}{l}0 \\
0\end{array}$ & 0 & & \\
\hline 0 & Re. & & $5-6$ Mal am Tage. Manchmal garnicht & Ja & $\mathrm{Ja}_{\mathrm{a}}$ & $J_{\mathrm{a}}$ & & 1 \\
\hline 1 & Go. & & Keine & 0 & 0 & 0 & & \\
\hline $\mathbf{2}$ & Tho. & & $\begin{array}{l}\text { Zeitweilig geringe heisse Uebergies- } \\
\text { sungen. }\end{array}$ & & $\ldots$ & & & $1^{1} /$ \\
\hline
\end{tabular}


erst nach der klimakterischen Zeit kommt. Gewöhnlich waren dann die heissen Uebergiessungen in dem ersten Vierteljahre nach ihrem Auftreten am stärksten und häufigsten. Fast immer ist eine Steigerung während der Zeit der nicht eintretenden Periode zu beobachten, zuweilen sind sie auf diese Zeit beschränkt. Nach drei bis sechs Monaten ist gewöhnlich der Höhepunkt erreicht, die Anfälle werden dann seltener und schwächer, bis sie nach einem Jahre gewöhnlich langsam ausklingen. In fast allen Fällen kommen sie auch Nachts und stören den Schlaf, doch gewöhnlich nur kurz und vorübergehend. Die Anfälle zur Nachtzeit sind bedeutend seltener, als am Tage und kommen in den schlimmsten Fällen nur $5-6$ Mal.

Die Häufigkeit und Zeit der Wallungen ist verschieden und sehr wechselnd. In den ersten Wochen treten sie gewöhnlich 10-12 Mal am Tage, oft ungefähr jede Stunde ein. Ihr Wiedereintritt ist aber unregelmässig, so dass sehr verschieden lange Pausen zwischen zwei Anfällen liegen. Als höchste Ausnahme behauptete eine Frau die heissen Uebergiessungen während der ersten Zeit fast alle fünf Minuten bekommen zu haben, als die seltensten sind zwei bis drei täglich notirt. Nur in einem Viertel der Fälle fehlen die Beklemmungen oder die Schweisse oder beide. Die kürzeste Dauer der Anfälle betrug $1 \mathrm{Jahr}$, gewöhnlich aber 11/2 bis 2 Jahre, ausnahmsweise auch noch viel länger, ja in einem meiner Fälle waren sie nach 6 Jahren, wenn auch nur in geringem Grade, noch vorhanden.

Die Erklärung dieser Erscheinungen stösst auf grosse Schwierigkeiten. Sicher ist wohl, dass die Ursache in dem Fortfalle der Ovarien zu suchen ist. Dafür spricht das ständige Vorkommen nach der Castration und das Vorhandensein im klimakterischen Alter. Die nächstliegende Erklärung ist, dass durch den Fortfall der Menstrualblutungen im Gesammtorganismus eine Plethora entsteht, die zu diesen Congestionen, zu diesen Wallungen führt. Diese Erklärung wurde früher auch allgemein gegeben, trifft aber meiner Meinung nach lange nicht in allen Fällen zu. Es spricht nämlich gegen sie, dass die Wallungen bei vielen Frauen, die durch starke Blutungen hochgradig anämisch geworden sind, zu einer Zeit auftreten, wo der Körper sich noch nicht wieder erholt hat, wo also eine allgemeine Plethora nicht vorliegt. Es ist mir überhaupt sehr zweifelhaft, ob es durch den Ausfall der vierwöchentlichen Menstruationsblutungen zu einer wirklichen Plethora 
im Gesammtorganismus kommen kann. Möglich ist es ja, dass durch den Fortfall der regelmässigen Blutungen die Gesammtblutmenge im Körper zunimmt, aber damit ist noch nicht gesagt, dass der Organismus mehr Blut hat, als er gebraucht, dass also durch den Fortfall der Menstruation ein Quantum überschüssiges Blut im Körper entsteht, welche Forderung der Begriff „Plethora“ doch in sich schliesst. Dass es zu einer Plethora in diesem Sinne kommen kann, möchte ich leugnen, da der Organismus durch seine Secretionsorgane jedes überflüssige Quantum Blut leicht beseitigen kann und wird. Wenn die Gesammtblutmenge nach der Castration zunimmt, so wird dieses grössere Quantum Blut zur besseren Ernährung des Organismus und zum Aufbaue von Geweben verwendet werden. Thatsächlich sehen wir auch, dass die Frauen sich nach der Castration gewöhnlich sehr erholen und bedeutend an Körpersubstanz ansetzen. Es lässt sich hierdurch also immer noch nicht das Zustandekommen eines Blutüberschusses im Körper erklären und daher möchte ich es doch bezweifeln, ob nach der Castration eine wirkliche Plethora im Organismus entstehen kann. Viel richtiger scheint mir schon die Bemerkung von Börner ${ }^{1}$ ) zu sein, dass diese Congestionen nach dem Kopfe nervösen Ursprungs sind. Es ist wohl anzunehmen, dass diese Wallungen auf Störungen des vasomotorischen Nervensystems beruhen, dass das Ovarium normalerweise ein Glied der Kette der das vasomotorische Nervensystem beeinflussenden Momente bildet, und dass durch seinen Fortfall Störungen im vasomotorischen Nervensysteme zu Stande kommen, als deren Ausdruck wir die heissen Uebergiessungen finden. Die Art und Weise des Anfalls, das plötzliche Auftreten, der Beginn mit einer Aura scheint mir dafür zu sprechen, dass es sich um nervöse Störungen, und zwar solche im Gebiete der vasomotorischen Nerven handelt.

\section{Schweisse.}

Börner²) erklärt, dass wohl sämmtliche Erauen im Verlaufe der klimakterischen Periode an Schweissen leiden. Krieger ${ }^{3}$ ) zeigt in einer Tabelle von Tilt, dass unter 500 Frauen in dem kritischen Alter:

1) Die Wechseljahre der Frau. Stuttgart 1886.

2) Ebendaselbst.

3) Die Menstruation. 
mit Hitze und Neigung zum Schweisse - 201 also 40,2 Proc. mit monatlich wiederkehrenden Schweissen 2 " 0,4 " mit triefenden Schweissen . . . . . . . 13 " 2,6 ", mit kalten Schweissen . . . . . . . 13 , 2,6,

behaftet seien. im Ganzen mit Schweissen 300 also 60,0 Proc.

Auch Brière de $B$ oismont ${ }^{1}$ ) und $\mathrm{K}$ is $\mathrm{ch}^{2}$ ) erwähnen sie. Nach Hegar ${ }^{3}$ ) kommen dieselben auch in der künstlichen Klimax vor. Ich kann die Angabe Hegar's durchaus bestätigen. Wenn ich von den Schweissen absehe, welche die heissen Uebergiessungen begleiten, fand ich sie in 43 Fällen $14 \mathrm{Mal}$, also in 32,5 Proc. Die Schweisse sind gewöhnlich über den ganzen Körper verbreitet, doch scheint das Gesicht bevorzugt zu sein, und zwei Frauen hatten sie nur an dieser Stelle bemerkt. Charakteristisch ist, dass sie die Frauen oft beim Stillsitzen überfallen. Sie werden manchmal durch äussere Hitze oder durch körperliche Anstrengungen angeregt oder vermehrt, kommen aber auch häufig ohne jede Veranlassung. Sie sind nicht an die Tageszeit gebunden, und kommen vorwiegend des Nachts vor. Meist treten sie nur mässig stark auf, bilden aber keine eigentlichen Beschwerden; nur zuweilen nehmen sie einen hohen Grad an und werden dann allerdings höchst lästig und schwächend. Die Schweisse kommen gewöhnlich erst etwa ein Vierteljahr nach der Operation, pflegen rasch anzusteigen und fallen allmälig wieder ab. Sie halten sich unter Umständen recht lange - wir fanden sie einmal im fünften Jahre noch -, meist enden sie jedoch nach $11 / 2-2$ Jahren.

Erklärungsversuche liegen nur über die im natürlichen Klimakterium auftretenden Schweisse vor. Die älteren Autoren sahen in ihnen einen Abzugskanal für den im Körper zurückgehaltenen Kohlenstoff und begriissten sie als eine heilsame, vicariirende Ausscheidung, die man auf keinen Fall unterdrücken dürfe. $\mathrm{Kisch}{ }^{4}$ ) erklärt sie für ein Symptom von Blutstockung, die ihren Grund in der allgemeinen Hyperämie hat. Börner ${ }^{5}$ ) lässt sie theilweise durch eine veränderte Erregbarkeit des Schweisscentrum sowie des gesammten Schweissnervenapparates zu Stande kommen, theilweise

1) Die Menstruation. Berlin 1842.

2) Das klimakterische Alter der Frauen. Erlangen 1874.

3) Die Castration der Frauen.

4) Klimakterisches Alter der Frauen.

5) Die Wechseljahre der Frau. 
seien sie durch Anämie bedingt, indem der Hämoglobin- und Sauerstoffmangel des Blutes auf das System der Schweissganglien reizend wirke. Geber ${ }^{1}$ ) glaubt, dass der vermehrte Schweiss in der Klimax durch eine Lähmung von Fasern des Sympathicus zu Stande komme.

Ich schliesse mich den beiden Letzten an, möchte aber bei der künstlichen Klimax mehr Gewicht auf die Veränderung in der Erregbarkeit der secretorischen Nervenfasern, weniger auf die Anämie legen. Letztere ist gewöhnlich vor der Operation in stärkerem Maasse vorhanden und trotzdem finden wir keine starken Schweisse. Ich halte dafür, dass die Ursache wieder in dem Fortfalle der Ovarien liegt, und dadurch ein nervöser Einfluss auf das Schweissnervensystem hervorgerufen wird. Ich gebe also hier eine ähnliche Erklärung, wie bei den heissen Uebergiessungen, mit denen die Schweisse sicher sehr viel Gemeinsames haben.

\section{Schwindel.}

Der Schwindel, welcher auch bei der natürlichen Klimax sehr häufig vorkommt, zeigte sich bei unseren 43 Fällen in 8 , also in 18,6 Proc., theils häufiger, theils seltener. Meist dauern die Anfälle nur einige Minuten, treten selten auf und belästigen wenig. Nur in einigen Fällen war er heftiger, so dass die Frauen sich am nächsten Gegenstande anklammerten, manchmal auch niederstürzten. Eine Frau klagte, dass sie besonders des Nachts im Bette daran leide und das angstvolle Gefühl habe, als ob sich Alles um sie herum drehe, und sie"mit dem Bette durch die Luft flöge; sie bat dringend, sie von diesem Zustande zu befreien. In zwei Fällen waren die Anfälle länger dauernd und heftiger. In einem derselben bestanden kurze Anfälle von petit mal, die mit Erblassen des Gesichts und vollkommener Bewusstlosigkeit, aber ohne Zuckungen einhergingen. Dieselben traten gewöhnlich nur in mehrwöchentlichen Pausen auf, häuften sich aber zuweilen so, dass sie mehrmals täglich kamen. Sie sollen meist durch Ueberanstrengung hervorgerufen gewesen sein. Im zweiten Falle war der Schwindel für gewöhnlich nur gering, steigerte sich aber zur Zeit der ausfallenden Periode dermaassen, dass ein Zustand von ,Pseudo-Narcotismus", wie er von Tilt²) bei klimakterischen Frauen beschrieben

1) Anomalien der Schweissdrüsen und ihrer Function. Ziemssen's Handbuch der speciellen Pathologie und Therapie. Bd. XIV. Zweite Hälfte.

2) On uterine and ovarian inflammation and on the physiology and diseases of menstruation. London 1862. 
worden ist, zu Stande kam. Die Frau befand sich zu dieser Zeit in einem fortwährenden Taumel, ging im höchsten Grade unsicher, so dass sie sich häufig festhalten musste, hatte das Gefühl beim Vorwärtsbewegen, als ob sie schwämme, und fühlte sich wie betrunken. Die Frau war ïbrigens vor der Castration hochgradig hysterisch und hatte nach derselben geringgradige geistige Störungen.

Man erklärte die Schwindelanfälle durch Hirnhyperämie entstanden. Ich möchte mich dieser Erklärung anschliessen, denn Hirnhyperämien können ganz gut durch nervöse Einflüsse auf die vasomotorischen Nerven zu Stande kommen.

\section{Fluor albus.}

Eine bei klimakterischen Frauen sehr häufig vorkommende Erscheinung ist Leukorrhoea. Tilt ${ }^{1}$ ) giebt an, dass unter 500 Frauen in der kritischen Zeit 158 an Leukorrhoea litten, also 32 Proc. Kisch ${ }^{2}$ ) fand bei 500 Frauen in der Wechselzeit den Weissfluss sogar 327 Mal, also 65 Proc. Bei der künstlichen Klimax ist der Weissfluss ebenfalls häufig beobachtet worden, wie Hegar ${ }^{3}$ ) und Schmalfuss ${ }^{4}$ ) anführen. Das Ergebniss aus meiner Zusammenstellung ist Folgendes: Ein stärkerer Ausfluss aus der Scheide ist nur in 16 von 43 Fällen beobachtet worden, also in 37 Proc. Die Absonderung stammte sowohl aus dem Uterus, bez. der Cervix, als auch aus der Scheide, und enthielt gewöhnlich zahlreiche Scheidenepithelien beigemengt. Sie war gewöhnlich dünnflüssig, milchig und in geringem Grade ätzend; auch bestand sie lediglich aus Schleim, namentlich wo wegen Myoma castrirt worden war. Nur zwei Mal war sie mehr eitrig, aber in beiden Fällen war schon vor der Castration ein starker, eitriger Ausfluss vorhanden, in dem einen Falle mit Verdacht auf Gonorrhoea, im zweiten mit Nachweis ron Gonococcen. Mikroskopisch fand ich in der Absonderung gewöhnlich zahlreiche Plattenepithelien aus der Scheide und nur spärliche Eiterkörperchen. In drei Fällen zeigte ein Trockenpräparat, mit Carbolfuchsin gefärbt, als Mikroorganismen nur kleine schlanke Kurzstäbchen, die man auch im Secrete normaler Schwangerer häufig findet, daneben, doch weniger zahlreich,

1) On the aterine and ovarian inflammation.

2) Klimakterisches Alter der Frauen.

3) Castration der Frauen.

4) Dieses Archiv, Bd. XXVI. 
kleine feine Coccen. In einem Falle waren auch kleine Diplococcen vorhanden, die aber keine Aehnlichkeit mit Gonococcen hatten.

Gewöhnlich entstand der Weissfluss bald nach der Castration, war in der ersten Zeit am stärksten, nahm mit der Rückbildung der Genitalien allmälig $a b$ und war in der Regel nach $1 \frac{1}{2}$ Jahren verschwunden. In einem Falle war er schon nach einem Jahre erloschen, in einem anderen bestand er volle $\breve{b}$ Jahre. Immer war der Ausfluss ein ununterbrochener, manchmal zur Zeit der Periode etwas verstärkt, aber niemals nur zur Zeit der nicht eintretenden Periode vorhanden. Höhere Grade desselben mit ernstlichen Beschwerden sah ich nie. Gewöhnlich wich er leicht einer nicht tief eingreifenden Behandlung.

Die Ausflüsse wurden wie die Schweisse als vicariirende Menses angesehen, zumal da sie in einzelnen Fällen auch bei der natürlichen Klimax zu den Zeiten der nicht eintretenden Periode erschienen. Ich glaube, dass diese Leukorrhoea in Bezug auf ihre Entstehung grosse Aehnlichkeit mit der Vaginitis vetularum hat, die wir ja nach dem natürlichen Klimakterium so häufig zu Stande kommen sehen. Wir werden im folgenden Kapitel sehen, dass nach der Castration die Genitalien schrumpfen. Durch die Rückbildung der Vagina kann eine leichtere Verletzbarkeit ihrer Schleimhaut, vielleicht eine Verdünnung ihrer Epithelschichten zu Stande kommen, und sich hier ein Katarrh entwickeln, zumal wenn die Frauen noch jung sind und die Vagina noch mechanischen Reizungen, wie z. B. beim Beischlafe, ausgesetzt ist.

5. Sonstige klimakterische Beschwerden.

Von klimakterischen Beschwerden sah ich am häufigsten Herzpalpitationen und Kopfschmerzen. Beide waren in 4 von 43 Fällen, also in 9 Proc. aller Fälle, vorhanden. Die Herzpalpitationen erreichten nie einen besonders hohen Grad und schlossen sich gewöhnlich an die Wallungen an. In einem Falle waren sie mit geringen Beklemmungen verbunden, die an Angina pectoris erinnerten. Die Kopfschmerzen dagegen waren oft sehr heftig und bereiteten den Kranken grosse Qualen. Zwei Mal wurden sie lediglich in der Stirn, ein Mal im Hinterkopfe gefühlt. Sie verstärkten sich gewöhnlich zur Zeit der nicht eintretenden Menses. In wenigen Fällen sahen wir Erscheinungen vom Magen-Darmschlauche ausgehen. So bestand in einem Falle nach der Castration mebrmaliges Uebelsein am Tage, in einem anderen kam es zeitweilig 
zum Erbrechen; einmal klagte die Kranke seit der Operation über häufige Diarrhoeen, zweimal bestand hartnäckige Stuhlverstopfung. Alle diese Erscheinungen finden gleichartige bei der natürlichen Klimax.

In einem Falle klagte die Kranke, dass nach der Operation sich ein ,unreiner Teint" im Gesichte eingestellt habe, worunter sie, wie bei näheren Nachfragen herauskam, Akneknötchen verstand. Etwa ein Jahr nach der Operation besserte sich der Zustand von selbst. Zwei Kranke litten an zunehmender Gedächtnissschwäche nach der Operation. Die eine derselben war übrigens eine stumpfsinnige Person, die sich jedenfalls auch vor der Operation keines grossen Gedächtnisses rühmen konnte. Auch Péan ${ }^{1}$ ) sah nach der Castration mehrfach ,des pertes de connaissance“ auftreten.

\section{Wirkung der Castration auf die zurückbleibenden Genitalien.}

Bei der natürlichen Klimax findet einerseits eine bindegewebige Entartung der Ovarien statt, die allmälig zur Schrumpfung führt, andererseits zeigt sich eine rückschreitende Umwandlung in dem Uterus, der Scheide und den äusseren Genitalien. Welcher dieser beiden Vorgänge der primäre, zeitlich vorangehende ist, wissen wir noch nicht genau. Hegar ${ }^{2}$ ) betont, dass das Erlöschen der Empfängnissfähigkeit vor dem Erlöschen der Menstruation. dafür spricht, dass der Schwund der Ovarien das Primäre sei, und er folgert weiter, dass die Schrumpfung der übrigen Genitalien eine Folge des Ovarialschwundes sei. Er braucht das Bild, dass gleich wie der Ausführungsgang einer Drüse atrophire, wenn diese schrumpft, auch Uterus und Scheide atrophiren müssen, wenn der Eierstock schrumpft.

Wenn diese Verhältnisse für die natürliche Klimax vorausgesetzt werden, so müssen wir auch für die künstliche Klimax folgern, dass auf die Fortnahme der Ovarien eine rasche Schrumpfung des Uterus und der Scheide folgt. In der Literatur ist über diese Verhältnisse sehr wenig zu finden. Kehrer ${ }^{3}$ ) ist der Sache auf dem Wege des Versuches am Thiere näher getreten. Er fand, dass bei jugendlichen Thieren der Uterus nach der Castration sich nicht

1) Gazette médicale de Paris 1880.

2) Castration der Frauen.

3) Beiträge zur klinischen und experimentellen Geburtskunde und Gynäkologie. Bd. II, 3, Heft. Giessen 1887. 
weiter entwickelt, während die Unterbindung der Tuben oder der Vasa spermatica einen hemmenden Einfluss auf das Wachsthum nicht hat. Er folgert daraus, dass entweder die von den Ovarien ausgehenden, regelmässigen Nervenreize und die dadurch entstehenden Reflexhyperämien im Uterus als Wachsthumsreize anzusehen seien, oder dass man dem Ovarium einen erregenden Einfluss auf die trophischen Nerven des Uterus zuschreiben müsse.

Hegarl) hat von Anfang an die Meinung ausgesprochen, dass die Castration zu einer Atrophie der Genitalien führen müsse, giebt aber keine ausführliche Beschreibung dieser Vorgänge. Wiedow ${ }^{2}$ ) und $\mathrm{Tissier}^{3}$ ) haben durch weitgehende Statistiken nachgewiesen, dass nach der Castration regelmässig ein rasches Schrumpfen des durch Myome ausgedehnten Uterus stattfinde, beide gehen aber auch auf die übrigen Verhältnisse nicht ein. Eine kurze Notiz finden wir bei Bruntzel'), der nur ganz im Allgemeinen bemerkt, dass er den weiblichen Habitus erhalten gefunden habe.

Von Prochownick ${ }^{5}$ ) finden wir die Ansicht vertreten, dass durch die Fortnahme der Ovarien nur ein Glied aus der Kette der Ursachen zur Menstruation entfernt werde. Demnach hören gewöhnlich die periodischen Uterusblutungen auf, nicht aber die sonstigen, mit der Menstruation verbundenen Congestionen zu den Genitalien, die zur Zeit der Menses nach wie vor Wallungen und andere nervöse Erscheinungen hervorriefen. Er glaubt, dass nach der Castration keine Klimax im strengen Wortsinne auftrete, wofür auch der Umstand spreche, dass er senile Veränderungen an Scheide, Uterus und Vulva nicht beobachtet habe.

Ich will hier kurz vorwegnehmen, dass ich zu ganz anderen Eirgebnissen gekommen bin, und ich glaube, Prochownick wird mir dieselben bestätigen, wenn er seine Castrirten noch weiter beobachtet und den Zustand der Genitalien aufgenommen haben wird, wie er $2-3$ Jahre nach der Castration vorhanden ist.

Die Ergebnisse meiner genauen, in den verschiedensten Zeiten nach der Castration gemachten Beobachtungen und Untersuchungen

1) Castration der Frauen.

2) Dieses Archiv, Bd. XXV.

3) De la castration de la femme.

4) Dieses Archiv, Bd. XVI.

5) Ebendaselbst, Bd. XXIX. 
habe ich in der Tabelle IV (S. 34 u. 35), zu der ich noch einige erläuternde Bemerkungen machen möchte, kurz zusammengestellt.

\section{Die Vagina.}

Zu meinem Bedauern habe ich den Zustand der Scheide vor der Castration anfangs nicht genau vermerkt, in Fällen, wo keine Klagen auf die Scheide hinwiesen und auch bei der Untersuchung keine Abweichungen gesehen wurden. Indess kann man aus der Anzahl der voraufgegangenen Geburten und aus dem Lebensalter der Frauen sich den Zustand der Vagina ungefähr zusammensetzen. Später achtete ich auf diese Verhältnisse mehr, und habe sie bei den letzten Fällen genau vermerkt. Die Befunde habe ich der Zeit nach in 2 Gruppen getheilt, 1) in solche, die ich bis zu einem Jahre nach der Operation, 2) in solche, die ich in noch späterer Zeit vorfand. Die Vagina macht nämlich nach der Castration verschiedene Wandlungen durch.

Gewöhnlich entwickelt sich anfangs eine Hyperämie der gesammten Vaginalschleimhaut; sie zeigt eine starke Injection, wird saftreicher, dadurch geschwellter, fühlt sich sammetartig weich an, ja sie geräth manchmal in einen Zustand, der dem bei beginnender Schwangerschaft sehr ähnlich ist. Dazu gesellt sich häufig vermehrte Absonderung. Dieser Zustand ähnelt dem bei der natürlichen Klimax. Börner ${ }^{1}$ ) betont ausdrücklich, dass die Scheide im Beginne der Wechseljahre fast regelmässig starke Hyperämie zeigte, der allmälig mit dem Veröden der Gefässe ein Abblassen und eine allgemeine Schrumpfung folgt. Die Erklärung, dass bei der natürlichen Klimax durch die fehlende Menstruationsblutung anfänglich eine dauernde Hyperämie der Sexualorgane unterhalten werde, passt auch für die künstliche Klimax, zumal da hier die Unterbrechung der Menstruation eine bedeutend schroffere ist. In 3 von 19 Fällen sah ich die Hyperämie nicht zu Stande kommen (Fall 8, 10, 14). Ich erkläre mir diese Thatsache so, dass entweder die Schrumpfung in der Vagina manchmal sofort ohne dieses Vorstadium eintritt, oder dass ich letzteres nur nicht beobachtet habe, weil es nur kurze Zeit gedauert hat. Die Dauer ist nämlich in allen Fällen nur kurz, beträgt gewöhnlich nur zwei bis drei Monate, dann macht das. erste Stadium dem zweiten Platz, auf das wir jetzt näher eingehen wollen. 
Tabelle IV. Wirkung der Castrati

\begin{tabular}{|c|c|c|c|c|c|}
\hline \multirow[b]{2}{*}{ Diagnose } & \multirow[b]{2}{*}{ Operation } & \multirow{2}{*}{$\mid \begin{array}{c}\text { An- } \\
\text { zahl d. } \\
\text { Ge- } \\
\text { burten }\end{array}$} & \multicolumn{3}{|c|}{ Scheide } \\
\hline & & & $\begin{array}{l}\text { Vor der } \\
\text { Operation }\end{array}$ & $\begin{array}{c}\text { Kurze Zeit nach der } \\
\text { Operation }\end{array}$ & $\begin{array}{c}\text { Längere Zeit nach c } \\
\text { Operation }\end{array}$ \\
\hline Myoma uteri & Castratio & 0 p. & - & $\begin{array}{l}\text { Etwas verengt. Wände } \\
\text { byperämisch, secerniren } \\
\text { reichlich }\end{array}$ & \\
\hline Myoma uteri & Castratio & $0 p$. & - & - & $\begin{array}{l}\text { Etwas enger, Schleim } \\
\text { hyperämisch }\end{array}$ \\
\hline $\begin{array}{l}\text { Gr. Cyste d. 'r. } \\
\text { Ovarium } \\
\text { Kl. Cyste d. l. } \\
\text { Ovarium }\end{array}$ & $\begin{array}{l}\text { Ovariot. } \\
\text { dupl. }\end{array}$ & $0 \mathrm{p}$. & 一 & - & $\begin{array}{l}\text { Eng. Geringer Grad vol } \\
\text { ginismus. In der U } \\
\text { bung d. Urethralmün } \\
\text { kleine rothe Punkte }\end{array}$ \\
\hline Myoma uteri & Castratio & VII $\mathrm{p}$ & 一 & - & $\begin{array}{l}\text { Vagina atrophirt, } \\
\text { Schleimbant blass }\end{array}$ \\
\hline $\begin{array}{l}\text { Narbenstenose des } \\
\text { Muttermundes. } \\
\text { Enges Becken }\end{array}$ & Castratio & IV p. & $\begin{array}{l}\text { Vagina weit, } \\
\text { klaffend }\end{array}$ & - & $\begin{array}{l}\text { Vagina etwas geschru } \\
\text { Schleimhant blass }\end{array}$ \\
\hline $\begin{array}{l}\text { Kystoma ovar. } \\
\text { dupl. }\end{array}$ & $\begin{array}{l}\text { Ovariot. } \\
\text { dupl. }\end{array}$ & III p. & Scheide weit & - & $\begin{array}{l}\text { Scheide eng und atroph } \\
\text { Schleimhaut blass }\end{array}$ \\
\hline Myoma uteri & Castratio & Ip. & $\begin{array}{l}\text { Scheidenwand } v . \\
\text { u. h. im vorderen } \\
\text { Drittel abgelöst } \\
\text { und vorgefallen }\end{array}$ & $\begin{array}{l}\text { Vagina mässig weit. } \\
\text { Schleimhaut blass. An } \\
\text { der Urethralmindung } \\
\text { einige intensiv rothe } \\
\text { Flecke (Hämorrhagien) }\end{array}$ & $\begin{array}{l}\text { Vagina für } 2 \text { Finger } \\
\text { durchgängig. Schleim } \\
\text { blass. Keine Flecke, } \\
\text { Prolabiren }\end{array}$ \\
\hline Myoma uteri & Castratio & $0 \mathrm{p}$. & - & $\begin{array}{l}\text { Vagina lang, eng. } \\
\text { Schleimhaut sebrblass }\end{array}$ & \\
\hline Myoma uteri & Castratio & 0 p. & $\begin{array}{c}\text { Vagina nicht sohr } \\
\text { weit. Schleim- } \\
\text { hant stark } \\
\text { hyperämisch }\end{array}$ & $\begin{array}{l}\text { Vagina eng, lang. } \\
\text { Schleimhaut hyper- } \\
\text { ämisch }\end{array}$ & $\begin{array}{l}\text { Vagina sehr eng, ents } \\
\text { den geschrumpft. Schl } \\
\text { haut etwas geröthet }\end{array}$ \\
\hline $\begin{array}{l}\text { Perimetritis ad- } \\
\text { haesiva }\end{array}$ & Castratio & VIIIp. & - & $\begin{array}{l}\text { Vagina beginnt zu atro- } \\
\text { phiren. Schleimhaut } \\
\text { blass }\end{array}$ & $\begin{array}{l}\text { Vagina ziemlich stark } \\
\text { schrumpft. Schleim } \\
\text { blass, stellenw. fast }\end{array}$ \\
\hline $\begin{array}{c}\text { Eystoma ovarii } \\
\text { dextri } \\
\text { Perioophoritis dupl. }\end{array}$ & Castratio & Ip. & - & $\begin{array}{l}\text { Vagina geschrumpft. } \\
\text { Schleimhaut starke, } \\
\text { fleckige Röthe }\end{array}$ & $\begin{array}{l}\text { Vagina kurz und eng, } \\
2 \text { Finger eben eindrir } \\
\text { Schleimhaut blass }\end{array}$ \\
\hline $\begin{array}{l}\text { Kyst. ovarii dextri } \\
\text { Perimetritisadhaes. }\end{array}$ & $\begin{array}{l}\text { Ovariot. } \\
\text { dupl. }\end{array}$ & $0 p$. & - & $\begin{array}{l}\text { Vagina mässig weit. } \\
\text { Schloimhant normal }\end{array}$ & $\begin{array}{l}\text { Scheide für den Peni } \\
\text { eng }\end{array}$ \\
\hline $\begin{array}{l}\text { Linkss. chroni- } \\
\text { sche Oophoritis. } \\
\text { Hysterie }\end{array}$ & Castratio & $V p$ & $\begin{array}{l}\text { Vagina klafft } \\
\text { weit. Wände } \\
\text { schlaff }\end{array}$ & $\begin{array}{l}\text { Vagina klaffe nicht, enger. } \\
\text { Schleimhaut hyperamin, } \\
\text { stark feckig injicirt, na: } \\
\text { mentl.i.d. Nahed.Urethra }\end{array}$ & $\begin{array}{l}\text { Vagiua zieml. stark geschr } \\
\text { fiz Finger nicht durchge } \\
\text { Schleimhaut blass, m. k1 } \\
\text { häroorrhagisch.Punkt.b }\end{array}$ \\
\hline $\begin{array}{l}\text { Linkss. Tubo-ova- } \\
\text { rialeyste. Rechtss. } \\
\text { Hydrosalpinx }\end{array}$ & $\begin{array}{l}\text { Ovariot. } \\
\text { Castratio }\end{array}$ & $0 p$. & - & $\begin{array}{l}\text { Vagina zieml. eng, lässt } \\
2 \text { Finger eben eindrin- } \\
\text { gen. Schleimhaut blass }\end{array}$ & $\begin{array}{l}\text { Aeussere Genitalien } \\
\text { schrumpft }\end{array}$ \\
\hline Myoma uteri & Castratio & IV p. & $\begin{array}{l}\text { Vag. weit, schlaff. } \\
\text { Schleimhant ge. } \\
\text { röth. Reichi. eitr. } \\
\text { Secret. Prolaps d. } \\
\text { vord.Vaginalwand }\end{array}$ & $\begin{array}{l}\text { Vagina etw.geschrumpft } \\
\text { f. } 2 \text { Fing. eben passirb. } \\
\text { Schleimhaut blass, mit } \\
\text { fleckiger Röthung }\end{array}$ & $\begin{array}{l}\text { Vagina für 2 Finger du } \\
\text { gängig. Schleimhau } \\
\text { mentlich im hinteren } \\
\text { schnitte hyperämiscl }\end{array}$ \\
\hline $\begin{array}{l}\text { Neuralgia ovarii } \\
\text { utriusque }\end{array}$ & Castratio & $0 p$ & $\begin{array}{l}\text { Vaging normal } \\
\text { weit. Sehleimhaut } \\
\text { stark geröthet. } \\
\text { starke Secretion } \\
\text { von eitr. Secret }\end{array}$ & $\begin{array}{l}\text { Schleinhant injicirt, da- } \\
\text { neben zablr.blassrothe } \\
\text { Punkte. Geringe Se- } \\
\text { cretion }\end{array}$ & $\begin{array}{l}\text { Vagina eng u. kurz. Sch } \\
\text { haut geröthet, dan } \\
\text { blassrothe Punkte. } \\
\text { ringe Secretion }\end{array}$ \\
\hline Myoma uteri & Castratio & II p. & - & $\begin{array}{l}\text { Vagina mässig weit, für } 2 \\
\text { Finger durchgängig. } \\
\text { Schleimhant mässig hy- } \\
\text { perämiseh }\end{array}$ & $\begin{array}{l}\text { Vagina eng, nicht sehr } \\
\text { Schleimhaut blass }\end{array}$ \\
\hline $\begin{array}{c}\text { Infarctus et } \\
\text { Retroflexio } \\
\text { uteri }\end{array}$ & Castratio & Vp. & $\begin{array}{l}\text { Scheideneingang } \\
\text { weit. Seheiden- } \\
\text { wände etwas ab- } \\
\text { gelöst }\end{array}$ & $\begin{array}{l}\text { Introitus eng. Vagina mäs- } \\
\text { sig weit. Scheidenwände } \\
\text { weich u. schlaff. Schleimo- } \\
\text { baut mässig injicirt, stel- } \\
\text { lenweise fleekig geröthet }\end{array}$ & - \\
\hline$\left|\begin{array}{c}\text { Haematosalpinx ot } \\
\text { Perimetritis lateris } \\
\text { utriusque }\end{array}\right|$ & $\left|\begin{array}{c}\text { Castratio u. } \\
\text { Salpingo- } \\
\text { tomia }\end{array}\right|$ & VIp. & - & Vagina mässig weit & $\begin{array}{l}\text { Vagina lang u, eng. Sch] } \\
\text { haut normal }\end{array}$ \\
\hline
\end{tabular}


f die zurückbleibenden Genitalien.

\begin{tabular}{|c|c|c|c|c|c|}
\hline \multicolumn{3}{|c|}{ Uterus } & \multicolumn{3}{|c|}{ Cervix } \\
\hline $\begin{array}{l}\text { or der } \\
\text { peration }\end{array}$ & $\begin{array}{l}\text { Kurze Zeit nach } \\
\text { der Operation }\end{array}$ & $\begin{array}{l}\text { Längere Zeit } \\
\text { nach der } \\
\text { Operation } \\
\end{array}$ & Vor der Operation & \begin{tabular}{|c} 
Kurze Zeit \\
nach der \\
Operation \\
\end{tabular} & $\begin{array}{r}\text { Längere Z } \\
\text { nach der } \\
\text { Operatior } \\
\end{array}$ \\
\hline $\begin{array}{l}\text { us } 2 \text { Fgr. br. } \\
\text { c dem Nabel }\end{array}$ & $\begin{array}{c}\text { Fundus } 3 \text { Fgr. br. } \\
\text { unter d. Nabel }\end{array}$ & - & $一$ & - & 一 \\
\hline $\begin{array}{l}2 \text { Fgr.br. } \ddot{i} . \tilde{d} . \\
\text { jondenl. } 10 \mathrm{~cm}\end{array}$ & $\begin{array}{l}\text { Fund.3 Fgr breit } \\
\text { unter d. Nabel }\end{array}$ & $\begin{array}{l}\text { Uterus kindskopfor. } \\
\text { Sondenlänge } 8,5 \mathrm{~cm}\end{array}$ & - & - & Portio kle: \\
\hline - & & $\begin{array}{l}\text { Uterus klein.Son- } \\
\text { denlänge } 5 \mathrm{~cm}\end{array}$ & - & - & $\longrightarrow$ \\
\hline $\begin{array}{l}\text { faustgross, } \\
\text { denl. } 8^{1} / 2 \mathrm{~cm} \\
\text { is etwas ver- } \\
\text { ssert }\end{array}$ & $\begin{array}{l}\text { Sondenlänge } \\
6^{1 / 2} \mathrm{~cm}\end{array}$ & $\begin{array}{l}\text { Uterus mittelgr. } \\
\text { Sondenl. } 6 \mathrm{~cm} \\
\text { Uterus sehr klein, } \\
\text { hart und derb }\end{array}$ & $\begin{array}{l}\text { Portio mässig vergrös- } \\
\text { sert, derb, blass } \\
\text { Cervix vergrössert. Tie- } \\
\text { fer seitl. Einrisse. Ek- } \\
\text { tropium. Excoriationen }\end{array}$ & 一 & $\begin{array}{l}\text { Portio at } \\
\text { phirt } \\
\text { C.schlank, wo } \\
\text { geformt. M } \\
\text { term. geschl } \\
\text { (Hysterokleis } \\
\text { portiolcl. }\end{array}$ \\
\hline- & & $\begin{array}{l}\text { Uterus klein, hart u. } \\
\text { derb. Sondenl.4 em }\end{array}$ & Portio klein & - & Portio kle \\
\hline $\begin{array}{l}\text { 3 faustgross, } \\
\text { t. } 8 \mathrm{~cm} \text { Son- } \\
\text { länge }\end{array}$ & $\begin{array}{l}\text { Sondenlänge } 6 \mathrm{~cm} \text {. } \\
\text { Uterus normal } \\
\text { gross }\end{array}$ & $\begin{array}{l}\text { Uterus unter mit- } \\
\text { telgross, liegt } \\
\text { nach vorn. Son- } \\
\text { dirungmisslingt }\end{array}$ & $\begin{array}{l}\text { Portio gross, derb. Mut- } \\
\text { termund klafft. Ge- } \\
\text { ringe Excoriationen }\end{array}$ & $\begin{array}{c}\text { Excoriationen } \\
\text { d. Port. verbeilt }\end{array}$ & $\begin{array}{l}\text { Portio kle } \\
\text { atrophisc }\end{array}$ \\
\hline $\begin{array}{l}\text { svergössert } \\
\text { denl. } 7,5 \mathrm{~cm}\end{array}$ & $\begin{array}{l}\text { Uterus kleiner. } \\
\text { Sondenl. } 7 \mathrm{~cm}\end{array}$ & & D) & - & Dopte 10. \\
\hline $\begin{array}{l}\text { annskopfor. } \\
\text { id. a. Nabel. } \\
\text { denl. } 13 \mathrm{~cm}\end{array}$ & $\begin{array}{l}\text { Uterus bed. klein. } \\
\text { Fuud.2 Fgr.breit } \\
\text { über d.Symphyse }\end{array}$ & $\begin{array}{l}\text { Uterus noch etw. } \\
\text { gröss.als normal. } \\
\text { Sondenl. } 7 \mathrm{~cm}\end{array}$ & Portio kurz, fest, derb & - & $\begin{array}{l}\text { Portio klein } \\
\text { zart, kypel } \\
\text { misch und } \\
\text { was wund }\end{array}$ \\
\hline $\begin{array}{l}\text { is stark ver- } \\
\text { isert. Son- } \\
\text { länge } 9 \mathrm{~cm}\end{array}$ & $\begin{array}{l}\text { Uterus normal } \\
\text { gross. Sonden- } \\
\text { länge } 6 \mathrm{~cm}\end{array}$ & $\begin{array}{l}\text { Uterus normal } \\
\text { gross. Sonden- } \\
\text { länge } 6 \mathrm{~cm}\end{array}$ & $\begin{array}{l}\text { Cervix bypertrophisch und } \\
\text { derb. Ziembich starkes Ek- } \\
\text { tropium. Geringer Cer- } \\
\text { vicalkatarrh }\end{array}$ & $\begin{array}{l}\text { Cervix verblei- } \\
\text { nert. Erosio- } \\
\text { nen vernarbt }\end{array}$ & $\begin{array}{l}\text { Portio kle } \\
\text { blass. Ke } \\
\text { Secret }\end{array}$ \\
\hline $\begin{array}{l}\text { is etwas ver- } \\
\text { isert }\end{array}$ & $\begin{array}{l}\text { Uterus normal. } \\
\text { Sondenl. } 6 \mathrm{~cm}\end{array}$ & Uterus klein & $\begin{array}{l}\text { StarkerCervicalkatarrh. } \\
\text { Muttermundslippen ek- } \\
\text { tropionirt } \mathrm{u} \text {. excoriirt }\end{array}$ & $\begin{array}{l}\text { Muttermunds- } \\
\text { lippen gering } \\
\text { exeorirt }\end{array}$ & $\begin{array}{l}\text { Portio zei } \\
\text { geringe E } \\
\text { coriation }\end{array}$ \\
\hline Is normal & $\begin{array}{l}\text { Uterus sehr klein. } \\
5 \mathrm{~cm} \text { Sondenlge. }\end{array}$ & - & & & \\
\hline $\begin{array}{l}\text { s normal. } \\
\text { leweit. Son- } \\
\text { änge } 7 \mathrm{~cm}\end{array}$ & $\begin{array}{l}\text { Uterus klein. } \\
\text { Sondenl. } 5 \mathrm{~cm}\end{array}$ & - & $\begin{array}{l}\text { Cervix tief eingerissen. } \\
\text { Muttermund klafft. Be- } \\
\text { deut. Cervicalkatarrh }\end{array}$ & $\begin{array}{l}\text { Ektropium der } \\
\text { Mmndslippen } \\
\text { vaginalisirto } \\
\text { Kein Katarrh }\end{array}$ & $\begin{array}{l}\text { Cervix kleij } \\
\text { Schleimh. ac } \\
\text { in geriug. Gre } \\
\text { ektropionir } \\
\text { Kein Secre }\end{array}$ \\
\hline $\begin{array}{l}\text { sklein. Son- } \\
\text { länge } 7 \mathrm{~cm}\end{array}$ & $\begin{array}{l}\text { Uterus normal. } \\
\text { Sondenl. } 6^{1} / 2 \mathrm{~cm}\end{array}$ & - & Portio zart und klein & $\begin{array}{l}\text { Portio klein } \\
\text { und zart }\end{array}$ & $\ldots$ \\
\hline $\begin{array}{l}\text {. 3 Fgr. breit } \\
\text { Symphyse. } \\
\text { denl } 8^{1} / 2 \mathrm{~cm} . \\
\text { indskopfgr. }\end{array}$ & $\begin{array}{l}\text { Uterus etw. grös- } \\
\text { ser als normal. } \\
\text { Sondenl. } 7 \mathrm{~cm}\end{array}$ & $\begin{array}{l}\text { Uterus etw. grös- } \\
\text { ser als normal, } \\
\text { hart und derb. } \\
\text { Sondenl. } 7 \mathrm{~cm}\end{array}$ & $\begin{array}{l}\text { Aus dem Muttermund wird } \\
\text { reiehl. eitriges Seeret ent- } \\
\text { leert. Cervix hypertroph. } \\
\text { Hintere Mmalippe wrand }\end{array}$ & $\begin{array}{l}\text { Portio nicht } \\
\text { wund }\end{array}$ & $\begin{array}{l}\text { Portio kle. } \\
\text { entleert i } \\
\text { was Secr }\end{array}$ \\
\hline $\begin{array}{l}\text { is normal. } \\
\text { denl. } 6,5 \mathrm{~cm}\end{array}$ & $\begin{array}{l}\text { Uterus normal. } \\
\text { Sondenl. } 6,3 \mathrm{~cm}\end{array}$ & $\begin{array}{l}\text { Uterus entschied. } \\
\text { klein. a.d.Norm. } \\
\text { Sondirung mit } \\
\text { Nr. } 4 \text { misslingt }\end{array}$ & $\begin{array}{l}\text { Hintere Mmdslippe ex- } \\
\text { coriirt. Aus dem Mm. } \\
\text { fliesst reichlich eitri- } \\
\text { ges Secret }\end{array}$ & $\begin{array}{l}\text { Cervix excoriirt, } \\
\text { sehlank u. zart. } \\
\text { Etwas grau- } \\
\text { gelbes secret }\end{array}$ & - \\
\hline $\begin{array}{l}\text { i vergrössert. } \\
\text { z. } 3 \text { Fróbribreit } \\
\text { r dem Nabel. } \\
\text { lenl. } 15 \mathrm{~cm}\end{array}$ & $\begin{array}{l}\text { U. gut mannsk opf- } \\
\text { gross. Kuppe } 2 \text { Fgr. } \\
\text { breit üb. d. Symph. } \\
\text { Sondenl. 12,5 cm }\end{array}$ & $\begin{array}{l}\text { Uterus lang, sehlank } \\
\text { Fund. noch ver- } \\
\text { breitert. Sonden- } \\
\text { länge } 8,5 \mathrm{~cm}\end{array}$ & $\begin{array}{l}\text { Portio recht gross, et- } \\
\text { was derb }\end{array}$ & $\begin{array}{l}\text { Portio klein, } \\
\text { virginal }\end{array}$ & $\begin{array}{l}\text { Portio kle } \\
\text { und zart }\end{array}$ \\
\hline $\begin{array}{l}\text { s vergrös- } \\
\text {, weich }\end{array}$ & $\begin{array}{l}\text { Oterus lang, aber } \\
\text { sehmal, fest und } \\
\text { derb. Sonden- } \\
\text { länge } 71 / 2 \mathrm{~cm}\end{array}$ & - & $\begin{array}{l}\text { Portio recht gross und } \\
\text { derb. Tiefer links- } \\
\text { seitiger Cervixriss }\end{array}$ & $\begin{array}{l}\text { Portio klein, } \\
\text { entschieden } \\
\text { atrophijt }\end{array}$ & - \\
\hline $\begin{array}{l}\text { : weich, faust- } \\
\text { Sondenlänge } \\
\text { a }\end{array}$ & $\begin{array}{l}\text { Uterus hart u. derb, } \\
\text { grösser als normal. } \\
\text { Sondenlänge } 8 \text { om }\end{array}$ & $\begin{array}{c}\text { Uterus Sondenlänge } \\
7 \mathrm{~cm} \text {. Cervix bis } \\
\text { Sonde } 5 \text { durchläss. }\end{array}$ & $\begin{array}{l}\text { Portio siark vergrössert, na- } \\
\text { mentl. d. hint. Mmadsppe. } \\
\text { Erosion a.d. hint.Mmlppe. }\end{array}$ & $\begin{array}{l}\text { Portio hyper- } \\
\text { troph. Erosion } \\
\text { verheilt }\end{array}$ & - \\
\hline
\end{tabular}


Die Scheide beginnt zu schrumpfen, blasst ab und zeigt entweder nur einzelne tief braunrothe Flecke, besonders am Urethralwulste, oder die ganze Vagina ist mit diesen Flecken ibersäet. Dasselbe finden wir bei der natürlichen Klimax auch sehr häufig. Die von Börner ${ }^{1}$ ) für diese Flecke gegebene Erklärung scheint mir für meine Fälle nicht zu passen. Börner meint, dass die Gefässe zeitig ungleich veröden, hält die blassen Stellen für schon gefässleere, die dunklen für noch hyperämische. Hiergegen spricht aber die tief dunkelbraunrothe Farbe. Auch war es mir oft nicht möglich, die Röthe durch Druck zu beseitigen. Einmal sah ich die Punkte in den verschiedensten Intensitäten nebeneinander und erkläre mir das durch theilweise Aufsaugung der Blutextravasate entstanden. Ich möchte die Flecken grösstentheils für Hämorrhagien halten, vielleicht Verletzungen beim Beischlafe entstanden, da die beginnende Atrophie zu einer leichteren Brüchigkeit der Gefässe führen kann.

Dieses Stadium ist von verschiedener Dauer, hält gewöhnlich nur neun Monate bis ein Jahr an; in einem Falle bestand es noch nach fünf Jahren. Nicht bei jeder Frau ist es vorhanden, ich sah es in 7 von 19 Fällen. Es wird häufig übersprungen, so dass die Vagina aus dem Stadium der Hyperämie unmittelbar in das der Atrophie übertritt.

Allmälig folgt nun das dritte Stadium, das der allgemeinen Atrophie. Zuerst wird die Schleimhaut blass und anämisch, dann blassen auch die rothen Punkte ab und die gesammte Schleimhaut wird fahl, grauröthlich. Die Vagina wird kürzer und bedeutend enger, die Querrunzeln und Falten glätten sich aus, die Wandung wird straffer und derber. Gewöhnlich verbleibt die Vagina so weit, dass man noch eben zwei Finger hineinführen kann, zuweilen aber wird sie, wie fünf Frauen mir angaben, so eng, dass der Beischlaf sehr schmerzhaft oder ganz unmöglich wird. Während bei der natürlichen Klimax die Schrumpfung sich über ein Jahr hinaus erstreckt und ganz allmälig zu Stande kommt, erfolgt sie bei der künstlichen Klimax viel rascher, auch wohl, weil bei der Castration die Ovarien mit einem Schlage gänzlich entfernt werden. Auf die grossen und kleinen Schamlippen, sowie den Mons Veneris erstreckte sich die Schrumpfung gewöhnlich nicht mit, wenigstens fand ich sie unter 19 Fällen nur ein Mal. Es scheint also auch für die künst-

1) Die Wechseljahre der Frau. 
liche Klimax zu gelten, was $\mathrm{K}_{\text {isch }}{ }^{1}$ ) für die natürliche angiebt, dass die Umwandlung der grossen Labien in schlaffe, welke Hautfalten keine klimakterische, sondern eine senile Veränderung sei.

Der Introitus vaginae verengert sich dagegen gewöhnlich recht stark. In mehreren Fällen fand ich, dass der vor der Castration weit klaffende Introitus nach derselben sich gut schloss. Hierin und in der allgemeinen Schrumpfung liegt auch die Erklärung, dass nach der Castration geringe Grade von Scheidenprolaps ohne jedes weitere Zuthun sich zurückbilden. So beobachtete ich drei Fälle (Fall 7, 15, 18), bei denen der Prolaps vollständig und mit ihm alle Beschwerden schwanden.

\section{Die Cervix uteri.}

Leider habe ich nur in 13 Fällen genaue Notizen über die Cervix gemacht. Der eine kommt nicht in Betracht, weil die gleichzeitig gemachte Hysterokleisis die Cervix veränderte und in zwei weiteren änderte sich die von Anfang an zarte und kleine Cervix nach der Operation nicht. Aus den 10 übrigen Fällen 'geht aber hervor, dass eine langsame Atrophie und Volumsabnahme der Cervix zu Stande kommt. Die Cervix wird schlanker und zarter, weniger kürzer. War ein Ektropium der Muttermundslippen vorhanden, so verschwindet dasselbe rasch, Erosionen oder Geschwïre am Muttermunde heilen bald, schon nach mehreren Monaten aus. Cervixkatarrhe vermindern sich bedeutend und verschwinden ohne weitere örtliche Behandlung, da die Cervicalschleimhaut gleich der Gesammtsubstanz der Cervix schrumpft.

\section{Der Uterus.}

Zunächst werde ich die Rückbildung des Uterus im Allgemeinen besprechen und später das Schrumpfen der im Uterus befindlichen Myome.

Die vorliegende Tabelle zeigt mit grosser Klarheit, dass der Uterus nach der Castration einer langsamen, aber stetigen Schrumpfung anheim fällt, und zwar in höherem Grade als alle anderen Geschlechtstheile. Dabei ist es gleichgültig, ob der Uterus durch Tumoren oder eine chronische Entzündung vergrössert, oder ob er von normaler Grösse war. Die Atrophie ist sehr beständig, blieb in keinem einzigen Falle aus. Nur die Fälle, in denen Ovarial-

1) Das klimakterische Alter der Frauen. 
gewebe zurückgeblieben war und die Menstruation fortdauerte, lassen die Schrumpfung vermissen.

Die Schrumpfung beginnt sofort nach der Castration, wenigstens habe ich nie eine, wenn auch nur vorübergehende, Vergrösserung des Uterus gesehen. Bei der natürlichen Klimax dagegen tritt, wie Börner betont, anfangs häufig eine Vergrösserung des Uterus auf, die erst später der Schrumpfung weicht. Ich habe daher an die Möglichkeit gedacht, dass auch bei der künstlichen Klimax eine vorübergehende Vergrösserung im Beginne erfolgen könnte, ich dioselbe nur nicht beobachtet hätte, weil ich die Frauen in der allerersten Zeit nach der Operation nicht habe untersuchen können. Die Vergrösserung müsste dann aber sehr rasch vorübergegangen sein, denn wenn ich, wie gewöhnlich, die Frauen kurz vor der Entlassung (also etwa drei bis vier Wochen nach der Operation) zuerst gründlich untersuchte, so konnte ich gewöhnlich schon eine Verkleinerung des Uterus nachweisen. Eine Vergrösserung habe ich jedenfalls nie gesehen. Um Täuschungen zu vermeiden, habe ich die Verkleinerung nicht blos abgeschätzt, sondern genau durch Messungen bestimmt. Hierbei stösst man freilich auf grosse Schwierigkeiten. Die brauchbarste und annähernd sichere Methode ist, die Sonde bis an den Fundus in die Uterushöhle einzuführen und die Länge der Uterushöhle mitsammt der dos Cervicalkanals zu bestimmen. Dabei ergiebt sich allerdings nur die Länge des Uterus, und diese nicht einmal genau, falls der Uterus durch wandständige Tumoren unregelmässig vergrössert sein sollte, aber man erhält doch immer ein bestimmtes feststehendes Maass und die Ergebnisse lassen sich mit einander vergleichen.

Die Schrumpfung des Uterus beginnt rasch und macht gewöhnlich schnelle Fortschritte, zumal wenn er durch interstitielle Myome oder chronische Metritis bedeutend über die Norm vergrössert war. Ich bin manchmal erstaunt gewesen, wie klein der Uterus schon nach einem Vierteljahre geworden war. In Fall 10 der Tabelle hatte die Sondenlänge des Uterus in drei Monaten bereits $3 \mathrm{~cm}$ abgenommen. Die Schrumpfung erfolgt gewöhnlich gleichmässig in allen Richtungen, das Organ wird härter, derber und straffer, weniger saft- und blutreich. Am stärksten pflegt die Schrumpfung bei krankhaften Zuständen des Uterus (Fall 9) zu sein, am geringsten bei normalem Uterus (Fall 16). Die grösste Abnahme der Sondenlänge (um $6 \mathrm{~cm}$ ) zeigt sich in Fall 9, die 
geringste in Fall 16 (um 0,2 cm). Durchschnittlich hat die Sondenlänge um 1,8 cm abgenommen, also recht erheblich. Wie in der Länge, nimmt der Uterus auch in der Dicke und Breite ab.

Von 11 Fällen wurde in 5 der Uterus unternormal, in 2 normal, in 4 blieb er übernormal. Er schrumpft also gewöhnlich noch unter die Norm, ähnlich wie nach der natürlichen Klimax. Dabei verengert sich, ja verschliesst sich der innere Muttermund, so dass es in 2 Fällen nicht möglich war, selbst die feinsten Sonden durch den Muttermund zu schieben. Am kleinsten sah ich den Uterus in Fall 6 werden, bei einer Frau, die nahe dem Klimakterium stand. Es betrug die Sondenlänge nur $4 \mathrm{~cm}$.

In einem einfachen mechanischen Circulationshindernisse darf die Erklärung der Schrumpfung nicht gesucht werden, denn die Arteria uterina obliterirt bei der natürlichen Klimax nicht und wird bei der künstlichen nicht unterbunden. Die Unterbindung der Vasa spermatica, die allerdings jedesmal bei der Castration stattindet, können wir ebenfalls nicht als Ursache der Schrumpfung ansehen, wie dies $\mathrm{Martin}^{\mathbf{1}}$ ), Veit ${ }^{2}$ ) und Andere thun. Denn erstens sendet die Arteria spermatica nur einen sehr kleinen Gefässast zum Uterus, und zweitens sprechen die Thierversuche von $\mathrm{Kehrer}{ }^{3}$ ) und ein von uns operirter Fall, den ich im ersten Kapitel näher beschrieben habe, dagegen. In diesem Falle konnte das eine Ovarium nicht gefunden werden, und auf dieser Seite wurden nur die Vasa spermatica unterbunden, während auf der anderen das Ovarium entfernt und die Vasa spermatica unterbunden wurden. Trotzdem trat keine Schrumpfung, sondern eine langsame Vergrösserung des Uterus ein. Auch den einen von K ehrer angeführten Grund, dass die Menstruationshyperämie des Uterus als Wachsthumsreiz anzusehen sei, kann ich hier nicht anziehen, denn er würde nur das Stehenbleiben des Uterus in seiner Entwickelung, wie Kehrer das auch meint, nicht aber die Schrumpfung erklären. Immerhin sprechen die durch Kehrer's Thierversuche gefundenen Thatsachen, dass die Exstirpation der Ovarien bei jugendlichen Thieren einen Stillstand in der Entwickelung des Uterus zur Folge hat, und die durch meine Untersuchungen festgestellte Thatsache, dass nach einer gelungenen

1) Artikel Castration in Eulenburg's Realencyklopädie.

2) Handbuch der Geburtshülfe, Bd. I.

3) Beiträge zur klinischen u. experimentellen Geburtskunde, Bd. II, 3. Heft. 
Castration regelmässig eine Schrumpfung und Atrophie der zurückbleibenden Genitalien stattfindet, dafür, dass ein Zusammenhang der Ovarien mit der Entwickelung und Ernährung der übrigen Genitalien besteht. Wahrscheinlich wird dieser Zusammenhang durch nervöse Einflüsse vermittelt. $O b$ aber durch die Ovarien besondere trophische Nerven des Uterus oder die vasomotorischen Nerven beinflusst werden, ob dieser Einfluss auf Nervenbahnen vom Ovarium geraden Wegs zum Uterus hin stattfindet, oder ob wir ihn auf reflectorischem Wege durch ein Centralorgan hindurch zustandekommen denken müssen, bleibt zunächst dahingestellt.

\section{E. Einwirkung der Castration auf die Tumoren des Uterus.}

Hegar ${ }^{1}$ ) hat zuerst auf das Schrumpfen der Uterusmyome nach der Castration aufmerksam gemacht und dasselbe später immer mehr betont. Seine Angaben wurden von Wenigen bestritten, von den Meisten bestätigt. Wiedow ${ }^{2}$ ) stellte die bis dahin bekannten, wegen Uterusmyom gemachten Castrationen zusammen und zeigte, dass nach Castration fast regelmässig eine Abnahme der Tumoren bis zum völligen Verschwinden stattfindet. Bei 76 Fällen schrumpfte der Tumor 62 Male theils mehr, theils weniger, also in 81 Proc. aller Fälle. Tissier ${ }^{3}$ ) kam zu demselben Ergebnisse, d. $\mathbf{h}$. in 80 Proc. aller von ihm zusammengestellten Fälle konnte ex das Schrumpfen des Myomes nach der Castration nachweisen.

Dieselben Ergebnisse lieferten auch alle später ausgeführten Castrationen, so dass es heute keinem Zweifel mehr unterliegt, dass nach der Fortnahme der Eierstöcke die Uterusmyome fast ausnahmslos einer langsamen Atrophie entgegengehen. Wenn ich trotzdem mein Material auch in dieser Beziehung zusammengestollt habe, so geschah es nur, um Einzelheiten dieses Vorganges näher zu beleuchten. (Siehe Tabelle V, S. 42 u. 43.)

Ich habe im Ganzen 23 Fälle, bei denen die Castration wegen Uterusmyom gemacht wurde. Mir fehlen aber von 3 Fällen die näheren Angaben. Von den übrigen 20 Fällen trat in 18 Fällen,

1) Castration der Franen.

2) Dieses Archiv, Bd. XXV.

3) De la castration de la femme. Thèse de Paris 1885. 
also 90 Proc., eine Schrumpfung der Myome ein, und nur in 2 Fällen blieb sie aus. Meine Ergebnisse sind also etwas günstiger als die von Wiedow und Tissier. In den beiden negativen Fällen handelte es sich um grosse submucöse Myome der Cervix, in dem einen derselben war sicher, in dem anderen wahrscheinlich Ovarialgewebe sitzen geblieben. Die Krankengeschichten dieser Fälle habe ich bereits im ersten Kapitel unter Aa-d. und D. kurz mitgetheilt. In beiden Fällen hat die Menstruation fortgedauert und ist auch sonst keine Klimax eingetreten. Man kann sie als misslungene Castrationen ansehen und käme dann zu dem Ergebnisse, dass in unseren Fällen nach der gelungenen Castration regelmässig ein Schrumpfen der Uterusmyome auftrat.

$\mathrm{Zu}$ den 17 genau beobachteten Fällen der Tabelle möchte ich noch folgende Bemerkungen machen. Ich habe die Befunde an den Myomen gewöhnlich zu vier verschiedenen Zeiten aufgeschrieben, nämlich vor der Castration, bei der Entlassung, gewöhnlich vier Wochen nach der Castration, dann in dem Zeitraume bis zu einem Jahre nach der Operation und schliesslich in einem Zeitraume von einem bis vier Jahren nach der Operation.

In einigen Fällen, wo es sich um Tumoren handelte, habe ich jedesmal die Länge und Breite derselben genau mit dem Tasterzirkel zu bestimmen gesucht, immer habe ich die Sondenlänge des Uterus zu den verschiedenen Zeiten gemessen.

Abgesehen von den beiden misslungenen Castrationen trat stets ein Schrumpfen und eine bedeutende Verkleinerung des Tumor ein, entweder langsam aber stetig fortschreitend (Fall 2, 3, 5), oder es nahm besonders in der ersten Zeit nach der Operation sehr rasch der Tumor ab, während das Schrumpfen des zurückgebliebenen Restes später langsamer von statten ging. So war in den Fällen 1, 4, 15 nach vier Wochen eine für die kurze Zeit ausserordentliche, mich geradezu in Erstaunen setzende Abnahme des Tumor nachzuweisen.

Im Falle 1 war der Tumor von Mannskopf- bis Kindskopfgrösse geschrumpft, sein Fundus, der vor der Operation am Nabel stand, war nach derselben zwei Finger breit über der Symphyse nachzuweisen und die Sondenlänge des Uterus hatte von $13 \mathrm{~cm}$ auf $10 \mathrm{~cm}$ abgenommen. Im Falle 4 stand der höchste Punkt des Tumor vor der Operation zwei Finger breit über, vier Wochen nach derselben drei Finger breit unter dem Nabel, seine Breite 
Tabelle V. Wirkung der Castratic

\begin{tabular}{|c|c|c|c|c|c|c|c|c|c|}
\hline \multicolumn{5}{|c|}{ Vor der Castration } & \multicolumn{5}{|c|}{ Vier Wochen nach der Castration } \\
\hline $\begin{array}{l}\text { Grösse des } \\
\text { Myomes }\end{array}$ & $\begin{array}{l}\text { Stand der } \\
\text { höchsten } \\
\text { Kuppe }\end{array}$ & 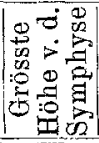 & 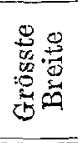 & $\begin{array}{c}\text { Sonden- } \\
\text { länge }\end{array}$ & $\begin{array}{c}\text { Grösse } \\
\text { des } \\
\text { Myomes }\end{array}$ & $\begin{array}{c}\text { Stand der höchsten } \\
\text { Kuppe }\end{array}$ & 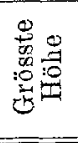 & 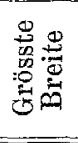 & $\begin{array}{l}\text { S } \\
d \\
\text { lä }\end{array}$ \\
\hline Mannskopf & $\begin{array}{l}\text { Bis zum } \\
\text { Nabel }\end{array}$ & $\begin{array}{c}\mathrm{cm} \\
11,7\end{array}$ & $\begin{array}{c}\mathrm{cm} \\
12,2\end{array}$ & $\begin{array}{c}\mathrm{cm} \\
13,0\end{array}$ & - & $\begin{array}{l}\text { Fundus } 2 \text { Fgr. breit } \\
\text { über der Symphyse }\end{array}$ & $\mathrm{cm}$ & cm & \\
\hline - & Nabel & 一 & - & 11,0 & $\begin{array}{l}\text { Bedeut. } \\
\text { kleiner }\end{array}$ & $\begin{array}{c}2 \text { Finger breit unter } \\
\text { dem Nabel }\end{array}$ & - & - & \\
\hline$\ldots$ & $\begin{array}{l}2 \text { Finger breit } \\
\text { überd. Nabel }\end{array}$ & - & - & - & - & $\begin{array}{c}1 \text { Finger breit unter } \\
\text { dem Nabel }\end{array}$ & 15,3 & 14,2 & \\
\hline 一 & $\begin{array}{l}\text { 2 Finger breit } \\
\text { überd. Nabel }\end{array}$ & 20,0 & 19,5 & 10,0 & - & $\begin{array}{c}3 \text { Finger breit unter } \\
\text { dem Nabel }\end{array}$ & 14,0 & 17,0 & \\
\hline - & Nabel & 一 & 19,5 & - & - & 1 Finger breit unter & - & 17,2 & \\
\hline Wallnussgross & - & - & - & 8,5 & - & - & - & - & \\
\hline Faustgross & - & - & - & 8,5 & $\begin{array}{l}\text { Etwas } \\
\text { kleiner }\end{array}$ & - & - & - & \\
\hline $\begin{array}{l}2 \text { mannsfaust- } \\
\text { gross }\end{array}$ & $\mid \begin{array}{c}3 \text { Finger breit } \\
\text { ubber der } \\
\text { Symphyse }\end{array}$ & - & - & - & - & $\begin{array}{l}3 \text { Finger breit über } \\
\text { der Symphyse }\end{array}$ & - & - & \\
\hline Faustgross & - & - & - & 8,0 & $\begin{array}{c}\text { Etwas } \\
\text { grösserals } \\
\text { ein norma. } \\
\text { ler Uterus }\end{array}$ & - & - & 一 & \\
\hline $\begin{array}{l}\text { Halbhühner- } \\
\text { eigross }\end{array}$ & - & - & 一 & 7,5 & - & - & - & - & \\
\hline $\begin{array}{l}\text { Mindestens } \\
\text { kindskopf- } \\
\text { gross }\end{array}$ & $\begin{array}{c}\text { 1Finger breit } \\
\text { unter } \\
\text { dem Nabel }\end{array}$ & - & - & - & - & - & 14,5 & 13,7 & \\
\hline $\begin{array}{l}\text { Kindskopf- } \\
\text { gross }\end{array}$ & $\begin{array}{c}3 \text { Finger breit } \\
\text { über der } \\
\text { Symphyse }\end{array}$ & $-\cdots$ & - & 8,5 & $\begin{array}{l}\text { Manns- } \\
\text { faust } \\
\text { gross }\end{array}$ & - & - & - & \\
\hline $\begin{array}{l}2 \text { mannsfaust- } \\
\text { gross }\end{array}$ & $\begin{array}{l}3 \text { Finger breit } \\
\text { unter } d . \text { Nabel }\end{array}$ & - & - & 一 & - & - & 一 & - & \\
\hline- & $\begin{array}{l}3 \text { Finger breit } \\
\text { unter d. Nabel }\end{array}$ & - & - & - & - & $\begin{array}{l}4 \text { Finger breit über } \\
\text { der Symphyse }\end{array}$ & 10,0 & 11,4 & \\
\hline- & $\begin{array}{l}3 \text { Finger breit } \\
\text { über d. Nabel }\end{array}$ & 16,5 & 15,4 & - & - & Nabel & 11,6 & 12,0 & \\
\hline - & $\begin{array}{l}2 \text { Finger breit } \\
\text { über d. Nabel }\end{array}$ & - & - & 13,5 & - & $\begin{array}{c}\text { Handbreit über der } \\
\text { Symphyse }\end{array}$ & - & - & \\
\hline $\begin{array}{l}\text { Ueberkinds- } \\
\text { kopfgross }\end{array}$ & $\begin{array}{c}\text { Nahezu bis } \\
\text { zum Nabel }\end{array}$ & 14,1 & 14,2 & - & $\begin{array}{c}\text { Manns- } \\
\text { faustgross }\end{array}$ & - & - & - & \\
\hline
\end{tabular}


f die Tumoren des Uterus.

\begin{tabular}{|c|c|c|c|c|c|c|c|c|c|c|}
\hline \multicolumn{5}{|c|}{ zu einem Jahre nach der Castration } & \multicolumn{5}{|c|}{ Bis zu vier Jahren nach der Castration } & \multirow[b]{2}{*}{ Bemerkungen } \\
\hline $\begin{array}{l}\text { ise des } \\
\text { us mit } \\
\text { yom }\end{array}$ & $\begin{array}{l}\text { Stand der } \\
\text { höchsten } \\
\text { Kuppe }\end{array}$ & 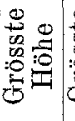 & 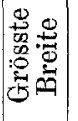 & $\begin{array}{l}\text { Son- } \\
\text { den- } \\
\text { länge }\end{array}$ & $\begin{array}{l}\text { Grösse des } \\
\text { Uterus mit } \\
\text { Myom }\end{array}$ & $\begin{array}{l}\text { Stand der } \\
\text { höchsten } \\
\text { Kuppe }\end{array}$ & 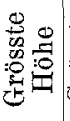 & 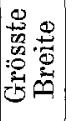 & 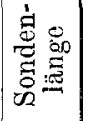 & \\
\hline $\begin{array}{l}\text { och mäs- } \\
\text { rgrössert }\end{array}$ & - & cm & $\mathrm{cm}$ & $\frac{\mathrm{cm}}{7}$ & Nicht mehr & nachzuweisen. & am $\mathrm{dt}$ & terus & norma & gross \\
\hline 一 & - & - & - & - & $\begin{array}{l}\text { Kindskopf- } \\
\text { gross }\end{array}$ & $\begin{array}{c}\text { Liegt im klei- } \\
\text { nen Becken }\end{array}$ & - & - & 11 & \\
\hline- & $\begin{array}{l}3 \text { Finger breit } \\
\text { unterd. Nabel }\end{array}$ & 14,8 & 13,1 & 14 & - & $-1 \cdot$ & - & - & - & \\
\hline $\begin{array}{l}\text { lskopf- } \\
\text { ross }\end{array}$ & -1 & 11,4 & 13,0 & 8,5 & - & - & - & - & - & \\
\hline $\begin{array}{l}\text { ropfgross } \\
\text { sleinen } \\
\text { zcken }\end{array}$ & $\begin{array}{l}2 \text { Fgr. breit ü. } \\
\text { der Symphyse }\end{array}$ & - & 8,0 & - & - & - & - & - & - & \\
\hline 一 & - & - & - & - & Normalgross & 一 & - & - & 6 & \\
\hline talgross & - & - & - & 6,5 & Mittelgross & - & - & - & 6 & $\begin{array}{l}\text { SubmucösesMyo } \\
\text { Ein Ovarium mu } \\
\text { aus Pseudomen } \\
\text { branen heraus. } \\
\text { gelöst werden }\end{array}$ \\
\hline $\begin{array}{l}\text { it ver- } \\
\text { sinert }\end{array}$ & $\mid \begin{array}{c}3 \text { Finger breit } \\
\text { über der } \\
\text { Symphyse }\end{array}$ & - & - & 一 & - & - & - & - & - & \\
\hline algross & - & - & - & 6 & $\begin{array}{l}\text { Uterus klein, } \\
\text { unter mittel- } \\
\text { gross }\end{array}$ & 一 & - & - & - & \\
\hline $\begin{array}{l}\text { n halb- } \\
\text { tussgross. } \\
\text { s normal }\end{array}$ & - & - & 一 & 7 & - & - & - & - & - & \\
\hline - & - & 14,2 & 13,7 & - & - & Nabel & 14,5 & 16,5 & - & $\begin{array}{l}\text { Nur ein Ovariu } \\
\text { entfernt. Das } \\
\text { zweite war nic } \\
\text { zu finden }\end{array}$ \\
\hline $\begin{array}{l}\text { is wenig } \\
\text { iser als } \\
\text { srmal }\end{array}$ & - & - & 一 & 7 & $\begin{array}{c}\text { Noch etwas } \\
\text { grösser als } \\
\text { normal }\end{array}$ & Symphyse & - & - & 7 & \\
\hline $\begin{array}{l}\text { ronen- } \\
\text { ross }\end{array}$ & - & - & - & 8 & - & - & - & - & - & \\
\hline $\begin{array}{l}\text { nsfaust- } \\
\text { ross }\end{array}$ & - & - & - & 12,5 & $\begin{array}{c}\text { Gut gänseei- } \\
\text { gross }\end{array}$ & $\begin{array}{l}1 \text { Fgr. breit ü. } \\
\text { der Symphyse }\end{array}$ & - & - & 8,5 & \\
\hline $\begin{array}{l}\text { nsfaust- } \\
\text { ross }\end{array}$ & $\begin{array}{l}2 \text { Fgr. breit ü. } \\
\text { derSymphyse }\end{array}$ & - & - & 一 & - & - & - & - & - & \\
\hline $\begin{array}{l}\text { nsfaust- } \\
\text { ross }\end{array}$ & $\begin{array}{l}2 \text { Fgr. breit ü. } \\
\text { der Symphyse }\end{array}$ & - & - & 8,5 & - & - & 一 & - & - & $\begin{array}{l}\text { Myomotomie ur } \\
\text { Castration }\end{array}$ \\
\hline $\begin{array}{l}\text { s grösser } \\
\text { normal }\end{array}$ & - & - & - & 7,5 & - & - & - & - & - & $\begin{array}{l}\text { Myomotomie ur } \\
\text { Castration }\end{array}$ \\
\hline
\end{tabular}


hatte von $19,5 \mathrm{~cm}$ auf $17 \mathrm{~cm}$ abgenommen und seine Höhe, d. $\mathrm{h}$. der Abstand der Kuppe von der Symphyse, sogar von $20 \mathrm{~cm}$ auf $14 \mathrm{~cm}$. Im Falle 15 ist die Kuppe des Tumor in der Zeit von vier Wochen von einer Höhe drei Finger breit über dem Nabel auf Nabelhöhe gesunken, die Breite von $15,4 \mathrm{~cm}$ auf $12 \mathrm{~cm}$ gefallen und die Höhe von $16,5 \mathrm{~cm}$ auf $11,6 \mathrm{~cm}$.

Solche Verkleinerung springt natürlich bei grossen Myomen am meisten in die Augen, bei den kleineren ist sie nur wenig zu bemerken, weil die Massenabnahme eine viel geringere ist. So ist z. B. im Falle 9 der Uterus mit dem interstitiell liegenden Myome vor der Operation als faustgross bezeichnet und vier Wochen nachher nur wenig grösser als ein normaler Uterus, indem die Sondenlänge von $8 \mathrm{~cm}$ auf $6 \mathrm{~cm}$ abgenommen hatte. Die Hauptmasse des Tumor ist meist bereits $1 / 4$ Jahr nach der Operation verschwunden, dann schrumpft der Rest langsam, aber doch stetig. Im Falle 1 war das mannskopfgrosse Myom nach einem halben Jahre beinahe vollkommen verschwunden, denn die Sondenlänge sank ron $13 \mathrm{~cm}$ auf $7 \mathrm{~cm}$, also um $6 \mathrm{~cm}$. Ein so rasches Verschwinden des Tumor nach der Operation habe ich bisher in der Literatur nicht gefunden. Nie habe ich anfangs eine vorübergehende Massenzunahme beobachtet, sondern stets die sofortige Schrumpfung.

Das Endergebniss ist gewöhnlich ein nahezu vollkommenes Schwinden des Tumor, von dem höchstens ein kleiner Rest übrig bleibt. Unsere Tabelle ist freilich in dieser Beziehung nur recht dürftig, denn es liegen nur von 5 Fällen Angaben vor über die Verhältnisse nach mehreren Jahren. In einem Falle war der Uterus kleiner als normal geworden, in 2 Fällen mittelgross (Sondenlänge $6 \mathrm{~cm}$ ), in einem Falle etwas übernormal (Sondenlänge $7 \mathrm{~cm}$ ) und nur in einem - zwei Jahre nach der Operation - zeigt er noch eine beträchtliche Grösse - Kindskopfgrösse mit $11 \mathrm{~cm}$ Sondenlänge - Mit Ausnahme dieses letzten Falles, der ja wahrscheinlich in den nächsten Jahren auch noch ein weiteres Schrumpfen aufweisen wird, sehen wir somit stets den Tumor fast vollkommen verschwinden und den Uterus auf seine normale Grösse, ja noch unter dieselbe zurückgehen. Die von Wiedow und Tissier gesammelten Fälle liefern ungefäbr dieselben Ergebnisse. Wiedow fand in den Fällen, die er fünf bis 6 Jahre beobachten konnte, stets nur noch ein Myom von Haselnuss- bis Orangengrösse. 
Durch die lege artis ausgeführte Castration wird also, wenn es gelingt, alles 0varialgewebe zu entfernen, fast jedesmal eine Verkleinerung, in einigen Fällen selbst ein vollständiges Verschwinden des Tumor herbeigeführt, oder es bleibt nur ein Rest zurück, der seiner Kleinheit wegen nicht weiter in Betracht kommt. Es würde also falsch sein, die Castration lediglich als eine Palliativoperation bei Myoma uteri anzusehen, durch die die wesentlichsten Beschwerden, Blutungen und Schmerzen beseitigt würden, sondern sie führt in nahezu allen Fällen zur Heilung des Myomes, die allerdings nicht sofort, wohl aber im Verlaufe ron einigen Jahren stattfindet. Ich glaube sogar, dass die endgültige Heilung vom Myome viel sicherer durch die Castration als durch die Enucleation wandständiger Tumoren herbeigeführt wird, denn nach der letzteren Operation ist ein Nachwachsen kleiner, bei der Operation allerdings schon vorhandener, aber wegen ihrer Kleinheit nicht bemerkter Myome stets möglich. Die Enucleation wird daher nur dann einen sicheren Erfolg bringen, wenn sie mit der Castration verbunden wird.

In zwei Fällen sah ich, wie kleinere submucöse Uterusmyome, welche vor der Operation mehr interstitiell in der Uteruswand lagen, nach der Castration zu gestielten submucösen Myomen sich umformten und Veranlassung zu unregelmässigen Blutungen gaben. In beiden liessen sich die Myome leicht entfernen, worauf die Blutung stand. Einen ähnlichen Fall giebt Wiedow ${ }^{1}$ ) an, wo Fehling drei Monate nach einer von Hegar ausgeführten Castration ein vorher intramural sitzendes Myom nach Verstreichen der Cervix ausschälen konnte. Ebenso sah Prochownick²) in einem Falle, wie ein vorher grösstentheils intramural sitzendes, apfelgrosses Myom etwa ein Vierteljahr nach der Castration nach abwärts drängte, so dass er es nach Kapselspaltung ausschälen konnte, was vorher nicht gelungen war.

In diesem Falle war der Uterus bei der Operation gleichzeitig aufgerichtet und an die vordere Bauchwand angenäht, welchem Umstande Prochownick das Tiefertreten des Tumor zuschreibt. Börner ${ }^{3}$ ) beobachtete denselben Vorgang der Stielung vorher interstitiell liegender Myome im Klimakterium, so dass wir hier

1) Dieses Archiv, Bd, XXV, Tabelle Fall 14.

2) Ebendaselbst, Bd. XXIX, S. 194.

3) Die Wechseljabre der Frau. 
wieder eine Gleichartigkeit der künstlichen mit der natürlichen Klimax finden.

Die früher angegebene Erklärung, wie dieses Schrumpfen der Tumoren zu Stande kommt, ist in neuerer Zeit mit Recht verlassen worden, nämlich die, dass durch die Castration eine Unterbindung der zum Tumor führenden Gefässe stattfände und derselbe dadurch atrophire. Die Gründe gegen diese Ansicht sind im vorigen Kapitel bereits auseinandergesetzt worden.

Ebenso muss man die Ansicht von Lawson Tait) zurückweisen, der das Hauptgewicht auf die Entfernung der Tuben legt und der Ansicht ist, dass durch den Fortfall dieser Gebilde erst die der Klimax eigenthümlichen Erscheinungen zu Tage treten. Bei einer ganzen Reihe der besprochenen Castrationen sind beide oder wenigstens eine Tube stehen geblieben, und trotzdem war der Erfolg immer gut, wenn nur die Ovarien mit Sicherheit entfernt waren. Zweifellos ist das die künstliche Klimax herbeiführende Moment die Exstirpation alles Ovarialgewebes und der Fortfall der Ovarien muss auch als die Ursache des Schrumpfens der Myome angesehen werden.

Die hier in Frage kommenden Beziehungen zwischen Ovarium und Uterus sind bereits im vorigen Kapitel näher besprochen worden. Es kommen dieselben Ursachen, welche die Atrophie des Uterus hervorrufen, auch bei dem Schrumpfen des myomatös entarteten Uterus in Betracht.

\section{F. Wirkung der Castration auf den allgemeinen \\ Frnährungszustand.}

Es ist allgemein bekannt, dass Frauen jenseits der Menopause häufig in der allgemeinen Ernährung des Körpers bedeutend zunehmen und fetter werden. Sie bekommen oft eine ganz andere Gestalt, werden dicker, runder und dadurch anscheinend kleiner, ja die Fettzunahme kann so hochgradig werden, dass die Frauen sehr schwerfällig werden und in allen ihren Körperbewegungen sehr lästig behindert sind. Das Unterhautfettgewebe pflegt überall zuzunehmen, am stärksten aber gewöhnlich an den Brüsten, dem Bauche und den Oberschenkeln. Am Bauche bilden sich oft solche Wülste von Fett, dass man den Zustand als diffuses Lipom

1) Bericht im Centralblatte für Gynäkologie 1884, Nr. 50. 
bezeichnen kann. Bei den Thieren ist Aehnliches bekannt, weshalb von den Thierzüchtern schon seit langer Zeit weibliche Thiere vor der Mästung castrirt werden, um letztere zu fördern.

Auch alle Forscher, die über diesen Gegenstand geschrieben haben, Brière de Boismont, Krieger, Kisch und Börner fanden eine vermehrte Fettzunahme nach der Menopause.

Die Fettzunahme findet sich aber keineswegs bei allen Frauen ohne Ausnahme, dann würden wir ja jenseits der Menopause nur noch dicke, fette Frauen erblicken, sondern sie ist nur häufig vorhanden und je nach der individuellen Anlage verschieden. Der Einzige, der hierüber statistische Erhebungen angestellt hat, ist Tilt ${ }^{1}$; derselbe fand bei 282 Frauen, die er fünf Jahre nach der Menopause untersuchte, dass

121 stärker geworden waren als früher,

71 ihren früheren Umfang behalten hatten und

90 magerer geworden waren.

Rechnen wir dies nach Procentzahlen um, so ergiebt sich, dass 43 Proc. stärker geworden sind, 25 Proc. sich gleich blieben und 32 Proc. magerer wurden.

Sowohl Hega $x^{2}$ ) als auch Koeberlé ${ }^{3}$ ) fanden, dass sich bei den Castrirten entschieden eine Neigung zur Fettleibigkeit bemerkbar mache. Auch Péan ${ }^{4}$ ) sah bei manchen seiner Operirten nachher Körperfülle auftreten.

Ich habe das Körpergewicht und den Fettansatz nach der Operation genau zu bestimmen gesucht und in Tabelle VI (S. 48) meine Ergebnisse zusammengestellt.

Zunächst ist zu bemerken, dass in einzelnen Fällen (16, 26, 30) ein ausserordentlich starker Verlust an Gewicht sich nach der Operation dadurch herausstellte, dass sehr grosse doppelseitige Cysten entfernt worden sind: Man darf als das eigentliche Körpergewicht dieser Patientinnen nicht das vor der Operation gefundene ansehen, sondern das bald hinterher bestimmte. Ich habe demgemäss als Gesammtzunahme immer den Unterschied zwischen dem Gewichte bei der Entlassung und dem späteren Körpergewichte gerechnet.

1.) Angeführt in Krieger: Die Menstruation.

2) Castration der Frauen.

3) Puech: Des ovaires et de leurs anomalies. Paris 1873. S. 121.

4) Gazette médicale de Paris 1880. 
48 Glaevecke, Körperl. u. geistige Veränderungen im weibl. Körper

Tabelle VI. Wirkung der Castration auf den allgemeinen Ernährungszustand.

\begin{tabular}{|c|c|c|c|c|c|c|c|c|}
\hline \multirow[b]{2}{*}{$\mathrm{Nr}$} & \multirow[b]{2}{*}{ Name } & \multirow[b]{2}{*}{ Alter } & \multirow[b]{2}{*}{$\begin{array}{l}\text { Körperge- } \\
\text { wichtv.d. } \\
\text { Operation } \\
\text { Pfund }\end{array}$} & \multicolumn{4}{|c|}{ Körpergewicht nach der Operation } & \multirow[b]{2}{*}{$\begin{array}{l}\text { Fettansatz } \\
\text { nach der } \\
\text { Operation }\end{array}$} \\
\hline & & & & $\begin{array}{l}4 \text { Wochen } \\
\text { später } \\
\text { Pfund }\end{array}$ & $\begin{array}{l}1 \mathrm{Jahr} \\
\text { Pfand }\end{array}$ & Pfund & $\begin{array}{l}\text { Gesammt- } \\
\text { zunahme }\end{array}$ & \\
\hline 1 & Vo. & 30 & - & - & - & - & Geringe Zunahme & Gering \\
\hline 2 & Ni I. & 31 & - & - & _- & - & 13 Pfd. & Bedeutend \\
\hline 3 & Schl. & 39 & 150 & - & 170 & 183 & $33 \mathrm{Pfd}$ & Bedeutend \\
\hline 4 & Wu. & 44 & 一 & - & - & - & Starke Zunahme & Bedeutend \\
\hline 5 & Fu. & 43 & - & 92 & 110 & - & 18 Pfd. & Bedeutend \\
\hline 6 & Pe. & 45 & - & - & - & - & 8 Pfd. & Gering \\
\hline 7 & Ha. & 42 & - & 103 & 114 & - & $11 \mathrm{Pfd}$ & Gering \\
\hline 8 & Ho. & 38 & - & - & - & - & Geringe Zunahme & Kein \\
\hline 9 & La. & 35 & - & - & - & - & Geringe Zunahme & Gering \\
\hline 10 & Nis. & 44 & - & - & - & - & Keine Zunahme & Kein \\
\hline 11 & Bo. & 36 & - & - & - & - & $20 \mathrm{Pfd}$ & Bedeutend \\
\hline 12 & L. & 43 & - & 106 & 120 & 137 & 31 Pfd. & Bedeutend \\
\hline 13 & Mo. & 27 & - & - & - & - & Geringe Zunahme & Kein \\
\hline 14 & Ga. & 25 & - & - & - & - & $12 \mathrm{Pfd}$ & Gering \\
\hline 15 & Ni. II. & 33 & - & 一 & - & - & Keine Zunahme & Kein \\
\hline 16 & Schr.I, & 44 & 143 & 83 & 104 & -- & $21 \mathrm{Pfd}$ & Gering \\
\hline 17 & v. L. & 43 & - & - & - & - & Bedeatende Zunahme & Bedeutend \\
\hline 18 & Aa. & 35 & - & - & - & - & Geringe Zunahme & Gering \\
\hline 19 & Ma. & 42 & - & 104 & 114 & 116 & 12 Pfd. & Kein \\
\hline 20 & Pet. I & 35 & 106 & 109 & 115 & 122 & 13 Pfd. & Gering \\
\hline 21 & Schm. & 42 & - & -- & - & - & $10 \mathrm{Pfd}$. & Bedeutend \\
\hline 22 & Kö. & 34 & - & - & - & - & 12 Pfd. & Gerìng \\
\hline 23 & Ka. & 44 & - & - & - & - & Geringe Zunahme & Gering \\
\hline 24 & Gr. & 21 & - & - & - & 一 & 15 Pfd. & Gering \\
\hline 25 & Schr. II & 31 & - & 100 & 108 & - & 8 Pfd. & Kein \\
\hline 26 & Fr. & 36 & 140 & 112 & 132 & 152 & $40 \mathrm{Pfd}$ & Bedeutend \\
\hline 27 & $\mathrm{Na}$. & 27 & 130 & 124 & 136 & 148 & 24 Pfd. & Bedeutend \\
\hline 28 & Fra. & 32 & - & - & - & - & Geringe Zunahme & Gering \\
\hline 29 & Bob. & 35 & - & - & - & - & Geringe Zunahme & Kein. \\
\hline 30 & Lü. & 35 & 114 & 103 & 117 & -- & 14. Pfd. & Bedeutend \\
\hline 31 & Sa. & 45 & - & - & - & - & Geringe Zunahme & Gering \\
\hline 32 & Je. & 36 & - & - & - & - & Starke Zunahme & Bedeutend \\
\hline 33 & Ap. & 37 & - & - & - & - & Geringe Zunahme & Gering \\
\hline 34 & Ju. & 29 & - & - & - & - & $22 \mathrm{Pfd}$ & Bedeutend \\
\hline 35 & Lüb. & 37 & - & - & - & - & Bedeutende Zunahne & Bedeutend \\
\hline 36 & Ro. & 43 & - & - & - & - & Geringe Zunahme & $\begin{array}{l}\text { Vorher schon } \\
\text { vorbandener } \\
\text { Fettansatz } \\
\text { gleich- } \\
\text { geblieben }\end{array}$ \\
\hline 37 & Pet. II. & 26 & - & - & - & - & Keine Zunahme & Kein \\
\hline 38 & He. & 38 & 120 & 116 & 140 & - & $24 \mathrm{Pfd}$ & Bedeatend? \\
\hline 39 & Re. & 41 & 145 & 120 & 145 & - & 25 Pfd. & Bedentend ${ }^{*}$ \\
\hline 40 & Go. & 37 & 131 & - & 143 & - & $12 \mathrm{Pfd}$ & Bedeutend \\
\hline
\end{tabular}

Nur in 3 Fällen, also in 7,5 Proc. aller Fälle, hat keine Gewichtszunahme stattgefunden. Es ist dies Fall 10, wo die Frau bei der Caștration bereits 44 Jahre alt war, also der Körper sich wohl schon auf die natürliche Menopause vorbereitete, ferner 
Fall 15, wo die Kranke hinterher in einem Armenhause wahrscheinlich sehr dürftig ernährt wurde, und Fall 37, bei dem die Menses noch in geringem Grade fortdauerten, also von einer richtigen künstlichen Klimax nicht gesprochen werden darf. In weiteren 14 Fällen, also in 35 Proc. aller Fälle, haben wir eine geringe Zunahme des Körpergewichtes zu verzeichnen, wozu ich die bis zu $10 \mathrm{Pfd}$. einschliesslich rechne. Eine Zunahme über $10 \mathrm{Pfd}$. hinaus finden wir in 23, also in 57,5 Proc. aller Fälle. Der Durchschnitt der Gewichtszunahme berechnet sich auf 17 Pfd. Als höchste Ziffern sind 31,33 und $40 \mathrm{Pfd}$. vermerkt.

Die Ergebnisse aus der zweiten Rubrik der Tabelle weisen keinen Fettansatz in 9 von 40 Fällen, also in 22,5 Proc., nach. In 14, also 35 Proc. aller Fälle, finden wir einen geringen Fettansatz, und in 17, also 42,5 Proc., ist derselbe bedeutend, so dass er den Frauen selber sofort aufgefallen ist.

Es hat also in fast allen Fällen eine Zunahme des Körpergewichtes stattgefunden, in gut einem Drittel der Fälle ist dieselbe nur gering, so dass sie durch die Convalescenz nach der Operation allein bedingt sein kann, in mehr als der Hälfte der Fälle geht sie aber hierüber hinaus und in einzelnen erreicht sie eine geradezu aussergewöhnliche Höhe. Ebenso finden wir in drei Viertel aller Fälle einen Fettansatz nach der Operation, aber in einem Drittel der Fälle ist er nur gering, so dass er durch die Kräftigung nach der Operation allein erklärt werden könnte, in nahezu der Hälfte aller Fälle erreicht er aber eine bedeutende Höhe.

Ich bin hier auf den Einwurf gefasst, dass die Frauen ja durch die eingreifende Operation und ein längeres Krankenlager mehr oder weniger heruntergekommen sein konnten, und dass es kein Wunder sei, wenn sie sich mit der Genesung wieder erholten und ibren Ernährungszustand aufbesserten. Bei geringer Gewichtszunahme und Fettansatz will ich dies gelten lassen; immerhin wären bedeutendere Gewichtszunahmen bei 57,5 Proc. und stärkerer Fettansatz bei 42,5 Proc. anders zu erklären, und nichts liegt näher, als das künstlich erzeugte Klimakterium heranzuziehen. Es stimmten die von mir gefundenen 42,5 Proc. der fetter werdenden Frauen. fast genau mit den 43 Proc., die Tilt nach der Menopause bei stärker werdenden Frauen fand, überein. Ein neuer Beweis dafür, dass nach der Castration eine wirkliche künstliche Klimax eintritt, ganz gleich der natürlichen. 
Brière de Boismont und Krieger sehen das Aufhören der Menses und der Geburten als die hauptsächlichste Ursache der Zunahme an, Kisch sucht sie besonders in der Entartung der Ovarien und dem Erlöschen des Geschlechtstriebes, Börner dagegen nimmt eine tief verborgene Umgestaltung in dem Lebensvorgange des weiblichen Organismus, die das eigentliche Wesen des Wechsels ausmacht, als Ursache an. Diese Ansichten sind nicht einwandsfrei. Das Aufhören der geschlechtlichen Erregungen ist nicht das Ursächliche, denn, wie wir im nächsten Kapitel sehen werden, erlischt der Geschlechtstrieb durchaus nicht immer nach der Castration, und ich kann nach meinen Forschungen auch nicht den Nachweis liefern, dass gerade die Dicken den Geschlechtstrieb einbüssen, oder dass die mit erhaltenem Geschlechtstriebe mager bleiben. Auch der Fortfall der Menses und der Geburten kann nicht als Ursache angesehen werden, da dasselbe Ergebniss auch nach der Totalexstirpation des Uterus eintritt und, wie wir sehen werden, nach dieser Operation die Neigung zur Fettleibigkeit nicht in dem Maasse vorhanden ist, wie nach der Castration. Es muss also der Ausfall der Ovarien und ihrer Functionen doch wieder das wesentlich Bestimmende sein und wieder muss man auf nervöse Einflüsse zurückgreifen.

Wir haben bei Besprechung der heissen Uebergiessungen schon den innigen Zusammenhang des Ovarium mit dem Sympathicus und dem vasomotorischen Nervensysteme betont und vermuthet, dass durch den Fortfall der Ovarien Störungen im vasomotorischen Nervensysteme auftreten könnten. Wenn wir diese Annahme weiter ausspännen, so könnte man annehmen, dass durch veränderte Innervation von Seiten der Vasomotoren die einzelnen Körpertheile besser mit Blut versorgt werden und ein erhöhter Stoffwechsel im gesammten Organismus zu Stande kommt, infolge dessen Zunahme des Körpergewichtes und des Fettpolsters entsteht. Vielleicht könnte man auch einen unmittelbaren Zusammenhang der Ovarien mit dem trophischen Nervensysteme annehmen, doch steht diese Vermuthung auf noch schwächeren Füssen, als die voraufgehende, da uns über die trophischen Nerven alle grundlegenden Kenntnisse fehlen. Ich muss mich begnügen, nur den Weg angedeutet $\mathrm{zu}$ haben, auf dem man vielleicht eine neue Erklärung für die längst bekannte Thatsache finden könnte.

Dass nicht alle Frauen, wie man erwarten sollte, nach Exstirpation der Ovarien an Körpermasse zunehmen, liegt in indi- 
viduellen Verhältnissen. Manche Personen sind eben mehr als andere zum Ansatze von Körpermasse und Fett beanlagt.

\section{G. Verhalten der Libido sexualis nach der Castration.}

Das Verhalten der Libido in der natürlichen Klimax steht nicht ganz fest, wohl wegen der peinlichen Behandlung der Frage. Nach Kisch ${ }^{1}$ ) überdauert die Geschlechtslust die Menopause oft noch um Jahre. Eine Statistik über das Alter der Bräute habe ergeben, dass in Preussen die Zahl der Bräute, welche über 45 Jahre alt waren, 2,583 Proc. beträgt, in England 1,380 Proc., in Irland 0,315 Proc., in Schweden 1,536 Proc. Ich meine indess, dass die Procentzahlen zu klein sind und auch gar nichts beweisen, da die Franen in späten Jahren die Ehe doch wohl weniger wegen der Geschlechtslust schliessen, sondern aus ganz anderen Gründen, wie namentlich wegen Aussicht auf Versorgung u. s. w. Börner ${ }^{2}$ ) fand in dem Verhalten des Geschlechtstriebes zur klimakterischen Zeit ganz eigenthümliche Verschiedenheiten. Nicht selten sah er ihn zu dieser Zeit geringer werden und vollkommen erlöschen, häufig blieb er aber auch über die ganze Wechselzeit hin bestehen, und in einigen Fällen konnte er eine ganz ausserordentliche Steigerung nachweisen, die für die Betreffenden ein geradezu qualvoller Zustand wurde und sie dahin brachte, denselben durch Onanie zu befriedigen. Solche Fälle müssen aber doch wohl als krankhafte Zustände angesehen werden, wohin Börner auch neigt, der bei denselben öfters abnorme Genitalbefunde faud. Es scheint hiernach allerdings die Libido nicht an die Function und Anwesenheit der Ovarien geknüpft zu sein. So erwähnt $\mathrm{Hauff}^{3}$ ) einen Fall, wo ein junges Mädchen nachweislich keine Ovarien hatte und trotzdem hochgradige Onanie betrieb.

Auf der Kieler gynäkologischen Klinik liegt gerade zur Zeit eine 30 jährige Puella publica, welcher der Uterus und die Ovarien vollständig fehlen, und die trotzdem behauptet, volle Libido während des Coitus zu haben. Aehnliche Fälle finden wir an-

1) Das klimakterische Alter der Frauen.

2) Die Wechseljahre der Frau.

3) Württembergisches Correspondenzblatt 1877, Nr. 5. 
gegeben von $\mathrm{Puech}$ ) und $\mathrm{Kussmaul^{2 }}$ ). Dieselben verschiedenen und sich widersprechenden Zustände sehen wir, wie bei der natürlichen Klimax, so auch bei der künstlichen, nach der Castration, zu Stande kommen. Hegar ${ }^{3}$ ) deutet an, dass er oft eine Abnahme des Geschlechtstriebes nach der Castration gesehen habe, dass dieselbe aber keineswegs beständig vorkomme, vielmehr betont er ausdrücklich, dass eine seiner Castrirten ihn versichert hätte, dass ihr in diesem Punkte nichts fehle. Zu demselben schwankenden Ergebnisse gelangt Schmalfuss. ${ }^{4}$ Derselbe fand einmal geringe geschlechtliche Neigung, einmal Abneigung, und einmal anfangs Abneigung, später wieder Neigung zum Beischlafe. Bruntzel ${ }^{5}$ ) berichtet, dass nach vier Castrationen zwei Mal die Libido erhalten geblieben, zwei Mal erloschen sei. Koeberlé6) meint, die Operirten sind weniger stark in der geschlechtlichen Liebe, aber sie behalten die Liebe zu ihren Verwandten und zu ihrem Manne. Er betont aber ausdrücklich, dass ihre Geschlechtsorgane reizbar bleiben. Peasle $e^{7}$ ) sagt, dass die Operirten glänzende Beispiele von Weiblichkeit bleiben, bei denen alle ihrem Geschlechte zukommenden Eigenschaften erhalten sind.

Péan ${ }^{8}$ ) sah nach der Operation gewöhnlich keinen Unterschied in dem Geschlechtstriebe, ist aber der Ansicht, dass die Frauen ihre noch vorhandenen geschlechtlichen Gefühle übertrieben schildern.

Spencer Wells ${ }^{9}$ ) sah ein Mal hinterher eine Steigerung der geschlechtlichen Erregung auftreten. Ebenso Tissier ${ }^{10}$, nach dessen Ansicht der Geschlechtstrieb gewöhnlich erhalten bleibt. Dagegen sah Bailly ${ }^{11}$ ) einmal, wo beide Ovarien wegen einer Geschwulst entfernt worden waren, die frühere übermässige Geschlechts-

1) Des ovaires et de leurs anomalies.

2) Von dem Mangel, der Verkümmerung und der Verdoppelung der Ge. bärmutter.

3) Castration der Franen.

4) Dieses Archiv, Bd. XXVI.

5) Ebendaselbst, Bd. XVI.

6) Bericht in Puech: Des ovaires et de leurs anomalies, p. 121.

7) Ovarian tumors. New-York 1872.

8) Gazette médicale de Paris 1880.

9) Angeführt in Tissier: De la castration de la femme.

10) De la castration de la femme.

11) Traitement des ovariotomisées, considérations sur la castration de la femme. Thèse de Paris 1871. 
lust vollkommen verschwinden. Eine ähnliche Beobachtung machte Anger ${ }^{1}$ ) und ebenso spricht sich Goodell ${ }^{2}$ ) aus.

Nach allen diesen Berichten würde sich ergeben, dass der Geschlechtstrieb trotz Fortnahme der Ovarien meist erhalten bleibt oder jedenfalls nur in geringem Grade geschmälert wird.

Meine eigenen Untersuchungen haben indess ein hiermit nicht ganz ïbereinstimmendes Ergebniss geliefert, denn ich fand nur in der Minderzahl keine Beeinträchtigung der Libido sexualis durch die Castration.

Ich habe nur bei 27 Frauen genaue Erkundigungen einziehen können, und habe nur solche Angaben berücksichtigt, welche mir durchaus glaubwürdig erschienen.

Meine Nachforschungen richtete ich auf drei verschiedene Punkte: erstens, ob durch die Castration der Geschlechtstrieb gelitten hätte; zweitens, ob die Frauen während des Beischlafes dieselben Wollustgefühle wie früher empfänden, und drittens, ob die Frauen während des Beischlafes überhaupt Unterschiede gegen früher bemerkten. Nach diesen drei Richtungen hin ist Tabelle VII (S. 54) zusammengestellt.

Die geschlechtliche Neigung ist $\left.\begin{array}{l}\text { vorhanden in } 6 \text { Fällen }=22 \text { Proc. } \\ \text { geringer in } 10 \text { Fällen }=37 \text { Proc. } \\ \text { erlosehen in } 11 \text { Fällen }=41 \text { Proc. }\end{array}\right\} 78$ Proe.

Die Libido während des Coitus ist vorhanden in 8 Fällen $=31$ Prac. $\left.\begin{array}{l}\text { geringer in } 10 \text { Fällen }=38 \text { Proc. } \\ \text { erloschen in } 8 \text { Fällen }=31 \text { Proc. }\end{array}\right\} 69$ Proc.

In einer ganzen Reihe von Fällen finden wir also, dass die Neigung zum Coitus zwar nicht ganz erloschen, aber doch sehr bedeutend verringert ist. In einer anderen Reihe war die Neigung zum Beischlafe vollständig erloschen, aber nur mit einer Ausnahme bestand kein Widerwille. Die Frauen gestatteten willig den Coitus, wenn der Mann es wünschte, nur waren sie vollkommen gleichgültig dabei.

Die grösste Anzahl von Frauen giebt an, dass das Wollustgefühl während des Coitus bedeutend, abgeschwächt, aber doch

1) Lebec* Archives générales de médecine 1882.

2) New-York medical Record 1883. 
Tabelle VII. Wirkung der Castration auf die sexuellen Functionen.

\begin{tabular}{|c|c|c|c|c|c|}
\hline Nr. & Name & $\stackrel{\substack{0\\
}}{4}$ & $\begin{array}{l}\text { Geschlechts- } \\
\text { trieb }\end{array}$ & Wollustgefühl & Verhalten beim Coitus \\
\hline 1 & Vo. & 30 & Vorhanden & Vorhanden & Kein Unterschied \\
\hline 2 & Schl. & 39 & Gering & Gering & - \\
\hline 3 & Wu. & 44 & Erloschen & Gering & - \\
\hline 4 & Fu. & 43 & Erloschen & Erloschen & Schmerzhaft \\
\hline 5 & Pe. & 45 & Erloschen & - & Nicht wieder vollzogen \\
\hline 6 & Ho. & 38 & Erloschen & Erloschen & Selten ausgeführt \\
\hline 7 & L. & 43 & Vorhanden & Vorhanden & Kein Unterschied \\
\hline 8 & Mo. & 27 & Erloschen & Erloschen & Widerwillen gegen Coitus \\
\hline 9 & Ga. & 25 & Geringer & Vorhanden & - \\
\hline 10 & Schr. I & 44 & Vorhanden & Vorhanden & Kein Unterschied \\
\hline 11 & Au. & 35 & Erlosehen & Erloschen & Schmerzhaft \\
\hline 12 & Pet.I & 35 & Erloschen & Gering & Schmerzhaft \\
\hline 13 & Schm. & 42 & Vorhanden & Vorhanden & Kein Unterschied \\
\hline 14 & Kö. & 34 & Vorhanden & Vorhanden & Kein Unterschied \\
\hline 15 & Ka. & 44 & Gering & Vorhanden & - \\
\hline 16 & Gre. & 21 & Gering & Gering & -- \\
\hline 17 & Schr. II & 31 & Erlosehen & Erloschen & Schmerzhaft \\
\hline 18 & Fr. & 36 & Gering & Gering & Schmerzhaft \\
\hline 19 & Bob. & 35 & Gering & Gering & - \\
\hline 20 & Na. & 27 & Erloschen & Erloschen & Schmerzbaft \\
\hline 21 & Fra. & 32 & Erloschen & Erloschen & Schmerzhaft \\
\hline 22 & Lü. & 35 & Erloschen & Erloschen & - \\
\hline 23 & Ap. & 37 & Gering & Gering & - \\
\hline 24 & Jü. & 29 & Gering & Gering & - \\
\hline 25 & He. & 38 & Gering & Gering & - \\
\hline 26 & Re. & 41 & Gering & Gering & - \\
\hline 27 & Go. & 37 & Vorhanden & Vorhanden & Kein Unterschied \\
\hline
\end{tabular}

noch ein Rest davon vorhanden sei, ein kleiner Bruchtheil von Frauen hat selbst diesen angeblich verloren.

Bei sieben Frauen, welche den Coitus als sehr schmerzhaft schilderten, fand ich eine starke Schrumpfung und Enge der Vagina. Bei diesen war das Wollustgefühl während des Actes entweder stark herabgesetzt oder vollkommen erloschen. Sie unterzogen sich ihm nur sehr ungern, aber ohne Abscheu dagegen und fürchteten nur die Schmerzen. Eine hochgradig hysterische Frau, die auch sehr starke Ausfallserscheinungen darbot, gab an, dass jedesmal der Versuch des Beischlafes durch starke hysterische Krämpfe vereitelt würde. Die Neigung, der Geschlechtstrieb, scheint immer zuerst und am meisten zu leiden, dann erst wird das Wollustgefühl während des Actes herabgesetzt. -Wir finden wenigstens in der Tabelle mehrere Angaben, dass der Trieb vermindert sei, während das Gefühl während des Actes noch vollständig fortbestehe. 
Nur bei wenigen Frauen finden wir, dass die Fortnahme der Ovarien den Geschlechtstrieb in keiner Weise gegen früher beeinträchtigte. Ich glaube nicht, dass diese Frauen unwahre oder übertriebene Angaben gemacht haben, denn in einzelnen Fällen bestätigten die Männer die Angaben der Frau und versicherten, dass sie keinen Unterschied an ihren Frauen bemerken könnten.

Ich habe versucht, über die Erzeugung des Wollustgefühls zu einer gewissen Klarheit $\mathrm{zu}$ kommen und das, was ich darüber in der Literatur gefunden, zusammengestellt. Hensen ${ }^{1}$ ) nimmt an, dass die directe Erregung des Geschlechtstriebes vom Nervus dorsalis penis seu clitoridis ausgeht, dass aber gewisse Zustände des Keimorganes die Empfindlichkeit der mit jenen Nerven im Zusammenhange stehenden Centralorgane steigern.

Der Geschlechtstrieb beim Manne soll nach Pflüger ${ }^{2}$ ) durch die pralle Füllung der mit reifem Samen angefüllten Hodenkanälchen und die dadurch bedingte Reizung der Hodennerven zu Stande kommen. Uebertragen wir diese Verhältnisse auf die Frau, so würde die Ursache des Geschlechtstriebes bei ihr im Ovarium und dessen Function zu suchen sein. Es ist auch eine allgemein anerkannte Thatsache, dass die geschlechtliche Erregung der Frau mit dem Ovarium in Verbindung $z u$ bringen ist.

Ich erkläre mir die Sache folgendermaassen: Die pralle Füllung der Samenkanälchen beim Manne oder die straffe Spannung der Follikelwand des Ovarium beim Weibe ruft durch Reizung der Hoden- bez. Ovarialnerven eine gesteigerte Empindlichkeit im Centralorgane hervor und versetzt den Menschen in einen Zustand, in dem er für geschlechtliche Reize sehr empfindlich ist. Kommen nun Erregungen durch die Phantasie vom Gehirn aus oder durch Berührungen und Betastungen von den sensiblen Nerven der äusseren Haut aus, oder irgendwelche andere äussere Erregungen hinzu, so entsteht der Geschlechtstrieb, die Neigung zum Coitus. Diese letzteren Erregungen allein werden jedoch nicht genügen, den Geschlechtstrieb hervorzurufen, wenn nicht vorher eine gesteigerte Erregbarkeit im Centralorgane vom Ovarium aus bewirkt ist. So sehen wir, wie zu Zeiten geschlechtlicher Erregung die kleinsten äusseren Reize genügen, um den Geschlechtstrieb zu er-

1) Physiologie der Zeugung. Leipzig 1881.

2) Die teleologische Mechanik der lebendigen Natur. Archiv für Physiologie, $\mathrm{Bd}$. XV. 
wecken, während zu anderen Zeiten, wo keine geschlechtliche Erregung vorliegt, dieselben und noch weit stärkere äussere Reize nicht den gewünschten Erfolg haben. Wird nun diese Neigung befriedigt, so wird das Wollustgefühl während des Beischlafes durch die Friction der Glans penis beim Manne, und der Glans clitoridis beim Weibe erzeugt. Diese beiden enthalten ja ein zahlreiches Geflecht sensibler Nervenfasern, die in die Kra use'schen Wollustkörperchen übergehen, und man muss annehmen, dass die mechanische Reizung dieser Endorgane in den zu diesen Nerven gehörenden Centren das Gefühl der Wollust hervorruft. Dass aber die Clitoris beim Beischlafe erigirt und dadurch rechtwinklig nach unten auf den eingeführten Penis gedrückt wird, so dass eine starke mechanische Reizung der Glans clitoridis während des Beischlafes zu Stande kommt, hat Kobelt') zur Genüge bewiesen.

Wir hätten also bei dem Weibe in dem Ovarium hauptsächlich die Grundursache des Geschlechtstriebes und in der Clitoris den Sitz des Wollustgefühles zu suchen, wobei zu bemerken wäre,' dass durch das Ovarium die Empfindlichkeit der Nervencentren, die zu den Nerven der Clitoris gehören, gesteigert wird, also eine Erhöhung des Wollustgefühles zustande kommt.

Nach Vorausschickung dieser Verhältnisse kann die Erklärung der Ergebnisse unserer Zusammenstellung nicht schwer fallen. Durch die Castration sind beim Weibe die Ovarien entfernt, aber die Clitoris mit ihrer Function ist geblieben. Es muss also nach der Castration hauptsächlich der.Geschlechtstrieb, die Neigung zum Coitus erlöschen, und das Wollustgefühl muss herabgesetzt werden. Unsere Angaben bestätigen dies. Wenn nun einige Frauen nach der Castration das volle Wollustgefühl behalten, so wird bei diesen eine individuell starke Reizbarkeit der Clitoris vorliegen, so dass durch diese allein das volle Wollustgefühl ausgelöst wird. Dass solche Frauen eine Neigung zum Beischlafe behalten, ist kein Wunder, da sie in demselben noch ihre volle geschlechtliche Befriedigung finden. So würde sich, wie ich glaube, das wechselvolle Verhalten des Geschlechtstriebes sowohl in der künstlichen als auch in der natïrlichen Klimax ganz gut erklären. Wir würden als Norm anzusehen haben, dass durch den Fortfall der Ovarien eine starke Abnahme des Triebes bis zum vollständigen Erlöschen

1) Die Wollustorgane des Menschen. Freiburg 1844. 
stattfindet, dass aber in einzelnen Fällen die Clitoris denselben unterhalten kann, wenn auch gewöhnlich in vermindertem Grade.

\section{H. Das geistige Verhalten der Frauen nach der Castration.}

Es ist seit Alters her bekannt, dass mit der Menopause der Charakter und das Temperament der Frauen sich zu ändern pflegt. Brière de Boismont ${ }^{1}$ ) sagt, dass sich zu dieser Zeit häufig ein Hang zur Melancholie, zur Schwermuth entwickele und theilt zwei Beobachtungen mit. Nach $\mathrm{Kisch}^{2}$ ) kann die Menopause grosse Einwirkungen auf das Seelenleben machen, und zwar seien diejenigen Frauen am meisten gefährdet, bei denen die Menopause ganz plötzlich einträte. Am häufigsten sah er das Bild tiefer Bedrückung des Gemüthes, das der Melancholie und Hypochondrie.

Börner ${ }^{3}$ ) fand, dass die geistigen Störungen zu den allerhäufigsten Begleiterscheinungen der Wechselzeit gehörten, die fast bei keiner Frau vermisst würden. Dabei wären die leichteren Formen aber so latent, dass den Frauen ihr verändertes Wesen oft nicht eher zum Bewusstsein käme, als bis sie von anderer Seite darauf hingelenkt würden. Die Aenderung in der Sinnesart gehöre zu den charakteristischen Erscheinungen, bilde häufig einen Vorläufer der Klimax und deute oft als das Erste mit Sicherheit auf sie hin. Meist treten melancholische Verstimmungen ein, viel seltener erhalten umgekehrt Frauen von mehr düsterem, ernstem Temperamente eine normale und zufriedene, selbst heitere Gemüthsstimmung. In sehr wenigen Fällen steigerte sich die Reizbarkeit zu Ungeduld, verdriesslichem Wesen, sogar Zornesausbrüchen.

Ueber das Verhalten des Temperamentes und der Gemüthsstimmung nach Castrationen liegen in der Literatur nur sehr spärliche Angaben vor. Hegar ${ }^{4}$ ) hat zuweilen eine ähnliche Veränderung des Temperamentes, wie zur Zeit der Menopause gesehen. Kleinwächter ${ }^{5}$ ) fand nach einer Castration die Stimmung entschieden froher und heiterer, und $\mathrm{Tissier}{ }^{6}$ ) sagt, dass

1) Die Menstruation. Uebersetzt von Krafft. Berlin 1842.

2) Das klimakterische Alter der Frau.

3) Die Wechseljahre der Frau.

4) Die Castration der Frauen.

5) Dieses Archiv, Bd. XVI.

6) De la castration de la femme. 
er bei castrirten Frauen niemals die tiefe Niedergeschlagenheit und Melancholie gefunden habe, die man oft bei castrirten Männern beobachte.

Ich habe in 33 Fällen genaue Angaben erhalten. Da die meisten Frauen aber ungebildet waren, konnte ich ihren Gemüthszustand nur mit grossen Schwierigkeiten erforschen und wurde oft nicht recht verstanden. Ich kann daher für das Ergebniss nicht ganz sicher einstehen. Auch kann bei meinen Zusammenstellungen ein zweiter Fehler mit untergelaufen sein. Viele der Frauen waren durch die Operation von schweren, jahrelangen Leiden befreit worden und ihr Befinden besserte sich nach der Operation bedeutend, so dass es leicht erklärlich ist, wenn sie zu einer heiteren und glücklicheren Gemüthsstimmung gelangten. Käme dieser Factor nicht mit in Betracht, so würden wir auf der Seite der Gemüthsverstimmung noch viel höhere Zahlen erhalten. (Siehe Tabelle VIII, S. 59.)

Die Tabelle ergiebt:

Keine Aenderung d. Gemüthsstimmung in 11 v. 33 Füllen $=33,3$ Proc. Aenderungen . . . . . . . . , 22,33 " $=66,7$ "

Die Aenderungen vertheilten sich nach folgenden Richtungen hin:

Melancholische, gedrückte Stimmung in 11 von 22 Fällen $=50$ Proc. Heitere, frohe Stimmung . . . . , $7,22, "=32$, Erregte, gereizte Stimmung . . . " 2 " 22 " $=9 "$ Wechselnde, bald gedrückte, bald heitere Stimmung . . . . " 2 " 22 " = 9 ,

In der Mehrzahl finden wir also eine gedrückte Gemüthsstimmung, einen schwermüthigen, melancholischen Zustand. Die Frauen haben keine Lust zu den sonst gewohnten Beschäftigungen, es fehlt ihnen der Muth und das Zutrauen zu sich selbst, in schlimmeren Fällen brüten sie dumpf vor sich hin und weinen oft ohne bestimmte Veranlassung. Dazu gesellt sich die Angst, doch an einer unheilbaren Krankheit zu leiden and schliesslich dem Tode verfallen zu sein. Die trübe Stimmung beherrscht ihre ganze Denkweise, jedes erhaschte Wort des behandelnden. Arztes deuten sie möglichst ungünstig für sich, wittern überall Gespenster und folgern aus jedem kleinen Eingriffe des Arztes, dass ihr Zustand wieder bedeutend schlechter sei. Bezeichnend ist dabei immer, dass diese Gemüthsstimmung keineswegs ihren Grund in 
Tabelle VIII. Wirkung der Castration auf den Gemüthszustand.

\begin{tabular}{|c|c|c|c|c|}
\hline \multirow[b]{2}{*}{ Nr. } & \multirow[b]{2}{*}{ Name } & \multirow[b]{2}{*}{ Alter } & \multicolumn{2}{|c|}{ Zustand des Gemüthes nach der Operation } \\
\hline & & & Kurze Zeit hinterher & $\begin{array}{l}\text { Längere Zeit } \\
\text { binterher }\end{array}$ \\
\hline 1 & Vo. & 30 & Keine Veränderung & \\
\hline 2 & Schl. & 39 & Heiterer als früher & \\
\hline 3 & $\mathrm{Wu}$. & 44 & Stiller, ernster als vor der Operation & \\
\hline 4 & Fu. & 43 & Keine Veränderung & \\
\hline 5 & $\mathrm{Ha}$ & 42 & $" \quad, \quad$ & \\
\hline 6 & Ho. & 38 & $"$ & \\
\hline $\begin{array}{l}7 \\
8\end{array}$ & La. & $\begin{array}{l}35 \\
44\end{array}$ & Scḧwermüthïger & \\
\hline $\begin{array}{l}8 \\
9\end{array}$ & $\begin{array}{l}\text { Nis. } \\
\text { Gr. }\end{array}$ & $\begin{array}{l}44 \\
48\end{array}$ & $\begin{array}{l}\text { Melancholie. Ausgesprochene Psy- } \\
\text { chose }\end{array}$ & netrerer, runget \\
\hline 10 & Bo. & 36 & Keine Veränderung & \\
\hline 11 & L. & 41 & Heiterer, froher & \\
\hline 12 & Mo. & 27 & Erregter, heftiger & \\
\hline 13 & Ga. & 25 & Keine Veränderung & \\
\hline 14 & Schr. I. & 44 & $" \quad \quad "$ & \\
\hline $\begin{array}{l}15 \\
16\end{array}$ & $\begin{array}{l}\text { Au. } \\
\text { Ma. }\end{array}$ & $\begin{array}{l}35 \\
42\end{array}$ & Hëiterer, energischer & \\
\hline 17 & Pet. I. & 35 & Erregter, ärgerlicher & $\begin{array}{l}\text { Ruhiger, } \\
\text { gleichmässiger }\end{array}$ \\
\hline 18 & Schm. & 42 & Heiterer & \\
\hline 19 & Ka. & 44 & Melancholie. Geringe Psychose & Besserung \\
\hline 20 & Gre. & 21 & $\begin{array}{l}\text { Stimmung wechselnd, oft heiter, oft } \\
\text { traurig }\end{array}$ & \\
\hline 21 & Schr. II. & 31 & $\begin{array}{l}\text { Stimmung wechselnd, oft heiter, oft } \\
\text { traurig }\end{array}$ & \\
\hline 22 & Fr. & 36 & Keine Veränderung & \\
\hline 23 & $\mathrm{Na}$ & 27 & Heiterer, ruhiger & \\
\hline 24 & Fra. & 32 & $\begin{array}{l}\text { Schwermüthiger. Periodische Psy- } \\
\text { chose }\end{array}$ & \\
\hline 25 & Bob. & 35 & Heiterer & \\
\hline 26 & Pe. & 45 & Keine Veränderung & \\
\hline 27 & Lü. & 35 & Gedrückter, muthloser & \\
\hline 28 & Sa. & 45 & Gedrickter, weinerlicher & \\
\hline 29 & Je. & 36 & Heiterer, froher & \\
\hline 30 & Ju. & 29 & Melancholischer, ärgerlicher & Ruhiger, zu- \\
\hline 31 & Lüb. & 37 & Schwermüthiger; ärgerlicher & friedener \\
\hline 32 & Re. & 41 & Etwas gedrückter & \\
\hline 33 & Go. & 37 & Etwas melancholischer u. gedrückter & \\
\hline
\end{tabular}

den vorliegenden Thatsachen findet, sondern mit denselben oft in directem Widerspruche steht. Trotzdem es den Kranken gut geht, trotzdem sie sich sichtlich erholen, verfallen sie in diese Schwermuth, für die sie selbst keinen Grund anzugeben wissen und die ihnen selbst bei ruhiger Ueberlegung ungerechtfertigt erscheint. Man findet die Schwermuth in allen Stadien, und verschieden ausgebildet, oft nur leise Anfänge, oft bis zur wirklichen Melancholie gesteigert. 
In drei Fällen entwickelten sich wirkliche Psychosen, welche eine der Kranken längere Zeit ans Irrenhaus fesselte, während die zwei anderen nach etwa einem Jahre völlig genasen.

In einem dieser Fälle hatte die tief schwermüthige Frau alle Energie und jeden Lebensmuth verloren und befand sich in fortwährender weinerlicher Stimmung. Nach $3 / 4$ Jahren trat allmälig Besserung und nach einem Jahre Heilung ein.

Im zweiten Falle bekam die hochgradig hysterische Frau zur Zeit der ausbleibenden Menses kurz dauernde, melancholische Anfälle mehr activer Form. Sie klagte dann laut über ihr unheilbares Leiden, malte sich die Zukunft in den schwärzesten Bildern aus, warf sich auf die Erde, rannte mit dem Kopf gegen die Wand und sprach von Selbstmordsabsichten, die auszuführen sie aber niemals Miene machte. Die Anfälle kamen nur in der Zeit von $4_{2}-1$ Jahr nach der Castration mehrmals vor und erschienen dann nicht wieder. Der Vater war im Irrenhause gestorben.

Der dritte Fall war der schwerste und ist als unheilbar aufzufassen. Bei einem von verschiedenen Seiten erblich sehr stark belasteten Fräulein entwickelte sich etwa sechs Wochen nach der Castration vollkommene Melancholie. Die Kranke hatte angeblich bei einem Spaziergange bemerkt, dass ihr im Leibe etwas zerrissen wäre, und glaubte seitdem schwer krank zu sein. Fis verschlimmerte sich ihr Zustand immer mehr, namentlich konnte sie nirgends mehr Ruhe finden. Da sie einen Selbstmordsversuch machte, musste sie in die Irrenanstalt überführt werden. Dort gestaltete sich nach längerem Aufenthalte ihr Zustand immer harmloser, so dass sie in die Heimath ungeheilt entlassen werden konnte, wo sie sich jetzt, nach drei Jahren, noch in demselben Zustande befindet. Nach Ansicht der Irrenärzte war hier die Castration nur als eine Gelegenheitsursache der Psychose anzusehen, die bei der stark erblich belasteten Kranken früher oder später doch wohl ausgebrochen wäre.

In der Literatur fand ich nur zwei ähnliche Fälle. Loss en und Fürstne ${ }^{1}$ ) berichten von einer Kranken, die am siebenten Tage nach der Hysterektomie eine acute Manie von sechs Wochen Dauer bekam und dann genas. Im zweiten Falle beobachtete $\mathrm{O}$ debrecht²)

1) Berliner klinische Wochenschrift 1880.

9) Beriner klinische Wochenschrift 1881, S. 220 . 
14 Tage nach einer schwierigen Castration ein zwei Tage lang dauerndes maniakalisches Irrsein, das auch vollkommen heilte.

In jüngster Zeit hat $\mathrm{Werth}^{\boldsymbol{x}}$ ) gezeigt, dass diese psychischen Störungen nach Operationen im Bereiche der Genitalien durchaus nicht so selten vorkommen, auch keineswegs auf die Castration beschränkt sind, sondern im selben Maasse nach Ovariotomien, Totalexstirpationen, überhaupt nach allen Laparatomien eintreten. Alle diese Psychosen sind gewöhnlich melancholischer Natur und heilen meist, wenn die Kranke nicht vorher einen Selbstmord begeht, was Werth in mehreren Fällen beobachtete. Ich möchte daher die drei von uns beobachteten Psychosen auch nicht der Castration allein zur Last legen, zumal da es sich zwei Mal um erblich belastete Individuen handelte, möchte aber doch den Satz aufrecht erhalten, dass sich nach der Castration leicht ein melancholischer Zustand entwickelt, der, falls erschwerende Umstände hinzutreten, in Psychose übergehen kann, und dass die Castration doch eine gewisse Praedisposition zu Psychosen schaffe. Es fanden ein ähnliches Verhalten bei der natürlichen Klimax Brière de Boismont2), Lou is Meyer ${ }^{3}$ ) und $\mathrm{Kisch} \mathrm{h}^{4}$ ).

In zwei Fällen trat nach der Operation eine gesteigerte Reizbarkeit auf, was auch Börner5) bei der natürlichen Klimax fand. Die Frauen waren ohne Veranlassung aufgeregt, konnten sich ohne Grund ärgern, wurden leicht heftig und zornig. Dieser $\mathrm{Zu}-$ stand dauerte gewöhnlich nur etwa ein Jahr, dann wurden die Frauen wieder ruhiger, gemässigter, milder und sanfter.

In zwei Fällen endlich gaben die Kranken an, dass ihre Stimmung äusserst wechselnd und launenhaft sei, ihre gemüthlichen Empfindungen schwankten immer zwischen den Extremen: himmelhoch jauchzend - zum Tode betrübt. Die Stimmungen wechselten oft rasch, 2-3 Mal am. Tage, oft hielt jede extreme Stimmung tage-, ja wochenlang an. Beide Frauen behaupteten bestimmt, vor der Operation nicht so gewesen zu sein und sahen ihren Gemüthszustand selbst als etwas Abnormes an. Welche Gemüthsstimmung auch anfangs nach der Castration herrschte, immer

1) Vortra.g auf dem Gynäkologen-Congresse in Halle 1888.

2) Die Menstruation.

3) Die Menstruation in Zusammenhang mit psychischen Störungen. Berlin 1872.

4) Das klimakterische Alter.

5) Die Wechseljabre der Frau. 
scheint sie später einer ruhigeren, gleichmässig heiteren, zufriedenen Stimmung zu weichen, die dann für das übrige Leben bleibt.

Die Ursache dieser Gemüthsveränderungen durch die Castration ist schwierig zu erklären. Dass wir nicht überall dieselben Sinnesveränderungen eintreten sehen, kann nicht auffallen, da die Charaktere der Frauen von Anfang an so verschiedene sind. Die melancholische Verstimmung im Klimakterium wurde früher immer durch den Gedanken, die Jugend und ihre Freuden nun aufgeben zu müssen und der weiblichen Reize verlustig zu werden, erklärt. Neben dieser Erklärung giebt $\mathrm{K}$ is $\operatorname{ch}^{\mathbf{1}}$ ) eine zweite an. Er meint, dass die durch die Klimax hervorgerufenen Congestivzustände im Cerebrum die Störungen des Seelenlebens veranlassen. Gegen diese Annahme spricht aber die herrschende Ansicht der Irrenärzte, dass die Melancholie oft auf einer Anämie des Gehirns beruhe. Börner ${ }^{2}$ ) wies das Haltlose der anderen Erklärung (Trauer über den Verlust der Weiblichkeit, Angst vor Krankheiten) nach, da die Bedrückung des Gemüthes häufig als erste Erscheinung die klimakterische Periode anzeige und die Frauen sich zu dieser Zeit oft noch gar nicht klar über ihren Zustand seien. Börner stellt dafür die Hypothese auf, dass zur klimakterischen Zeit eine grosse Allgemeinveränderung im Organismus vor sich gehe, als deren Theilerscheinung die Veränderung in der Gemüthsstimmung aufzufassen sei. Das ist freilich keine Erklärung, sondern nur eine Umschreibung der Thatsachen. Ich glaube, wir können hier nicht alle Thatsachen auf dieselbe Weise erklären. Für einen Theil passt entschieden die Erklärung der Trauer über den Verlust der weiblichen Eigenschaften. Denn wenn wir auch den Frauen nicht die volle Wahrheit sagten, so entnahmen sie doch aus unseren Fragen nach dem Fortfalle der Menstruation und der Wollustgefühle beim Beischlafe bald, wie es mit ihnen bestellt sei, und es bemächtigte sich ihrer dann doch eine gewisse Niedergeschlagenheit. Im Gegensatze zu Tissier ${ }^{3}$ ) muss ich sagen, dass die castrirten Frauen, wenn sie die volle Wahrheit erfuhren, stark bedrückt und niedergeschlagen wurden. Schüle ${ }^{4}$ ) fasst die Psychosen im allgemeinen als Trophoneurosen auf, die in einem

1) Das klimakterische Alter.

2) Die Wechseljahre der Frau.

3) De la castration de la femme.

4) Handbuch der speciellen Pathologie und Therapie von Ziemssen. Bd. XVI, S. 614. 
pathologischen Zustande des Sympathicus ihre anatomische Grundlage haben, und zwar beruhe die Melancholie auf einem Reiżzustande des Sympathicus, der zu einer Ernährungshemmung im Gehirne führe.

Schon bei den heissen Uebergiessungen haben wir den $\mathrm{Zu}$ sammenhang des Ovarium mit dem Sympathicus hervorgehoben und könnte vielleicht auf demselben Wege die Castration einen Einfluss auf die geistige Stimmung ausüben.

Die entgegengesetzte heitere Gemüthsstimmung erklärt sich leicht aus der Freude über das gute Operationsergebniss, wie ich bereits oben gesagt habe.

Somit entwickeln sich im geistigen Verhalten der Frauen dieselben Veränderungen nach der Castration, wie im natürlichen Klimakterium.

Als Gesammtwirkung der Castration sowohl auf körperlichem, als auch geistigem Gebiete ergiebt sich also:

Die Menstruation erlosch dauernd in 88 Proc. aller Fälle entweder sofort oder später, in 12 Proc. wurde sie erheblich seltener und spärlicher. Wir erklärten dies aus der in der Einleitung aufgestellten Menstruationstheorie, nach der der Anstoss zur Menstruation doch immer vom Ovarium gegeben wird und mit der Fortnahme desselben erlischt. Nur selten führte die Unterdrückung der Menstruation $\mathrm{zu}$ vicariirenden Blutungen, die aber immer so unbedeutend waren, dass ihnen keine Bedeutung beigelegt werden kann. Dagegen traten in ungefähr der Hälfte der Fälle zur Zeit der nicht wiederkehrenden Menstruation Molimina menstrualia auf. Diese erklärten wir so entstanden, dass nach der Fortnahme der Ovarien doch noch aus alter Gewohnheit eine Zeitlang periodisch alle vier Wochen ein Reiz von den bei der Menstruation thätigen Nervencentren nach dem Uterus hin stattfände und hier Hyperämie hervorriefe.

Im Uebrigen traten nach der Castration alle die Beschwerden auf, die wir sonst im Klimakterium zu sehen gewohnt sind: die heissen Uebergiessungen, die unbegründeten Schweisse, die Kopfschmerzen, der Schwindel, Fluor albus u. s. w. Ferner trat nach der Castration regelmässig eine Atrophie der zurückbleibenden Genitalien, Vagina und Uterus auf. War der Uterus vor der Castration durch Myome oder chronische Entzündung stark ver- 
grössert, so kehrte er bis auf die Norm, ja unter dieselbe zurück. Namentlich beobachteten wir ein rasches und starkes Schrumpfen der Myomata uteri nach der Castration, welche Erscheinungen auch wieder in der natürlichen Klimax vorkommen. Der allgemeine Ernährungszustand des Körpers wurde durch die Castration fast immer sichtlich gebessert und in 42 Proc. aller Fälle trat eine mehr oder weniger starke Körperfülle auf. Beachtenswerth war ferner die Wirkung der Castration anf die Libido sexualis, die in der Mehrzahl der Fälle bedeutend, bis zum völligen Verschwinden litt und nur in der Minderzahl erhalten blieb. Sehr auffallend waren die Veränderungen auf geistigem Gebiete, wo wir fast immer eine Bedrückung des Gemüthszustandes nachweisen konnten, die sich oft bis zur ausgesprochenen Melancholie steigerte und in drei Fällen in wirkliche Psychose überging. Die Castration entwickelt also ein künstiiches Klimakterium, welches in allen Punkten genau dem natürlichen gleicht, und die Fran tritt durch die Castration vor der Zeit in das klimakterische Alter.

\section{Körperliche und geistige Veränderungen im weiblichen Organismus bei künstlichem Verluste des Uterus.}

Die Totalexstirpationen des Uterus sind viel seltener als die der Ovarien, weil die meisten Fälle von Carcinoma uteri in nicht mehr operirbarem Zustande dem Gynäkologen zu Gesichte kommen und die meisten operirten. Frauen wegen der bald nach der Operation eintretenden Riückfälle für meine Untersuchungen nicht zu verwerthen sind. Es blieben mir so leider nur 14 Fälle von Totalexstirpation des Uterus bei Erhaltung der Ovarien übrig, von denen bei 12 die Totalexstirpation des Uterus wegen beginnenden Uteruscarcinoms, bei einer wegen hochgradiger Menorrhagien infolge von chronischer Metritis and Endometritis gemacht wurde. Im letzten Falle wurde der Uterus bei der Herausschälung submucöser Myome, die zu einer theilweisen Inversion des Uterus geführt hatten, breit perforirt und die Exstirpation so zur Stillung der profusen Blutung nothwendig. Von den zwölf Frauen, welche wegen Carcinom operirt wurden, haben bisher sechs einen Rückfall bekommen, alle aber erst in $3 / 4-1 \frac{1}{2}$ Jahren nach der Operation. Die anderen sechs sind vollkommen frei von Rückfällen geblieben, darunter zwei bereits drei Jahre und zwei über zwei Jahre nach der Operation. 
In allen diesen Fällen hatten wir es also mit gesunden Frauen zu thun und ich konnte die nach der Operation auftretenden Erscheinungen mit Fug und Recht auf den Verlust des Uterus schieben. Um aber die Folgen dieses Verlustes richtig beurtheilen zu können, ist es nothwendig, die angewandte Operationsmethode etwas näher zu beschreiben. Nach Umschneidung der Portio vaginalis, möglichst weit vom Carcinomherde entfernt, wurde die Blase stumpf vom Uterus abgelöst, dann das hintere Scheidengewölbe vollkommen durchtrennt und das Peritoneum an dieser Stelle eröffnet. Hierauf wurde auch die vordere Pexitonealfalte zwischen Uterus und Blase breit eröffnet, der Fundus uteri durch schrittweise höher eingesetzte Zangen nach vorn aus der Peritonealwunde herausgeholt und zur Unterbindung der Ligamenta lata geschritten. Es wurde zunächst ein Ligamentum latum in zwei oder mehreren Partien, von oben beginnend, mit ein und derselben elastischen Ligatur (dünnen Drainageschläuchen) umstochen und fest zusammengeschnürt; dann ziemlich breit vor der Ligatur der Uterus abgesetzt und das andere Ligament ebenso behandelt. Immer herrschte dabei das Bestreben vor, die Ligaturen so weit wie möglich nach aussen zu bringen, so dass sie gewöhnlich nahe dem Ovarium, in manchen Fällen hart am medialen Rande desselben und in einem Falle in der Substanz des Ovarium zu liegen kamen. Die Scheidenbauchfellwunde blieb offen, wurde aber gewöhnlich nahezu vollständig durch die Schnürstümpfe und die naheliegenden Ovarien verlegt und der frei bleibende Raum mit Jodoformgaze lose tamponirt. Nach Eintritt vollkommener Nekrose der Schnürstümpfe wurden die Fäden gewöhnlich am 18. bis 24. Tage durch Zug entfernt. Dabei zeigte sich, dass die Nekrose nicht hart am äusseren Rande der Ligatur begrenzt war, sondern noch etwa $1 \mathrm{~cm}$ breit nach aussen vor der Ligatur fortgeschritten war. Wenn also bei der Operation auch die Ligaturen nur hart am medialen Rande der Ovarien gelegen hatten und letztere selbst ganz unberührt geblieben waren, so konnten sie doch noch später durch die fortschreitende Nekrose vor den Ligaturen theilweise zerstört oder in Narbengewebe umgewandelt werden. Nur in einem Falle wurden die Ligamenta lata in der Weise unterbunden, dass von der Basis an schrittweise, nach oben hin fortschreitend, die Ligamente in kleinen Partien mit Seidenfäden umstochen und dann schrittweise der Uterus abgetragen wurde. Auf diese Weise entstanden kleinere Stümpfe und eine nur geringe Nekrose der Gewebe. In den erstArchiv f. Gynäkologie. Bd. XXXV. Hft. 1. 
genannten Fällen, die eigentlich allein in Frage kommen, haben die Ovarien durch das Operationstrauma mebr oder weniger gelitten, in zweien sind sie wohl grösstentheils zu Grunde gegangen.

Wenn wir auch im vorigen Abschnitte gesehen haben, dass die Menstruationsfunction der Ovarien durch das kleinste Stückchen Ovarialgewebe erhalten bleibt, so ist es doch nicht gleichgültig, ob die Ovarien in der oben bezeichneten Weise in Mitleidenschaft gezogen sind oder nicht. Die hier aufgeführten Totalexstirpationen sind also zum Theile keine reinen uncomplicirten Operationen, sondern das Operationstrauma hat neben dem Verluste des Uterus $\mathrm{zu}$ einer theilweisen Zerstörung oder jedenfalls Ernährungsbeeinträchtigung der Ovarien geführt. Bei der Besprechung der einzelnen Folgezustände der Operation werde ich auf diese Punkte zurückkommen.

Tabelle IX. Angewandte Operationsmethoden bei Unterbindung der Ligamenta lata.

\begin{tabular}{|c|c|c|}
\hline Nr. & Name & Angewandtes Verfahren und Material \\
\hline 1 & 01. & $\begin{array}{l}\text { Ligamente schrittweise mit Seidenfäden umstochen. Stümpfe } \\
\text { mit den Ovarien liegen nach der Operation in der } W \text { unde vor. }\end{array}$ \\
\hline 2 & Lu. & Beide Ligamente mit Gummiligatur in einer Partie unterbunden. \\
\hline 3 & Re. & $\begin{array}{l}\text { Gummiligaturen in } 2 \text { Partien. Ovarien liegen in der Peritoneal- } \\
\text { wunde. }\end{array}$ \\
\hline 4 & Ra. & Gummiligaturen in 2 Partien. Beide Ovarien intact sichtbar. \\
\hline 5 & Wa. & $\begin{array}{l}\text { Gummiligaturen in mehreren Partien unmittelbar vor den } \\
\text { Ovarien. }\end{array}$ \\
\hline 6 & Bl & Gummiligaturen. \\
\hline 7 & Schm. & $\begin{array}{l}\text { Grmmiligaturen am lateralen Rande der Ovarien. Abtrennungs- } \\
\text { schnitt geht durch die Mitte der Ovarien. }\end{array}$ \\
\hline 8 & Br. & Gummiligaturen. Ovarien nicht gesehen. \\
\hline 9 & Hа. & Gummiligaturen in 2 Partien. Ovarien nicht gesehen \\
\hline 10 & Hn. & $\begin{array}{l}\text { Gummiligaturen in mehreren Partien. Später linke Tube in die } \\
\text { Wunde vorgefallen. }\end{array}$ \\
\hline 11 & An. & $\begin{array}{l}\text { Gummiligaturen in mehreren Abtheilungen weit nach aussen } \\
\text { umgelegt. Beim Entfernen der Ligaturen haften sie recht } \\
\text { fest und zeigen jenseits der Ligatur grosse nekrotische Gr- } \\
\text { websbundel. }\end{array}$ \\
\hline 12 & Schi. & $\begin{array}{l}\text { Das 1. Lig. latum an der Basis mit Kocher'schen Klemmzangen } \\
\text { gefasst, oben mit Gummiligatur umstochen. Das r. Lig. latum } \\
\text { ganz mit Gummiligatur umstochen. Später eine Tube vor- } \\
\text { gefallen. }\end{array}$ \\
\hline 13 & Pe. & $\begin{array}{l}\text { Gummiligaturen in mehreren Theilen möglichst weit nach aussen } \\
\text { umgelegt. Beide Tuben fallen vor und werden nachträglicn } \\
\text { durch den Thermokauter entfernt. }\end{array}$ \\
\hline 14 & To. & $\begin{array}{l}\text { Gummiligaturen. Linke Ligatur nahe dem Uterus. Beide } \\
\text { Ovarien sind unverletzt. }\end{array}$ \\
\hline
\end{tabular}


Wie wir im vorigen Abschnitte die Verhältnisse im Klimakterium zum Vergleich herangezogen haben, können wir in diesem Abschnitte die Fälle von angeborenem Defecte des Uterus bei erhaltenen und functionirenden Ovarien als Analoga betrachten.

Zahlreiche solche Fälle sind von Thudichum (Uebersicht über 21 Fälle von Mangel und rudimentärer Bildung des Uterus. 1855), Kussmaul (Von dem Mangel, der Verkümmerung und der Verdoppelung der Gebärmutter. Würzburg 1859), Battey (Normal ovariotomy. Atlanta, Georgia. 1873) und Hegar (Die Castration der Frauen. Leipzig 1878) zusammengestellt worden.

In den meisten Fällen fand sich der übrige Körper normal gestaltet und von echt weiblichem Typus, manchmal aber die Entwickelung des ganzen Individuum etwas gehemmt und zurückgeblieben. So werden die Brüste in einigen Fällen als klein und schlaft bezeichnet, und nicht ganz selten hat das Becken die gleichmässig allgemein verengte Form. Fast immer ist die Vagina rudimentär, gewöhnlich kurz und eng oder sie fehlt in einzelnen Fällen ganz. Nur selten findet sich eine mangelhafte Ausbildung der äusseren Genitalien, die sich in einem mangelhaften oder verkümmerten Zustande der grossen und kleinen Schamlippen, oder der Clitoris, oder in einer Fettarmuth des Mons Veneris und spärlicher Behaarung kundgiebt. Am interessantesten ist das Verhalten der Ovarien bei Defect und rudimentärer Bildung des Uterus, denn wir finden hier alle nur denkbaren Verschiedenheiten vertreten, die zugleich eine Stufenleiter vom Unvollkommenen zum Vollkommenen darstellen. In verhältnissmässig nur seltenen Fällen sind die Ovarien vorhanden, ohne dass aber irgendwelche, auf die Ovulation hindeutende Symptome bei der Lebenden beobachtet worden wären. In der Leiche fanden sich in solchen Fällen entweder verkümmerte oder wohl ausgebildete Ovarien mit mehr oder weniger normalen Graaf'schen Follikeln, aber keine Zeichen von Follikelberstung, keine Corpora lutea. In ungefähr der Hälfte aller Fälle konnten aber trotz Mangel des Uterus normal gestaltete Ovarien, die während des Lebens auch normal zu functioniren schienen, nachgewiesen werden. Einzelne dieser Fälle sind durch die Section oder durch Beobachtung an der Lebenden bei Gelegenheit einer Operation erhärtet worden. Man fand durchaus normal functionirende Ovarien, bei denen die stattgehabte Ovulation durch ein oder mehrere Corpora lutea nachzuweisen war. Bei einer kleinen Minderzahl machte die bestehende Ovulation ohne Menstruation keinerlei Beschwerden. 
In weitaus den meisten Fällen traten aber zur Zeit der stattfindenden Ovulation regelmässig Molimina menstrualia auf. Dieselben bestanden gewöhnlich in ziehenden Kreuz- und Leibschmerzen, oft bis in die Beine hinein, in einem Druckgefühle in der Beckengegend, Drängen in der Schoossgegend, Kopfschmerzen und Magenschmerzen. Ferner wurden Congestivzustände, die zu Schwinkel, Herzklopfen, Kopfschmerzen, Oedemen und serösen Ergüssen in die Körperhöhlen führten, beschrieben und endlich allerlei nervöse Erscheinungen: Neuralgien in allen Körpergegenden, Halblähmungen, Chorea, hystero-epileptische Zustände u. s. w. Gewöhnlich waren diese Beschwerden nur geringfügig, oft aber auch so heftig, dass ihretwegen zur Operation geschritten wurde und die normal functionirenden Ovarien entfernt wurden. Mehrmals sollen vicariirende Blutungen aus Nase, Mund und Mastdarm eingetreten sein, die sich zuweilen regelmäsig in vierwöchentlichen Pausen wiederholten. Vom Gesehlechtstriebe wird erwähnt, dass er in einzelnen Fällen rollkommen gefehlt, sogar eine Abneigung gegen Männer bestanden habe, in anderen sei der Geschlechtstrieb normal, ja in mehreren unnatürlich gesteigert gewesen, so dass solche Frauen ein sehr liederliches Leben führten. Ueber den Gemüthszustand dieser Frauen finde ich leider keine Angaben, nur ein Mal ist bemerkt, dass die geistigen Eigenschaften immer mehr bis zum Schwachsinne abnahmen.

Nach Besprechung dieser ähnlichen Verhältnisse will ich die Folgezustände der Totalexstirpation in einzelnen Abschnitten erörtern.

\section{A. Wirkung der Totalexstirpation des Uterus auf die Menstruation.}

Wir können uus hier sehr kurz fassen. Der Uterus ist das menstruirende Organ, es muss also nach Entfernung desselben die Menstruation erlöschen. Ich habe demgemäss auch nie eine Spur von Menstruation nach der Operation erlebt. Wo Andere noch Blutungen nach der Totalexstirpation beobachtet haben sollten, müssen sie aus irgend einer anderen Quelle geflossen sein, z. B. aus einem recidivirten Carcinom.

\section{B. Auftreten von vicariirenden Blutungen nach der Totalexstirpation des Uterus.}

Auch hier ist nur Weniges zu sagen.

Wir haben gesehen, dass nach der Castration es nur in vereinzelten Fällen zu geringen Blutverlusten aus Mund, Nase oder 
After kam, denen keine Bedeutung beigelegt werden konnte. Ebenso ist es nach der Totalexstirpation des Uterus der Fall. In 4 von 11 Fällen, also in 36 Proc., trat zur Zeit der Menstruation unbedeutendes Nasenbluten ein, bei einer Frau nur ein Mal, bei zweien zwei Mal und bei der letzten mehrere Male. Das Auftreten von vicariirenden Blutungen auch nach Totalexstirpation erklärt sich wieder daraus, dass die Menstruation kein auf den Uterus beschränkter Vorgang ist. Die wichtigsten Lebensvorgänge des Weibes verlaufen in Wellenbewegungen, die mit dem Rhythmus der Periode gleichzeitig sina. Jacoby ${ }^{3}$ ) und von $\mathrm{Ott}^{2}$ ) haben gefunden, dass der arterielle Blutdruck in der Zwischenzeit zwischen zwei Menstruationen allmälig ansteigt, in der prämenstrualen Zeit sein Maximum erreicht und während der menstruellen Blutung bedeutend sinkt. Es wäre anzunehmen, dass, wenn die menstruelle Blutung nicht eintritt, der erhöhte Blutdruck sich längere Zeit hält und die kleinen Blutungen aus der Nase zu Stande bringt oder wenigstens begünstigt. Wahrscheinlich wird er nur die Nasenschleimhaut $\mathrm{zu}$ Blutungen prädisponiren, und irgend eine zufällige Ursache ruft dann die Blutung hervor. So würde sich auch die Seltenheit dieser Blutungen erklären.

\section{Das Auftreten von Ausfallserscheinungen nach der Totalexstirpation.}

Dieselben Ausfallserscheinungen wie nach der Castration werden wir in veränderter Menge und Beschaffenheit nach der Totalexstirpation wieder finden und sehen, dass sie hier wie dort sowohl in der Zeit der nicht eintretenden Periode als auch in der menstruationsfreien Zwischenzeit auftreten.

I. Körperliche Beschwerden, die zux Zeit der nicht wiederkehrenden Menstruation nach der Totalexstirpation auftreten.

Molimina menstrualia.

Die nach der Castration auftretenden Molimina menstrualia erklärten wir aus dem Nervenreize, welcher von den bei der Menstruation thätigen Centren nach dem Uterus hin noch eine Zeitlang ausgeübt wird. Wir werden erwarten müssen, dass nach der Totalexstirpation des Uterus diese Molimina in demselben oder

1) On the menstrual wawe. Berichtet in: The american Journal of obstetrics. Bd. XV, 1882.

2) Angeführt in: Rein 1, Die Lebensprocesse des Weibes. 
noch höherem Maasse vorhanden sind, da die Ovarien anversehrt bleiben, also immer wieder ein Nervenreiz von den wachsenden Graaf'schen Follikeln aus auf die bei der Menstruation thätigen Centren hin stattfindet. Mit dieser Annahme stimmen auch die Thatsachen der klinischen Beobachtung überein.

In der Literatur finde ich nur von Brennecke ${ }^{1}$ ) eine kurze Angabe über die Folgezustände der Totalexstirpation, alle anderen Autoren schweigen über diesen Punkt, wahrscheinlich weil die Erscheinungen nicht sehr in die Augen springen. Brennecke sah nach seinen Totalexstirpationen in den ersten Monaten regelmässig, in vierwöchentlichen $Z$ wischenzeiten wiederkehrend, sehr verschieden starke Beschwerden, welche als menstruale aufgefasst werden mussten. Sie bestanden in Kreuzschmerzen, Druck und Gefühl von Brennen im Becken, Herzklopfen, fliegender Hitze und Kopfschmerzen. Sie nahmen sämmtlich mit jeder Menstruationsepoche ab, bestanden immer nur kurze Zeit und waren nach einem halben Jahre regelmässig verschwunden. Brennecke folgert daraus, dass nach der Totalexstirpation eine rasche Atrophie der Ovarien eintritt.

Meine Beobachtungen über diesen Punkt leiden unter einer Kleinheit des Materials und machen durchaus keinen Anspruch auf Vollkommenheit. Immerhin werden sie ein Beitrag zur Lösung dieser Fragen sein und vielleicht das Interesse der mit grösserem Material ausgestatteten Forscher auf diesen Punkt leiten. Tabelle X (S. 71) stellt 13 Fälle von Totalexstirpation des Uterus zusammen, bei denen Molimina menstrualia vor und nach der Operation auftraten.

Zunächst geht aus dieser Tabelle hervor, dass von 13 Frauen wur 4, also 30,8 Proc., ganz frei von Beschwerden sind, in den übrigen 69,2 Proc. finden wir sie. Wir begegnen hier einem Unterschiede mit den Ergebnissen, die nach der Castration zu verzeichnen waren. Dort war die Hälfte aller Operirten frei von Beschwerden, hier kaum ein Drittel.

Wir finden die Molimina menstrualia bei Frauen, die auch vorher bei den Menses Beschwerden hatten, aber auch, und das ist wohl zu beachten, bei solchen, die vor der Operation schmerzfrei menstruirt hatten. Die Beschwerden waren nach der Totalexstirpation gewöhnlich anderer Art und intensiver als vorher,

1) Zeitschrift für Geburtshülfe und Gynäkologie. Bd. XII. 
nach künstl. Verluste d. Ovarien einerseits u. d. Uterus andererseits.

Tabelle X. Molimina menstrualia nach der Totalexstirpation.

\begin{tabular}{|c|c|c|c|c|c|}
\hline \multirow[b]{2}{*}{ Nr. } & \multirow[b]{2}{*}{ Name } & \multicolumn{2}{|c|}{ Beschreibung der Molimina menstrualia } & \multirow{2}{*}{ 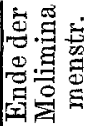 } & \multirow{2}{*}{ 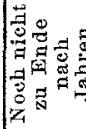 } \\
\hline & & $\begin{array}{l}\text { Vor der } \\
\text { Operation }\end{array}$ & Nach der Operation & & \\
\hline 1 & Ol. & Angabe fehlt & $\begin{array}{l}\text { Etwas Druck und Völle im Ab- } \\
\text { domen. Allmälige Abnahme }\end{array}$ & $11 / 2 \mathrm{~J}$ & - \\
\hline 2 & Bl. & Keine & Keine & & - \\
\hline 3 & Lu. & Keine & $\begin{array}{l}\text { Schwellung der Brüste, nur wäh- } \\
\text { rend der ersten Menstruations- } \\
\text { epochen beobachtet }\end{array}$ & $1 / 2 \mathrm{~J}$ & - \\
\hline 4 & Re. & Keine & $\begin{array}{l}\text { Ziehen im Kreuze und Unterleibe. } \\
\text { Auftreibung und Spannung im } \\
\text { Abdomen. Kopfschmerz }\end{array}$ & $1 \mathrm{~J}$. & - \\
\hline 5 & Ra. & $\begin{array}{l}\text { Schmerzen im } \\
\text { Kreuze und } \\
\text { Unterleibe }\end{array}$ & $\begin{array}{l}\text { Abwärtsdrängen im Abdomen. } \\
\text { Congestionen nach dem Kopfe. } \\
\text { Uebelkeit und Erbrechen }\end{array}$ & $1 \mathrm{~J}$ & - \\
\hline 6 & Wa. & Keine & $\begin{array}{l}\text { Aufsteigende Hitze, } 7-8 \text { Mal } \\
\text { am Tage }\end{array}$ & -- & $\mathbf{1}^{3 / 4} \mathrm{~J}$ \\
\hline 7 & Schm. & Keine & Keine & - & - \\
\hline 8 & Ha. & Keine & $\begin{array}{l}\text { Wühlen und Völle im Leibe. } \\
\text { Auftreiben des Abdomen. Fla- } \\
\text { tulenz }\end{array}$ & $2 \mathrm{~J}$. & - \\
\hline 9 & Hn. & Kreuzschmerzen & $\begin{array}{l}\text { Kopfschmerzen und aufsteigende } \\
\text { Hitze mit Beklemmungen, } 5-6 \\
\text { Mal am Tage }\end{array}$ & - & $3 / 4 \mathrm{~J}$ \\
\hline 10 & An. & Keine & Keine & - & - \\
\hline 11 & Schi. & Angabe fehlt & $\begin{array}{l}\text { Kopfschmerzen. Mattigkeit. } \\
\text { Schlaflosigkeit. Böse Träume }\end{array}$ & $1 / 4 \mathrm{~J}$ & - \\
\hline 12 & Pe. & Keine & Keine & - & - \\
\hline 13 & To. & Keine & $\begin{array}{l}\text { Schmerzen im Kreuze. Starke } \\
\text { Kopfschmerzen. Allgemeines } \\
\text { Unwohlsein }\end{array}$ & $2 J$ & - \\
\hline
\end{tabular}

niemals aber waren Beschwerden, die vorher bestanden, durch die Operation beseitigt, wie wir solches bei der Castration doch in einigen Fällen sahen.

Durchgehends waren es dieselben Beschwerden, wie nach der Castration. Wenn einige derselben, z. B. die Exantheme, fehlten, so lag dies wohl an der geringen Anzahl der hier beobachteten Fälle. Die Klagen der Frauen waren Schmerzen im Kreuze und in der Gegend der Symphyse, ein Gefühl von Völle und Druck in den unteren Theilen des Bauches, Wühlen im Leibe und Meteorismus, ferner Kopfschmerzen, oft hohen Grades. Dieselben sind nicht halbseitig, auch weniger an den Verlauf der Nerven gebunden, sondern äussern sich als ein Gefühl von Schwere und Druck im ganzen Kopfe. In zwei Fällen wird über Uebolkeit, in einem über Erbrechen geklagt. Nerröse Beschwerden, wie allgemeine Abgeschlagenheit, Mattigkeit, böse Träume, Schlaflosigkcit u. s. w. 
kommen wenn auch selten vor. Nur eine einzige Frau machte die bestimmte Angabe, dass sie jedesmal zur Zeit der Periode noch längere Zeit hindurch 2-3 Tage einen milchigen Ausfluss aus der Scheide gehabt habe. Sie hatte in ihrer Jugend wahrscheinlich eine Gonorrhoea durchgemacht. Uebrigens ist der Ausfluss nicht von mir beobachtet. Da der Uterus mit der Cervix entfernt war und die Vagina eigentlich kein Secret liefern kann, so wird die Frau wohl eine geringe Secretion aus den Drüsen der Vulva um diese Zeit gehabt haben. In zwei Fällen waren Anfälle von aufsteigender Hitze vorhanden, in einem kam es in den ersten Menstruationsepochen zu einer Schwellung der Mammae, verbunden mit einem prickelnden Gefühle. Die Beschwerden waren immer in der ersten Zeit am stärksten, die Dauer wechselte, von $1 / 4$ bis zu 2 Jahren, betrug durchschnittlich $=1,17 \mathrm{Jahr}$.

Die Erklärung kann nicht allzu schwer fallen. Es ist nur der Uterus entfernt, die Ovarien and die Nervencentren sind zurückgeblieben, nach wie vor findet Ovulation statt und die reifenden Follikel üben einen nervösen Reiz auf das Centrum aus. Infolge dessen wird alle vier Wochen von den Centren aus eine Hyperämie der Beckenorgane ausgelöst, die sich allerdings nur auf die Uterusanhänge und das Beckenbindegewebe erstrecken kann. Die Hyperämie erfährt keine Entlastung durch die Menstruationsblutung und es entstehen die geschilderten Beschwerden in der Bauchgegend. Ebenso lassen sich die Kopfschmerzen, die MagenDarmerscheinungen und die nervösen Beschwerden so erklären, dass im Organismus noch der nervöse Anstoss zu einer Menstruationsblutung gegeben wird. Es werden also auch die sonst mit der Menstruation verbundenen Beschwerden durch die Nerventhätigkeit noch leicht ausgelöst werden können.

II. Sonstige, nach der Totalexstirpation anftretende Beschwerden, die in die menstruationsfreie Zeit hineinfallen.

Nach der Totalexstirpation finden wir die menstruationsfreie Zeit in den meisten Fällen frei von Beschwerden, in den seltenen, wo sie auftreten, bleiben sie sehr gering, wie Tabelle XI (S. 73) zeigt.

Von 12 Fällen blieben 8, also 66 Proc., ganz frei von Beschwerden. Das ist ein gewaltiger Unterschied gegenüber der Castration, wo nur 10 Proc. frei blieben. Es sind hier dieselben Beschwerden, wie nach der Castration. Obenan stehen wieder die heiss en Uebergiessungen und die Schweisse, daneben kommen nur 
nach künstl. Verluste d. Ovarien einerseits u. d. Uterus andererseits.

Tabelle XI. Beschwerden, die in die menstruationsfreie Zeit hineinfallen, nach der Totalexstirpation.

\begin{tabular}{|c|c|c|c|c|}
\hline $\mathrm{Nr}$. & Name & Nähere Beschreibung der Beschwerden & $\mid \begin{array}{c}\text { Einde der } \\
\text { Be- } \\
\text { scliwerden }\end{array}$ & $\begin{array}{c}\text { Noch vor } \\
\text { handen } \\
\text { nach }\end{array}$ \\
\hline 1 & 01. & Keine & - & $\ldots$ \\
\hline 2 & Lu. & Keine & 一 & - \\
\hline 3 & Re. & Keine & - & - \\
\hline 4 & Ra. & Keine & $\ldots$ & - \\
\hline 5 & Wa. & $\begin{array}{l}\text { Jeden } 2-3 \text {. Tag aufsteigende Hitze ohne } \\
\text { Angst. Selten Schweisse }\end{array}$ & $3 / \mathrm{J}$ & - \\
\hline 6 & Schm. & $\begin{array}{l}\text { Aufsteigende Hitze. Hitze im Körper. Be- } \\
\text { klemmungen, Herzklopfen, Schweisse }\end{array}$ & - & $1 / 2 \mathrm{~J}$. \\
\hline 7 & Ha. & Keine & - & - \\
\hline 8 & Hn. & Keine & - & - \\
\hline 9 & An. & $\begin{array}{l}\text { Heisse Uebergiessungen, anfangs } 6-7 \text { Mal, } \\
\text { später } 2-3 \text { Mal, anfangs auch Nachts. } \\
\text { Hinterher Beklemmungen und Angst. } \\
\text { Manchmal Herzklopfen }\end{array}$ & $8 / 4 \mathrm{~J}$ & - \\
\hline $\begin{array}{l}10 \\
11\end{array}$ & $\begin{array}{c}\text { Schi. } \\
\text { Pe. }\end{array}$ & $\begin{array}{l}\text { Keine } \\
\text { Häufiger aufsteigende Hitze, besonders }\end{array}$ & & \\
\hline 12 & Te. & $\begin{array}{l}\text { Häufiger aufsteigende Hitze, besonders } \\
\text { Nachts. Manchmal auch Herzklopfen } \\
\text { Keine }\end{array}$ & $3 / 4 \mathrm{~J}$ & - \\
\hline
\end{tabular}

noch Kopfschmerzen und Herzklopfen vor. Die Anfälle waren genau ebenso, wie bei der Castration, nur weniger stark und von kürzerer Dauer. In zwei Fällen waren sie mit Beklemmungen und Angstgefühlen verbunden. Die Anfälle traten nur selten auf, im schlimmsten Falle anfangs 6-7 Mal täglich, später 2-3 Mal täglich; im geringsten Falle von Anfang an nur jeden zweiten bis dritten Tag. In zwei Fällen sahen wir dieselben auch Nachts kommen, in einem Falle sogar zu dieser Zeit besonders häufig: Das Herzklopfen trat gewöhnlich im Anschlusse an die heissen Uebergiessungen auf, manchmal ohne dieselben. Die Frauen wurden nicht sehr davon belästigt. Eine noch geringere Rolle kommt den nur selten auftretenden unmotivirten Schweissen zu, die wir nur in zwei Fällen angeführt finden. Allen diesen Beschwerden wurde von den Frauen keine grosse Bedeutung beigelegt.

Es ist auffällig, dass wir diese Ausfallserscheinungen in der menstruationsfreien Zeit, die sonst nur nach Castration oder im Klimakterium vorzukommen pflegen, auch nach der Totalexstirpation auftreten sehen, zumal da sie in den Fällen von angeborenem Mangel des Uterus mit unversehrten Ovarien niemals angegeben werden. Wahrscheinlich haben wir es hier mit zufälligen Complicationen zu thun, die in dem Defecte des Uterus allein ihre Erklärung nicht finden. Dafür scheint zu sprechen, dass diese Be- 
schwerden nur in einem Drittel der Fälle vorkommen und von untergeordneter Bedeutung sind. In unseren vier Fällen, welche die sogenannten klimakterischen Beschwerden zeigen, wurden jedesmal die Ovarien bei der Operation verletzt oder berührt, infolge dessen später theilweise pathologisch verändert.

Bei Frau Schm. (Fall 6 der Tabelle XI, Fall 7 der Tabelle IX), welche die meisten Beschwerden nach der Operation zeigt, sind die elastischen Ligaturen am lateralen Ende der Ovarien geknüpft. Die eine Hälfte der Orarien ist also gleich bei der Operation abgeschnitten, die andere wohl später nekrotisch zu Grunde gegangen und mit den Ligaturen entfernt, so dass wir hier wohl einen nahezu vollkommenen Defect der Ovarien vor uns haben. Bei Frau Wa. (Fall 5 der Tabellen IX und XI) liegen beide Gummiligaturen hart am medialen Rande der Ovarien, so dass später jedenfalls ein Theil der Ovarien nekrotisch zu Grunde gegangen ist und mit den Ligaturen entfernt wurde. Für diese Annahme spricht auch der Umstand, dass bei dieser Kranken bei wiederholten späteren Untersuchungen keine Ovarien zu fuihlen waren. Bei Frau Pe. (Fall 11 der Tabello XI und Fall 13 der Tabelle IX) und bei Frau An. (Fall 9 der Tabelle XI und Fall 11 der Tabelle IX) ist in der Operationsgeschichte ausdrücklich gesagt worden, dass die Ligaturen möglichst weit nach aussen gelegt sind, da in beiden Fällen das Carcinom schon ziemlich weit vorgeschritten war und die Parametrien sich verdächtig verhärtet anfühlten. Bei Frau A n. ist in der Krankengeschichte vermerkt, dass an beiden Ligaturen jenseits derselben sehr viel nekrotisches Gewebe haftete. Später ist dann noch eine Tube in die Scheidenwunde vorgefallen und nachträglich entfernt worden. Dem entsprechend wurde auch später das eine Ovarium fest mit der Scheidennarbe verwachsen gefunden. Bei Frau Pe. sind hinterher beide vorgefallenen Tuben entfernt worden, und eine spätere Untersuchung ergab beide Ovarien mit der Scheidennarbe verwachsen.

Ferner finden wir in der Tabelle über die Operationsmethoden, dass nur die Fälle, welche eine Beeinträchtigung der Ovarien durch das Operationstrauma nahe legen, diese Beschwerden zeigen. Ich bin also wohl zu dem Schlusse berechtigt, dass diese klimakterischen Beschwerden nicht durch den Defect des Uterus hervorgerufen sind, sondern lediglich durch die gleichzeitige pathologische Veränderung der Ovarien. Diese Beschwerden sind also durchaus uicht als Folgezustände der Totalexstirpation zu betrachten, son- 
dern sind nur Complicationen, die durch die gleichzeitige, durch das Operationstrauma bedingte Beeinträchtigung der Ovarien hervorgerufen sind.

\section{Wirkung der Totalexstirpation auf die zurückbleibenden Genitalien.}

Bei diesem Kapitel hat sich mir der Mangel an Material recht fühlbar gemacht, so dass meine sieben Beobachtungen kaum ein sicheres Resultat liefern.

Tabelle XII. Wirkung der Totalexstirpation auf die zurückgebliebenen Genitalien.

\begin{tabular}{|c|c|c|c|c|}
\hline Nr. & Name & Vagina & Ovarien & $\begin{array}{c}\text { Beobachtungs } \\
\text { dauer }\end{array}$ \\
\hline 1 & $\mathrm{Lu}$. & $\begin{array}{l}\text { Vagina weit, schlaff. } \\
\text { Neigung zu Descensus. } \\
\text { Keine Veränderung d. } \\
\text { Schleimhaut }\end{array}$ & $\begin{array}{l}\text { R. } 0 \text {. etwas verkleinert } \\
\text { L. } 0 \text {. bohnengross }\end{array}$ & $41 / 2$ Jahre \\
\hline 2 & Wa. & $\begin{array}{l}\text { Weit. Schleimhaut } \\
\text { weich, schlaff } u \text {. blass }\end{array}$ & Ovarien nicht zu fühlen & $1 \frac{1}{2}$ Jahre \\
\hline 3 & Hn. & $\begin{array}{l}\text { Weit, schlaff. Finger- } \\
\text { lang. Schleimhaut } \\
\text { blass. Etwas krüm- } \\
\text { liches Secret }\end{array}$ & $\begin{array}{l}\text { R. O. vielleicht etwas } \\
\text { kleiner } \\
\text { L. O. normal }\end{array}$ & $1 / 2 \mathrm{Jahr}$ \\
\hline 4 & An. & $\begin{array}{l}\text { Kurz und weit. Schleim- } \\
\text { haut blass }\end{array}$ & $\begin{array}{l}\text { R. O. normal gross } \\
\text { L. O. mandelgross, hängt } \\
\text { mit d. Scheidennarbe } \\
\text { zusammen }\end{array}$ & $11 / 4$ Jahre \\
\hline 5 & Sch. & $\begin{array}{l}\text { Weit u. kurz. Es besteht } \\
\text { keine Veränderung } \\
\text { der Schleimhaut. Kein } \\
\text { Fluor }\end{array}$ & $\begin{array}{l}\text { Beide Ovarien normal } \\
\text { gross, hart u. derbe }\end{array}$ & $1 \frac{1}{2}$ Jahre \\
\hline 6 & Pe. & $\begin{array}{l}\text { Weit und ziemlich lang. } \\
\text { Schleimhaut etwas hy- } \\
\text { perämisch. Geringe } \\
\text { Secretion }\end{array}$ & $\begin{array}{l}\text { Beide Ovarien wallnuss- } \\
\text { gross, sind mit der } \\
\text { Scheidennarbe ver- } \\
\text { wachsen }\end{array}$ & $1 / 2 \mathrm{Jahr}$ \\
\hline 7 & To. & $\begin{array}{l}\text { Weit und lang. Wände } \\
\text { weich und schlaff. } \\
\text { Schleimhaut blass, et- } \\
\text { was milchige Secre- } \\
\text { tion }\end{array}$ & $\begin{array}{l}\text { R. O. anfangs tauben- } \\
\text { eigross, dann krach- } \\
\text { mandelgross. L. } 0 . \\
\text { ebenso }\end{array}$ & $21 / 2$ Jahre \\
\hline
\end{tabular}

Zwei Frauen konnte ich recht lange, nämlich $4^{1} / 2$ und $21 / 2$ Jahre, drei 1 Jahr und darüber, und zwei nur $1 / 2$ Jahr beobachten.

Irgend eine Schrumpfung oder Veränderung der Vagina und Vulva trat in keinem Falle ein, selbst nicht nach $4 \frac{1}{2}$ Jahren. Interessanter ist auch die Frage, was aus den Ovarien wird und ob die Ovulation weitergeht, wenn die Menstruation durch die Entfernung des Uterus unterdrückt ist. In den zwei Fällen, die nach 
1/2 Jahre untersucht wurden, waren die Ovarien fast unverändert, in den beiden am längsten beobachteten auf die Grösse einer Krachunandel bezw. Bohne geschrumpit. In dem einen Falle ging der Schrumpfung eine vorübergehende Vergrösserung der Ovarien voraus. Bei Frau A n. (Fall 4) finden wir das linke Ovarium nach $5 / 4$ Jahren krachmandelgross und mit der Scheidennarbe verwachsen; bei Frau Wa. (Fall 2) wurden die Ovarien uberhaupt nicht wieder gefiihlt. Die beiden Fälle lassen sich wohl durch eine Schädigung der Ovarien bei der Operation erklären. Bei Frau Wa. (Fall 5 der Tabelle IX) sind die Ligaturen hart am medialen Rande der Ovarien geknüpft worden, so dass der grösste Theil der Ovarien hinterher nekrotisch zu Grunde gegangen sein wird, und bei Frau An. (Fall 11 der Tabelle IX) ist später die linke Tube vorgefallen und mit dem Thermokauter entfernt worden, wodurch das linke Ovarium mit der Scheidenwunde verklebte and sich wohl theilweise in Narbengewebe umwandelte.

Die beiden am längsten beobachteten Fälle (Fall 1 und 7) legen den Schluss nahe, dass die Ovarien nach der Totalexstirpation im Verlaufe von einigen Jahren etwas an Grösse abnehmen. Wenn sich dieser Befund bei weiteren Beobachtungen wiederholen sollte, so halte ich dafür, dass nicht der Verlust des Uterus, sondern eine Beeinträchtigung in der Ernährung der Ovarien die Ursache hierzu abgiebt.

Atrophie der Ovarien würde nicht eintreten, wenn es gelänge, den Uterus ohne Beeinträchtigung der Ovarien abzusetzen. Ich möchte es als sicher feststehend annehmen, dass nach der Totalexstirpation des Uterus die Ovulation ungestört bis zu der natürlichen Klimax weitergeht; hierfür sprechen zunächst zahlreiche Fälle von angeborenem Mangel des Uterus, bei denen normale Ovarien und Ovulation nachgewiesen wurden, ferner der Umstand, dass auch an den äusseren Genitalien, dem Scheidenreste und der Vulva keine Atrophie eintritt, schliesslich die Annahme, dass die Ovulation arhythmisch, unabhängig von der Menstruation, stattfinden kam.

Kurz meine Ansicht geht dahin, dass nach der Totalexstirpation des Uterus, wenn dieselbe ohne Beeinträchtigung der Ovarien gemacht wird, keine Atrophie "der zurückbleibenden Genitalien erfolgt und die Ovulation ungestört erhalten bleibt. 
nach künstl. Verluste d. Ovarien einerseits u. d. Uterus andererseits.

E. Wirkung der Totalexstirpation auf die Gesammternährung des Organismus.

Die von mir gewonnenen Ergebnisse habe ich in Tabelle XIII zusammengestellt.

Tabelle XIII. Wirkung der Totalexstirpation auf die Gesammternährung des Organismus.

\begin{tabular}{|c|c|c|c|c|c|c|c|c|}
\hline \multirow[b]{2}{*}{ Nr. } & \multirow[b]{2}{*}{ Name } & \multirow{2}{*}{$\begin{array}{c}\text { Gewicht } \\
\text { v.d. Ope-- } \\
\text { ration } \\
\text { Pfund }\end{array}$} & \multicolumn{4}{|c|}{ Gewicht nach der Operation } & \multirow{2}{*}{$\begin{array}{l}\text { Ge- } \\
\text { sammt- } \\
\text { zu- } \\
\text { nahme } \\
\text { Pfund }\end{array}$} & \multirow[b]{2}{*}{$\begin{array}{l}\text { Fett- } \\
\text { ansatz }\end{array}$} \\
\hline & & & $\begin{array}{c}\stackrel{4}{\text { Wochen }} \\
\text { Pfund }\end{array}$ & $\begin{array}{l}1 / 2-1 \\
\text { Jahr } \\
\text { Pfund }\end{array}$ & $\begin{array}{l}1-2 \\
\text { Jahre } \\
\text { Pfund }\end{array}$ & $\begin{array}{l}2-5 \\
\text { Jahre } \\
\text { Pfund }\end{array}$ & & \\
\hline 1 & Ol. & & & & & & Keine & Keiner \\
\hline 2 & $\begin{array}{l}\text { Lu. } \\
\text { Bl. }\end{array}$ & 95 & & & & $\begin{array}{l}5 \text { Jahre } \\
\text { später } \\
98\end{array}$ & $\begin{array}{r}3 \\
16\end{array}$ & $\begin{array}{l}\text { Keiner } \\
\text { Geringer }\end{array}$ \\
\hline 4 & Wa. & 120 & 111 & $\begin{array}{l}1 \mathrm{Jahr} \\
120\end{array}$ & $\begin{array}{c}1 \frac{1}{2} \mathrm{Jahre} \\
132\end{array}$ & & 21 & Bedeutender \\
\hline 5 & Schm. & 107 & 102 & $\begin{array}{c}1 / 2 \mathrm{Jahr} \\
107\end{array}$ & & & 5 & Keiner \\
\hline 6 & $\mathrm{Br}$. & & & & & & 14 & Bedeutender \\
\hline 7 & Ha. & 100 & 98 & $\begin{array}{c}1 \mathrm{Jahr} \\
103\end{array}$ & & & 5 & Keiner \\
\hline 8 & Hn. & & & & & & Keine & Keiner \\
\hline 9 & An. & 100 & 97 & $\begin{array}{c}3 / 4 \mathrm{Jahr} \\
120\end{array}$ & $\begin{array}{c}1 \mathrm{Jahr} \\
121\end{array}$ & & 24 & Bedeutender \\
\hline 10 & Schi. & 133 & 130 & $\begin{array}{c}1 / 2 \mathrm{Jahr} \\
139\end{array}$ & & & 6 & Keiner \\
\hline 11 & Pe. & & & & & & Keine & Keiner \\
\hline 12 & To. & 105 & 102 & & $\begin{array}{c}\text { 2 Jahre } \\
106\end{array} \mid$ & & 4 & Keiner \\
\hline
\end{tabular}

Ich habe, um später einen Vergleich mit den Ergebnissen nach der Castration anstellen zu können, auch hier als Gesammtzunahme immer den Unterschied zwischen dem Gewichte bei der Entlassung und dem späteren gerechnet, nicht den Unterschied zwischen den Gewichten vor und lange Zeit nach der Operation. Es fand sich in Bezug auf das Gewicht:

Keine Zunahme . . . . . in 3 von 12 Fällen, also $=25$ Proc. Geringe Zunahme bis zu 10 Pfd. "5 " 5 " $"=42$ " Bedeutende Zunahme . . , "4 $412, ",=33,3$,

In Bezug auf den Fettansatz:

Kein Fettansatz . . . . in 8 von 12 Fällen, also $=66,6$ Proc. Geringer Fettansatz . . . "1 " $12 \quad, \quad,=8,4$ " Bedeutender " . . " 3 " 12 " $=25,0$ "

Im Durchschnitte beträgt die Gewichtszunahme, aus allen einzelnen Zunahmen berechnet, $11 \mathrm{Pfd}$. Der Einfluss der zufälligen Verletzung der Ovarien bei der Operation machte sich auch hier 
wieder geltend. Frau An. und Frau Wa. (Fälle 9 und 4 der Tabelle) zeigen die höchsten Zunahmen des Körpergewichtes und den bedeutendsten Fettansatz. Es sind dies die zwei Frauen (Fall 11 und 5 der Tabelle IX), bei denen wir eine theilweise Zerstörung der Ovarien durch die Operation angenommen haben. Wir müssten streng genommen alle Fälle, bei denen eine Verletzung der Ovarien sicher oder wahrscheinlich stattgefunden hat, ausschalten und würden dann ein reineres Ergebniss erhalten, welches noch klarer die verhältnissmässig geringen Zunahmen in der Gesammternährung zeigt. Ich habe hiervon abgesehen, weil die von mir gesammelten Fälle dann auf so wenige zusammenschmelzen würden, dass man aus ihnen gar keine Schlüsse mehr ziehen kann. Wir sehen, dass nach der Totalexstirpation des Uterus allerdings meist eine geringe, selten eine bedeutende Zunahme des Körpergewichtes zu Stande kommt, beobachten also keineswegs die bedeutende Steigerung, die wir bei den castrirten Frauen fanden, wie die folgende Gegenüberstellung in Procentzahlen es ergiebt.

Körpergewicht:

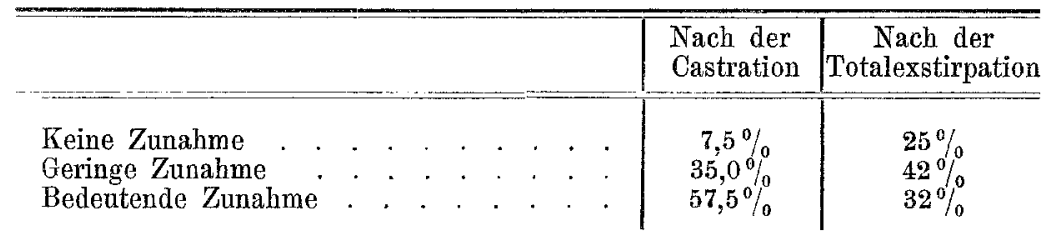

Fettansatz:

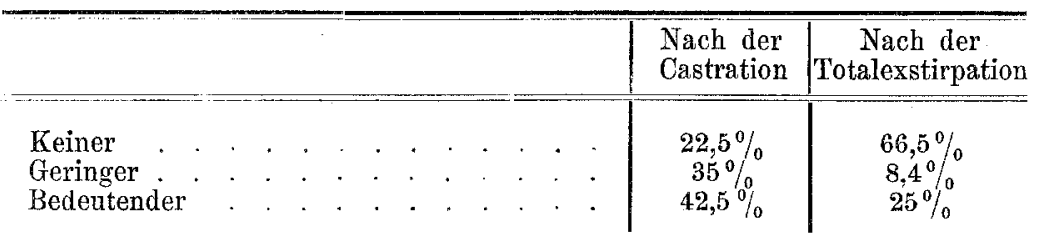

Wie wir bereits bei der Castration auseinandersetzten, ist also bei der Entwicklung des bedeutenden Fettansatzes das Fehlen der Ovarien als Grundursache anzusehen.

Wenngleich das Ergebniss dieses Kapitels vollkommen negativ ausfällt, so haben wir es doch angeführt, damit durch dasselbe ein noch grelleres Licht auf die Steigerung der Gesammternährung nach der Castration geworfen werde. 
nach künstl, Verluste d. Ovarien einerseits u. d. Uterus andererseits.

F. Wirkung der Totalexstirpation auf die Libido sexualis.

Leider stehen mir für dieses Kapitel wieder nur 10 Fälle zu Gebote, was ich um so mehr bedaure, als bei einer kleinen Anzahl von Fällen eine mit untergelaufene Zufälligkeit das Gesammtergebniss sehr stark beeinflussen kann.

Tabelle XIV. Wirkung der Totalexstirpation auf den Geschlechtstrieb.

\begin{tabular}{r|c|c|l|l}
\hline \hline Nr. & Name & Alter & Geschlechtstrieb & \multicolumn{1}{|c}{ Wollustgefühl } \\
\hline 1 & Ol. & 45 & Erloschen & Erloschen. \\
2 & Bl. & 43 & Erloschen & Erloschen. Beischlaf schmerzhaft. \\
3 & Lu. & 44 & Geringer & Bedeutend geringer. \\
4 & Wa. & 41 & Vorhanden & Vorhanden. \\
5 & Ha. & 37 & Vorhanden & Vorhanden. \\
6 & Hn. & 41 & Vorhanden & Geringer. \\
7 & An. & 42 & Vorhanden & Vorhanden. \\
8 & Schi. & 30 & Geringer & Geringer. \\
9 & Pe. & 36 & Stärker & Stärker. \\
& To. & 34 & Stärker & Vorhanden.
\end{tabular}

Wie bei der Castration habe ich wieder Geschlechtstrieb und Wollustgefühl während des Beischlafes getrennt.

In zwei Fällen (Fall 1 und 2) war beides vollkommen erloschen, in einem (Nr. 3) beides, namentlich aber das letztere, bedeutend geringer geworden. In vier Fällen fanden die Frauen gegen früher keinen Unterschied, und in einem (Nr. 9) glaubte der Mann ein stärkeres Geschlechtsbedürfniss seiner Frau bemerken zu können; in zwei Fällen sind Geschlechtstrieb und Wollustgefühl geringer geworden, namentlich letzteres. Im allgemeinen hat also die Libido während des Beischlafes mehr gelitten, als die geschlechtliche Neigung. Bei der Castration war das Umgekehrte der Fall. Es muss dies darin seinen Grund haben, dass bei der Castration die Ovarien, die hauptsächlichen Organe des Geschlechtstriebes, entfernt werden. Dieses Ergebniss ist sehr auffällig, denn lediglich nach theoretischen Erwägungen sollte man annehmen, dass die Libido sexualis nach der Totalexstirpation des Uterus in keiner Weise litte, da ja die Ovarien und die Clitoris unversehrt bleiben. Ich glaube auch, dass dieser Satz im Grossen und Ganzen genommen richtig ist und dass die dagegen sprechenden Fälle sich als durch Nebenumstände entstanden erklären lassen. Jedenfalls möchte ich dies von den drei Fällen annehmen, in denen der Geschlechtstrieb ganz oder nahezu ganz erloschen ist. Zunächst 
müssen wir bedenken, dass wir es hier vorwiegend mit älteren Frauen zu thun haben, bei denen der Trieb naturgemäss schon im Sinken begriffen ist. Und gerade die drei Fälle, welche die stärkste Abnahme aufweisen (Fall 1,2 und 3), betreffen die drei ältesten Frauen, im Alter von 43-45 Jahren, also unmittelbar vor der natürlichen Klimax. Dazu kommt, dass die beiden ersten Frauen (Fall 1 und 2) zu der Zeit, wo sie die Angaben machten, bereits an einem Riückfalle litten, was bei der ersten eine starke Depression des Gemüthes, bei der zweiten Schmerzen während des Beischlafes zur Folge hatte, wodurch die Abneigung gegen den Coitus sich erklärt. Man muss diese Verhältnisse sehr berücksichtigen und mehr aus ihnen das völlige Erlöschen des Geschlechtstriebes erklären, als aus der Totalexstirpation. Ich habe nicht unterlassen, auch bei diesem Kapitel auf den Einfluss der gleichzeitigen Verletzung der Ovarien zu achten, finde aber keinen. Gerade die Fälle, in denen eine theilweise Zerstörung der Ovarien wahrscheinlich ist (Fall 7, 4 und 9), zeigen keine geschlechtliche Veränderung. Ich glaube also hieraus schliessen zu können, dass zur Erregung des Geschlechtstriebes nicht die vollkommen unverletzten Ovarien nothwendig sind, sondern dass ein Theil derselben genügt, um diese Gefühle unverändert zu erhalten. Es würden sich also die Ovarien in Bezug auf diesen Punkt ebenso verhalten, wie bei der Menstruation, wo auch das kleinste Stïckchen vom Ovarialgewebe genügte, um die Function zu unterhalten. Fassen wir noch einmal Alles zusammen, so sprechen sowohl die theoretischen Erwägungen wie auch die Thatsachen dafür, dass der Geschlechtstrieb gewöhnlich nach der Totalexstirpation unverändert bleibt, in einzelnen Fällen allerdings geringer wird, aber niemals durch die Operation allein vollständig erlischt.

\section{G. Wirkung der Totalexstirpation auf die geistigen Zustände der Frau.}

Wir betreten mit diesem Kapitel wieder ein Gebiet, auf dem bisher noch sehr wenig gearbeitet ist. Nachdem 1885 in der Londoner Gesellschaft für Geburtshülfe, anknüpfend an einen Vortrag von Barwell, und 1887 in der Berliner geburtshülflichen Gesellschaft nach einem bisher noch nicht veröffentlichten Vortrage von $\mathrm{Gnauck}{ }^{1}$ ) ïber die Entstehung von Psychosen nach gynäkologischen Operationen verhandelt worden war, stellte zuerst

1) Zeitschrift für Geburtshülfe und Gynälzologie XVI, S. 546. 
Werth ${ }^{1}$ ) in einem Vortrage auf dem Gynäkologen-Congresse in Halle alle bisher bekannten Fälle von Psychosen nach gynäkologischen Operationen am Bauchfelle zusammen. Er selbst hatte zwei Mal eine Psychose nach der Totalexstirpation entstehen sehen.

Die von Werth damals geschilderten Fälle befinden sich mit unter denen, die ich hier besprechen werde. Ich hatte früher Gemüthsveränderungen nach der Castration beobachtet, und fand erst später, dass auch die Totalexstirpation nicht so selten einen Einfluss auf das Gemüthsleben der Frau äussert.

Tabelle XV. Wirkung der Totalexstirpation auf den Gemüthszustand.

\begin{tabular}{r|c|c|l}
\hline \hline Nr. & Name & Alter & Zustand nach der Operation \\
\hline \hline 1 & Ol. & 45 & Schwermäthiger. Neigung zur Melancholie. \\
2 & Bl. & 43 & Keine Veränderung. \\
3 & Lu. & 44 & Keine Veränderung. Heiter wie früher. \\
4 & Br. & 57 & Melancholie. Ausgesprochene Psychose. \\
5 & Me. & 57 & Melancholie. Leichte Psychose. \\
6 & Wa. & 41 & Heiterer. Mehr Energie und Lebensmuth. \\
7 & Sehm. & 46 & Keine Veränderung. \\
8 & Ha. & 37 & Keine Veränderung. Heiter wie früher. \\
9 & Hn. & 41 & Keine Veränderung. Ernst wie früher. \\
10 & An. & 42 & Heiterer. Dabei ruhiger und gleichmässiger. \\
11 & Sch. & 30 & Keine Veränderung. \\
12 & Pe. & 36 & Schwermüthiger. Hang zur Melancholie. \\
13 & To. & 34 & Melancholie. Ausgesprochene Psychose. \\
& &
\end{tabular}

Bei 6 von 13 Frauen, also bei 46,4 Proc., ist keine Veränderung der Stimmung und des Gemüthes eingetreten, bei 5 , also bei 38,4 Proc., war Depression des Gemüthes nachzuweisen, und bei 2, also bei 15,2 Proc. war die Stimmung entschieden heiterer und lebenslustiger geworden. Diese beiden hatten ein sehr gutes Operationsergebniss gehabt und bis heute keinen Rückfall; ibre Gesammternährung hatte sich nach der Operation bedeutend gehoben, was wohl, wie schon bei der Castration erwähnt, einen günstigen Einfluss auf die Stimmung ausübt. Aber auch mehrere der schwermüthig gewordenen Frauen konnten mit den Operationserfolgen durchaus zufrieden sein. Von den 5 Fällen, in denen sich Schwermuth entwickelte, waren 2 (Fall 1 und 12) leichterer Art. Beide Frauen waren nur ernster und nachdenklicher geworden, konnten

1) Verhandlungen der deutschen Gesellschaft für Gynäkologie. Zweiter Congress 1888. S. 60. 
sich über ihr Wohlergehen nicht freuen, weil sie immer einen Rückfall fürchteten, der bei beiden auch verhältnissmässig rasch eintrat. Ausserdem waren die trüben Gedanken durch thatsächlich vorhandene kleine Beschwerden gerechtfertigt. In den iibrigen drei Fällen aber steigerte sich die Schwermuth zur ausgesprochenen Melancholie. Da dergleichen Fälle, soviel ich weiss, noch nicht veröffentlicht sind, will ich hier einen kurzen Auszug der Krankengeschichten geben. Der leichteste dieser Fälle war Fall 5 der Tabelle:

Frau Me., 57 Jahre alt, Händlersfrau. Am 13. Juli 1886 wegen Cervixcarcinom Totalexstirpation. Operation und Nachbehandlung ohne Zwischenfall und am 11. August 1886 Entlassung mit dreimarkstückgrosser granulirender Wunde. Schon in der letzten Zeit ihres klinischen Aufenthaltes war die Kranke gegen früher sehr wortkarg, still und nachdenklich geworden. Zu Hause angelangt, nahm ihr Arzt mehrfache Aetzungen der stark wuchernden Granulationsfläche vor, was zur Folge hatte, dass die Kranke fest einen Rückfall annahm. Sie wurde vollkommen schwermüthig, legte ihre häusliche Thätigkeit ganz nieder, sprach nur von Sterben und bereitete sich fortwährend auf ihren Tod vor. Unter den Aetzungen heilte die Wunde aber allmälig aus, und als der Arzt nach etwa sechs Wochen dem Manne die geheilte Wundfäche im Speculum zeigte und dieser seiner Frau versicherte, dass er keine Wucherungen mehr gesehen hätte, besserte sich der Zustand langsam. Hallucinationen und Wahnideen fehlten.

\section{Heftiger war schon Fall 4 der Tabelle:}

Frau Br. aus Kiel, 57 Jahre. Am 27. August 1884 wegen Carcinoma cervicis Totalexstirpation. Nachbehandlung normal, nur fielen beide Tubeninfundibula vor und geriethen in stark granulirenden Zustand. Am 4. October auf dringenden Wunsch entlassen mit der Weisung, sich noch weiter behandeln zu lassen. Nach mehrfachen Aetzungen war die Wunde glatt verheilt. Schon während der letzten Zeit ihres Aufenthaltes in der Klinik war die Frau sehr weinerlich und schwermüthig und bald entwickelte sich zu Hause eine vollkommene Psychose. Die Kranke hat fortwährend Unruhe und Angst, fühlt sich von allen Seiten verfolgt, sieht Gerichtsdiener, die sie abholen wollen, glaubt dem Staatsanwalt verfallen zu sein, weil sie bei der Aufnahme in der Klinik ihre Vermögenslage ungünstiger dargestellt hätte, als es den Thatsachen entspräche u. s. w. In diesem Zustande verlegte die Frau ihren Wohnsitz und kam mir aus den Augen. Erst zwei Jahre später kam ich wieder auf ihre Spur und erfuhr brieflich vom Manne, dass die Psychose noch etwa sechs Monate gedanert hätte, dann allmälig verschwunden sei. Eine Anstaltsbehandlung ist bei der Frau nicht nöthig geworden, da sie bei ihren Wahnideen immer harmlos blieb und keine Selbstmordgedanken hatte. In körperlicher Beziehung geht es der Frau vorzüglich, sie ist von jedem Rückfalle verschont 
geblieben und hat sich sehr erholt und gekräftigt. Dieser Fall muss als eine richtige Psychose mit Hallucinationen und Wahnideen angesehen werden.

\section{Am hartnäckigsten war Fall 13 der Tabelle:}

Frau To., 33 Jahre, Fischersfrau. Wegen beginnenden Carcinoms des Uterus am 18. Januar 1886 Totalexstirpation. Heilung ohne Störung und Entlassung am 25. Februar mit nahezu verheilter Wunde. Ein halbes Jahr nach der Operation begann gedrückter und schwermüthiger Zustand, der sich nach etwa einem Jahre zur vollkommenen Melancholie gesteigert hatte. Alle Lust zur Arbeit war verloren, die Kranke sass tagelang still, grübelte vor sich hin und weinte. Schlaf unruhig und gestört; oft im Traume und auch im Wachen vor dem Einschlafen erschienen Gestalten und Thiere, die die Frau angreifen wollten. Dabei körperliches Wohlbefinden und kein Rückfall. Dieser Zustand blieb etwa ein Jahr lang bestehen. Die Kranke war jetzt zum Bewusstsein desselben gekommen. Seitdem ist eine geringe Besserung eingetreten. Die Kranke beschäftigt sich wieder normal, hat aber noch periodenweise das schwermüthige, weinerliche Wesen. In letzter Zeit ist sie sehr heftig geworden, und in Zornesausbrüchen zertrümmert sie alles sich ihr Darbietende. So war noch der Zustand, als ich die Frau das letzte Mal, etwa $2 \frac{1}{2}$ Jahre nach der Operation, sah.

Trotzdem dieser Fall der intensivste und langdauerndste unter allen ist, scheint er doch jetzt einer Naturheilung entgegenzugehen, and so können wir wohl den Schluss ziehen, dass die nach der Totalexstirpation auftretenden Psychosen im allgemeinen doch eine gïnstige Prognose geben und fast immer mit vollkommener Heilung enden. Das Charakteristische in den beiden letzten Fällen ist, dass die Psychose durch keine äussere Veranlassung zu erklären ist. Beiden Frauen ging es nach der Operation sehr gut, sie erholten sich rasch und gut, und bei beiden liegt heute nach mehreren Jahren kein Rückfall vor. Dabei ist wohl zu bemerken, dass beide Frauen in psychischer Beziehung hereditär nicht belastet waren und die letzte von allen Bekannten als eine früher besonders heitere Frau geschildert wird. Es liegt also nahe, die Ursache der Melancholien in der Operation zu suchen. Bei allen Operationen ist Jodoform angewandt worden, und man könnte dieses als Urheber der Psychosen ansehen. Das Jodoform wurde jedoch stets in so geringer Menge verwendet, dass man mit Sicherheit eine Intoxication ausschliessen kann. Auch haben wir in den zahlreichen Fällen, wo Jodoformgelatinestäbchen, die $5 \mathrm{~g}$ reines Jodoform enthielten, nach der Geburt in den Uterus eingelegt wurden, niemals dergleichen Geistesstörungen gesehen. Schliesslich könnte ein so langes Bestehen der Psychosen durch eine einmalige Intoxication mit Jodoform nicht erklärt werden.

Die Entfernung des Uterus allein darf man als Ursache der Psychosen nicht anschuldigen, da sie auch nach der Castration und sonstigen Laparatomien vorkommen. Bei allen diesen Ope- 
rationen werden zahlreiche Nervenplexus, die vorwiegend vom Sympathicus versorgt werden, theils gereizt, theils verletzt und somit ist wohl ein Reizzustand des Sympathicus herbeigeführt. Da nun nach Schüle ${ }^{1}$ ) die Melancholie auf einem Reizzustande des Sympathicus beruht, der zu einer Ernährungshemmung im Gehirn führt, so könnte man den kühnen Schluss ziehen, dass auf diesem Wege die Operation direct einen Einfluss auf das Gehirn ausiubt.

Wenn wir auch keine feststehende Erklärung zu geben im Stande sind, so bleiben darum die Thatsachen doch als sicher stehen, und diese zwingen uns, den Satz aufzustellen, dass nach der Totalexstirpation sich bei der Frau leicht ein schwermüthiger, melancholischer Zustand entwickelt, der zuweilen einen solchen Grad annimmt, dass man von einer Psychose sprechen muss.

Ueberblicken wir zum Sehlusse kurz die Folgen, welche die Totalexstirpation auf körperlichem und geistigem Gebiete hervorruft, so sahen wir zunächst, dass nach derselben selbstverständlich die Menstruation ausnahmslos erlischt, und dass trotz dieser Unterdrückung der Menses niemals vicariirende Blutungen von irgendwelcher praktischen Bedeutung sich einstellen. Dagegen sahen wir in der ersten Zeit nach dez Operation fast regelmässig zur Zeit der fortbleibenden Menstruation Molimina menstrualia auftreten, die vorwiegend in Schmerzen und Beschwerden in der Gegend des Unterleibes bestehen. Wir erklärten diese durch die Fortdauer der Ovarialthätigkeit und die dadurch reflectorisch alle vier Wochen ausgelöste Beckenhyperämie entstanden. In einzelnen Fällen waren auch in der menstruationsfreien Zeit Beschwerden vorhanden, doch waren diese stets auf eine gleichzeitige Verletzung der Ovarien unter der Operation zurückzuführen und sie kommen daher als Folgeerscheinungen der Totalexstirpation nicht weiter in Betracht. Auf die zurückbleibenden Genitalien übte die Entfernung des Uterus keinen bedeutenden Einfluss. Die Vulva und der Scheidenrest blieben unverändert, und dasselbe konnte man im Grossen und Ganzen auch von den Ovarien sagen. Allerdings schienen die zurückbleibenden Ovarien nach mehreren Jahren etwas

1) Handbuch der Geisteskrankheiten. Handbuch der speciellen Pathologie und Therapie ron Ziemssen. Bd. XVI. 
an Grösse abzunehmen, doch bezogen wir diese langsame und geringe Atrophie auf Ernährungsstörungen, die durch die Operation im Bereiche der die Ovarien versorgenden Gefässe erzeugt waren. Jedenfalls stellten wir als feststehend hin, dass die physiologische Thätigkeit der Ovarien, die Ovulation, nach der Fortnahme des Uterus ungehindert fortdauert, bis sie im natürlichen Klimakterium erlischt. Auf den allgemeinen Ernährungszustand des Körpers hatte die Operation gewöhnlich einen ganz günstigen Einfluss, indem die Kranken die vorher durch die Krankheit verlorene Körpersubstanz bald und rasch wieder gewannen. Auf diesem Punkte blieben die Frauen aber gewöhnlich stehen, und wir sahen nicht jene oft excessive Gewichtszunahme und jenen hochgradigen Fettansatz, wie nach der Castration, zu Stande kommen. In einzelnen wenigen Fällen schien dies allerdings auch vorzukommen, doch konnte ich in diesen Fällen stets eine gleichzeitige Beeinträchtigung der Ovarien durch die Operation nachweisen. Der künstliche Defect des Uterus hatte ferner auf den Geschlechtstrieb im allgemeinen wenig Einfluss, was in dem Unversehrtbleiben der Ovarien und der Clitoris seinen Grund findet. In einzelnen Fällen war allerdings eine Abnahme des Wollustgefühles während des Beischlafes festzustellen, doch waren diese in der Minderzahl. In vereinzelten Fällen zeigte sich die Libido vollkommen erloschen, was wir aber auf Nebenumstände, Rückfall, hohes Alter u. s. w., zurückzuführen geneigt waren. In Bezug auf den Gemüthszustand der Frau sahen wir in nahezu der Hälfte aller Fälle keine Veränderung durch den Fortfall des Uterus hervorgerufen werden. In reichlich einem Drittel der Fälle entwickelte sich aber nach der Operation eine bald geringere, bald stärkere Depression des Gemüthszustandes, die in nicht ganz seltenen Fällen unter begünstigenden Umständen zur Psychose ausartet.

Stellen wir noch einmal die nach der Castration auftretenden Folgezustände denen nach der Totalexstirpation gegenüber, so gewahren wir einen grossen Unterschied in den Folgen dieser beiden Operationen.

Die im weiblichen Organismus nach der Castration hervorgerufenen Veränderungen waren bedeutend und zahlreich, und sie glichen fast in allen Punkten den Veränderungen, die sonst im natürlichen Klimakterium aufzutreten pflegen. Wir konnten also folgern, dass durch die Castration die Frau vorzeitig in das Klimakterium übergeführt werde. 
Einen ganz anderen Zustand sahen wir dagegen nach der Totalexstirpation des Uterus auftreten. Die Folgezustände sind gering und nicht sehr in die Augen springend, ja sie sind ungleich geringer, als man es von vornherein erwarten sollte. Sie bestehen eigentlich einzig und allein darin, dass sich nach der Operation zur Zeit der nicht eintretenden Periode Molimina menstrualia einstellen, die aber auch allmälig abklingen und gewöhnlich nach Jahresfrist verschwunden sind, und dass sich schliesslich in einigen Fällen ein Hang zur Melancholie entwickelt, der nicht ganz selten zur Psychose führt.

Es schneidet also die Castration viel tiefer in den gesammten Organismus der Frau ein, als die Totalexstirpation, und wir haben die verstümmelnde Wirkung der ersteren viel höher anzuschlagen a.ls die der letzteren.

Zum Schlusse ergreife ich mit Vergnügen die Gelegenheit, meinem hochverehrten Lehrer und Chef, Herrn Professor Werth, für die gütige Ueberlassung des gesammten Materials, sowie für das rege der Arbeit gewidmete Interesse meinen tiefgefühltesten Dank auszusprechen.

\section{Literatur - Verzeichniss.}

Pflüger: Untersuchungen aus dem physiologisehen Laboratorium zu Bonn. Berlin 1865.

Litzmann: Schwangerschaft und Physiologie des weiblichen Organismus ẗberhanpt. Handwörterbuch der Physiologie von $W$ a gner. Braunschweig 1846.

Kundrat und Engelmann: Untersnchungen über die Uterussehleimhaut. Wiener medicinische Jalurbücher 1873.

Leopold: Studien ïber die Uterusschleimhaut während Menstruation, Schwangerschaft und Wochenbett. Dieses Archiv, Bd. XI.

Wyder: Beiträge zur normalen und pathologischen Anatomie der menschlichen Uterusschleimhaut. Dieses Archiv, Bd. XIII.

Williams: Obstetrical Journal, Vol. I, 1874-75 und Vol. IV, 1877.

Möricke: Die Uterusschleimhant in den verschiedenen Altersperioden und zur Zeit der Menstruation. Zeitschrift für Geburtshüllfe und Gynäkologie, Bd. VII. 1881.

Leopold: Untersuchungen über Menstraation und Ovalation. Dieses Archiv, Bd. XXI.

Goodman: The eyclical Theory of Menstruation. American Journal of Obstetries, Vol. XI. 1878. 
nach künstl. Verluste d. Ovarien einerseits u. d. Uterus andererseits.

Stephenson: On the menstrual wawe. American Journal of $\mathrm{Ob}^{-}$ stetrics, Vol. XV. 1882.

Rein 1: Die Wellenbewegung der Lebensprocesse des Weibes. Volkmann'sche Vorträge, Nr. 243.

Feoktistow: Einige Worte über die Ursache und den Zweck des Menstrualprocesses. Dieses Archiv, Bd. XXVII.

Hegar: Die Castration der Frauen. Leipzig 1878.

Schmalfuss: Zur Castration bei Neurosen. Dieses Archiv, Bd. XXVI.

Wiedow: Die Castration bei Uterusfibrom. Dieses Archiv, Bd. XXV.

Ormières: Sur la menstruation après l'ovariotomie et l'hysterectomie. Thèse de Paris 1880.

Tissier: De la castration de la femme. Thèse de Paris 1885.

Heitzmann: Vicariirende Menstruation und Menstrual-Exantheme. Wiener medicinische Jahrbücher 1884.

Brière de Boismont: Die Menstruation in ihren physiologischen, pathologischen und therapeutischen Beziehungen. Aus dem Französischen von Krafft. Berlin 1842.

Veit: Physiologie der weiblichen Geschlechtsorgane. Handbuch der Geburtshülfe von $\mathrm{M} u ̈ l l e r$.

Krieger: Die Menstruation. Berlin 1869.

Tauffer: Beiträge zur Lehre der Castration der Frauen. Zeitschrift für Geburtshülfe und Gynäkologie, Bd. IX, 1833.

Prochownick: Beiträge zur .Castrationsfrage. Dieses Archiv, Bd. XXIX.

Péan: De l'ablation des tumeurs du ventre, considérée dans ses rapports avec la menstruation, les appetits vénériens, la fécondation, l'état de grossesse et l'accouchement. Gazette médicale de Paris 1880.

Börner: Die Wechseljahre der Frau. Stuttgart 1886.

$\mathrm{Kisch}$ : Das klimakterische Alter der Frauen in physiologischer und pathologischer Beziehung. Erlangen 1874.

Geber: Anomalien der Schweissdrüsen und ihrer Function. Ziem ssen's Handbuch der speciellen Pathologie und Therapie, Bd. XIV. Zweite Hälfte.

Kehrer: Versuche über Castration und Erzeugung von Hydrosalpinx. Beiträge zur klinischen und experimentellen Geburtskunde und Gynäkologie. Bd. II, 3. Heft. Giessen 1887.

Bruntzel: Vier Castrationen. Dieses Archiv, Bd. XVI.

Puech: Des ovaries et de leurs anomalies. Paris 1873.

Tilt: On uterine and ovarian inflammation and on the Physiology and diseases of menstruation. London 1862.

Lawson Tait: Ueber Myome des Uterus. Verhandlungen der Londoner geburtshülflichen Gesellschaft, Bd. XXV. Referat im Centralblatt für Gynäkologie 1884, Nr. 50 . 
88 Glaevecke,Körperl. u. geistige Veränderungen im weibl. Körper u. s. w.

Hegar: Der Zusammenhang der Geschlechtskrankheiten mit nervösen Leiden und die Castration bei Neurosen. Stuttgart 1885.

Kussmau 1: Von dem Mangel, der Verkümmerung und der Verdoppelung der Gebärmutter. Würzburg 1859.

Hensen: Physiologie der Zeugung. Leipzig 1881. Handbuch der Physiologie von Hermann.

Pflüger: Die teleologische Mechanik der lebendigen Natur. Arcliv für Physiologie, Bd. XV.

Kobelt: Die männlichen und weiblichen Wollustorgane des Menschen. Freiburg 1844.

Kleinwächter: Ein Beitrag zur Battey-Hegar'schen Operation. Dieses Archiv, Bd. XVI.

Lossen und Fürstner: Eine Péan'sche Hysterotomie mit nachfolgender Manie. Berliner klinische Wochenschrift 1880.

Odebrecht: Ein Beitrag zur Castration des Weibes. Berliner klinische Wochensehrift 1881.

Mayer, Louis: Die Menstruation im Zusammenhange mit psychischen Störungen. Beiträge der Gesellschaft für Geburtshülfe in Berlin 1872, Heft I.

Schüle: Handbuch der Geisteskrankheiten. Handjuch der speciellen Pathologie und Therapie von $\mathrm{Ziemssen,} \mathrm{Bd.} \mathrm{XVI.}$

Brennecke: Ueber die vaginale Totalexstirpation des Uterus. Zeitschrift für Geburtshülfe und Gynäkologie, Bd. XII.

Werth: Ueber Entstehung von Psychosen im Gefolge von Operationen am weiblichen Genitalapparate. Verhandlungen der Deutschen Gesellschaft für Gynäkologie. Zweiter Congress 1888. 